\title{
THE NUCLEAR PATTERN AND FIBER CONNECTIONS OF THE NON-CORTICAL CENTERS OF THE TELENCEPHALON OF THE RABBIT (LEPUS CUNICULUS)
}

\author{
M. WHARTON YOUNG ${ }^{1}$ \\ Laboratory of Comparative Neurology, Department of Anatomy, \\ University of Michigan" \\ TWENTY-EIGHT FIGURES
}

(Acepted for publication September 21, 1935)

CONTENTS

Introduction $\ldots \ldots \ldots \ldots \ldots \ldots \ldots \ldots \ldots \ldots \ldots \ldots \ldots \ldots \ldots \ldots \ldots \ldots$

Nuclear arrangement in the teleneephalon $\ldots \ldots \ldots \ldots \ldots \ldots \ldots \ldots \ldots \ldots .296$

The olfactory bulb ............................ 296

The accessory olfactory bulb $\ldots \ldots \ldots \ldots \ldots \ldots \ldots \ldots \ldots \ldots \ldots \ldots, 301$

Nucleus olfactorius anterior $\ldots \ldots \ldots \ldots \ldots \ldots \ldots \ldots \ldots \ldots \ldots \ldots \ldots, 303$

The nuclear groups in the ventromedial portion of the hemisphere .... 308

The basal centers of the lateral wall of the hemisphere .......... 318





Intercalated nucleus of the internal capsule $\ldots \ldots \ldots \ldots \ldots \ldots \ldots \ldots 21$

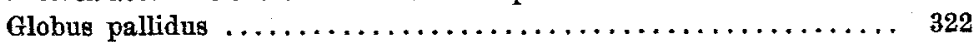

The entopeduncular nuelear group $\ldots \ldots \ldots \ldots \ldots \ldots \ldots \ldots \ldots \ldots \ldots, \ldots \ldots \ldots$

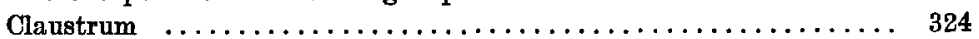

The amygdaloid group $\ldots \ldots \ldots \ldots \ldots \ldots \ldots \ldots \ldots \ldots \ldots \ldots \ldots, 325$

Interstitial nucleus of the stria terminalis $\ldots \ldots \ldots \ldots \ldots \ldots \ldots \ldots 31$

Preoptic region $\ldots \ldots \ldots \ldots \ldots \ldots \ldots \ldots \ldots \ldots \ldots \ldots \ldots \ldots \ldots \ldots \ldots, 333$

Fiber connections of the telencephalon $\ldots \ldots \ldots \ldots \ldots \ldots \ldots \ldots \ldots \ldots \ldots, 336$

Olfactory nerve, vomeronasal nerve, terminal nerve .......... 336



Tertiary olfactory connections within the hemisphere $\ldots \ldots \ldots \ldots \ldots \ldots 341$

Interconnections between olfactory centers of the hemisphere and lower

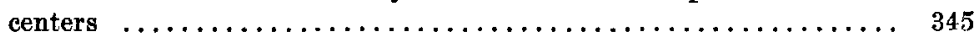

Medial forebrain bundle $\ldots \ldots \ldots \ldots \ldots \ldots \ldots \ldots \ldots \ldots \ldots \ldots, 345$

2 Fellow in anatomy, General Education Board.

A dissertation submitted in partial fulfilment of the requirements for the degree of doctor of philosophy in the University of Michigan. May, 1934. 


\begin{tabular}{|c|c|}
\hline Hippocampal commissure and fornix complex . & 347 \\
\hline Stria medullaris $\ldots \ldots \ldots \ldots \ldots \ldots \ldots \ldots$ & 351 \\
\hline 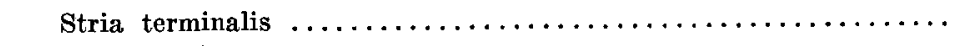 & 355 \\
\hline Anterior commissure $\ldots \ldots \ldots \ldots \ldots \ldots \ldots \ldots \ldots \ldots \ldots \ldots \ldots$ & 360 \\
\hline $\begin{array}{c}\text { Intrahemispheric connections of striatum (exclusive of amygdaloid } \\
\text { complex) } \quad \ldots \ldots \ldots \ldots \ldots \ldots \ldots \ldots \ldots \ldots \ldots \ldots \ldots \ldots \ldots \ldots \ldots \ldots \ldots \ldots \ldots\end{array}$ & 364 \\
\hline $\begin{array}{l}\text { Interconnections between the striatum (exclusive of the amygdaloid } \\
\text { complex) and lower centers } \ldots \ldots \ldots \ldots \ldots \ldots \ldots \ldots \ldots \ldots \ldots \ldots \ldots \ldots \ldots\end{array}$ & 366 \\
\hline Internal capsule $\ldots \ldots \ldots \ldots \ldots$ & 369 \\
\hline hypothalamo-hypophyseal & 371 \\
\hline
\end{tabular}

\section{INTRODUCTION}

This paper constitutes one of a series of projected studies on the mammalian forebrain undertaken at the Laboratory of Comparative Neurology at the University of Michigan and is based on material from the Huber Neurological Collection. It deals particularly with the non-cortical telencephalic centers in the rabbit-their nuclear configuration, their positional interrelations, and their fiber connections. The knowledge of the fiber connections has been extended somewhat by a study of the medullated fiber tracts in the guinea pig. The pertinent literature is considered under each section, since such a method facilitates comparisons.

I am appreciative of the opportunity accorded me by Prof. G. Carl Huber to work in his laboratory and study from the rich collection of neurological serial sections. I am grateful to him, and especially to Dr. Elizabeth C. Crosby, for the constant help, supervision and inspiration given me throughout the prosecution of this work. Whatever of value is contained herein is due to them rather than to my efforts.

NUCLEAR ARRANGEMENT IN THE TELENCEPHALON

The olfactory bulb

The olfactory bulb has been the subject of study of numerous investigators for many years and the accumulated literature on this subject is very extensive. Among the early anatomists who studied this structure were Owsiannikow 
(1860), Clark (1862), Meynert (1872), Henle (1871), and Broca (1879), all of whom employed the old methods of investigation and staining. Their results showed a wide variation in the number of layers described and in the morphological and functional relations of the different elements found therein. In 1875 Golgi published his "Sulla fina anatomia dei bulbi olfatorii," which incorporated the results of his investigations carried out with the aid of his new method of chrome-silver staining. He described for the first time the finer connections of the olfactory cells in the glomerulus and other layers of the bulb. Ramón y Cajal (1890), Pedro Ramón (1890), and van Gehuchten and Martin (1891), using the chrome-silver method of Golgi, made further contributions to the finer anatomy of the olfactory bulb. Many other observers have contributed to the knowledge of the structure of the olfactory bulb in different animals, and complete descriptions and bibliographies can be found in the textbooks on nervous anatomy by Barker (1899), Dejerine ('01), van Gehuchten ('06), Ramón y Cajal ('11) and Ariëns Kappers, Huber and Crosby ('36).

The olfactory bulb of the rabbit (figs. 1, 2, 3, 17, 18, 27, 28) is represented by a club-shaped enlargement at the cephalic extreme of the telencephalon. It is connected with the more caudal and ventral aspect of the telencephalon by the prominent olfactory peduncle, which in turn blends caudally with the medial, ventral, and pyriform areas of the hemisphere. In serial cross sections the bulb extends farther caudally on the medial than on the lateral aspect of the sections, hence it is obliquely attached to its peduncle and is overlapped caudally by the hemisphere. Cross sections of cell preparations of the olfactory bulb reveal, even macroscopically, its concentrically laminated structure (figs. 1, 2). The term 'olfactory formation' as employed here includes the internal granular layer and all tissues of the olfactory bulb lying external to this layer. The caudal limits of the olfactory formation are marked on the external surface by the fissura circularis (figs. 2 to 5 ). 
The outermost layer is composed of incoming non-medullated olfactory fibers (figs. 1 to $5,18,27,28$ ). These fibers are more numerous about the ventral and rostral aspects of the bulb and become fewer as the dorsal surface is approached. On this surface only scattered fibers are found, which soon disappear entirely as the sections are traced caudally (fig. 2). In the silver preparations of sagittal series of the entire head of very young rabbits, the olfactory fibers can be followed (sometimes in a single section) from their origin in the olfactory mucous membrane, through the cribriform plate, and into the fibrous layer of the bulb. As a result of differential staining the nervus terminalis, which was described from this material by Huber and Guild ('13), appears very dark brown or almost black in these sections. The olfactory fibers approach the bulb in compact bundles, separate into smaller funiculi as they reach its outer surface, and then course for a short distance in an unorganized manner before turning inward to terminate in the glomeruli of the layer next to be described.

The glomerular layer (figs. 1 to $5,17,18,27,28$ ) in cross sectioned tigroid preparations gives the appearance of a layer of unstained circular islands closely approximating each other and lying immediately inside the outer fibrous layer. On these granulo-fibrillar islands the axons of the olfactory fibers terminate, coming into intimate synaptic relation with the chief dendrites of the mitral cells, as was first demonstrated by Golgi (1875). There is apparently a wide layer of these glomeruli since some are placed nearer the periphery than others, but in any one plane the layer is only one glomerulus thick. They vary somewhat in size and shape, hence the general outline of this layer is irregular.

The external granular layer (figs. 1 to 4,17 ) has a concentric arrangement, central to the glomerular layer (Winkler and Potter, '11, fig. 1). It is composed of small and medium sized, rounded cells which cap over the central aspect of the glomeruli and extend outward between them. The majority of these cells are of the intra- or peri-glomerular type (Ramón y Cajal, 
'11). Occasionally a few small mitral cells are seen in this layer. Due to the fact that this layer is so intimately applied to the inner aspect of the irregular glomerular layer and its cells dip in between the individual glomeruli, it has in general outline a somewhat corrugated appearance. This corrugation also molds the peripheral aspect of the inner lying molecular layer.

The molecular or external plexiform layer (figs. 1 to 3,17 , 18, 27 and 28) lies immediately inside the external granular layer. It is a broad fiber layer composed of radially disposed fibers, most of which are the dendritic processes of the cells of the next inner layer. Scattered throughout the molecular layer are many mitral cells, most of which are more drawn out or elongated than the typical mitral cell. These belong to the class of so-called 'displaced mitral cells' (Ramón y Cajal, '11). They occur in other mammals, such as the bat (Humphrey, '36). There are also certain spherical cells in this layer which resemble closely the larger granule cells.

The inner border of the molecular layer is formed by the mitral cell layer (figs. 1 to $5,17,18$ ) which is composed of granule cells and mitral cells. The mitral cells are large, triangular, and deeply stained. The granule cells are in the majority in this layer; they are rounded or oval in outline, less deeply stained than the mitral cells, and slightly larger than the ordinary granule cells of the bulb. They are apparently synonymous with the 'cellulae a houpette' of Ramón y Cajal ('11), and according to this author synapse in the glomeruli and otherwise function as true mitral cells. On the whole, the mitral cells occupy a position nearer the periphery of this cell layer; however, the granule cells are freely disposed among and between them. The granule cells give a characteristic appearance to the deeper part of the mitral cell layer. Certain of the mitral cells have migrated peripherally into the outlying molecular layer and even into the external granular layer. Hence mitral cells are scattered from the mitral cell layer throughout the two overlying layers as far as the inner aspect of the glomerular layer, an observation in accord 
with that made by C. L. Herrick (1892) in opossum. The position of the mitral cells at the periphery of their layer and their migration outward as far as the inner aspect of the glomerular layer may well be considered as the result of the neurobiotactic influence of the glomeruli. The fact that the deeper lying cells of the mitral layer are distinctly granular in type would seem to support the opinion of Crosby ('17) that the mitral cells are differentiated from the granule cells in phylogeny under the operation of neurobiotaxis (Ariëns Kappers, '14, '28). In this connection an observation made by Leslie Smith ('28) on the relative difference in the comparative number of mitral and granule cells in Norway and albino rats is of interest. This observer found from a study of the number of nerve cells in the olfactory bulbs of rats that, while the Norway rats have more granule cells than the albinos, the latter possess a correspondingly larger number of mitral cells.

The internal granular layer (figs. 1 to $4,17,18$ ) lies central to the mitral cell layer from which it is separated by a narrow fiber layer which is called the internal plexiform layer by Ramón y Cajal ('11). The cells of this layer vary from medium sized to very small cells. They are oval or rounded in outline and have been called 'the olfactory granules' by many authors. This layer occupies the inner portion of the bulb and extends almost to the ventricle. It is composed of alternate concentric layers of cells and fibers. The groups of cells do not form complete circles but are broken by the fibers into many arc-shaped islands of cells, which are larger and have a more orderly arrangement in the peripheral part of this layer. As the center is approached the groups of cells become smaller and their concentric lamination becomes less marked. The cells of this layer are thought to provide a reinforcing mechanism for the olfactory stimuli which enter the olfactory bulb.

Inside the internal granular layer the medullated axons of the olfactory tracts form a medullary layer (figs. 2, 3, 18) surrounding the olfactory ventricle. Certain authors (for 
example, McCotter, '12) do not consider this as one of the primary layers of the olfactory bulb and it is not included under the 'olfactory formation' of the present description, because the olfactory formation disappears caudally while the olfactory tracts continue into secondary and tertiary olfactory centers. The core of the olfactory bulb is formed by the olfactory ventricle (figs. 2 to 5 ), which is a direct rostral extension of the lateral ventricle and continues almost to the anterior end of the olfactory bulb. It is tubular in form and has a small circular outline in cross section. It joins the vertical lateral ventricle in the plane of the rostral extreme of the tuberculum olfactorium. Surrounding the ependymal lining of the olfactory ventricle is a narrow band of small cells forming the periventricular gray which is continuous with the internal granular layer rostral to the cephalic extreme of the ventricle (figs. 1 to 5,17 ).

The olfactory formation occupies completely the rostral extreme of the bulb (figs. 1, 2, 17, 27, 28), but as the sections are traced caudally it begins to disappear from the dorsal surface and gradually fades away from the medial and lateral aspects, until finally there is only a small arc of the olfactory formation occupying the medioventral aspect of the peduncle (fig. 5). It is between the two limbs of the disappearing olfactory formation that the rostral end of the accessory olfactory bulb appears (fig. 3). The caudal limits of the olfactory formation are marked on the surface by the fissura circularis. The caudal extremity of the olfactory formation is overlapped by the rostral extreme of the neopallium, and finally it disappears entirely a short distance caudal to the plane of disappearance of the accessory olfactory bulb.

\section{The accessory olfactory bulb}

The first description of the accessory olfactory bulb is generally accredited to von Gudden, who in 1870 described it in the rabbit. However, C. Balogh (1860) traced nerve filaments from Jacobson's organ in the sheep, through the cribriform plate to their termination in 'Jacobson's Hill' on the dorsal 
aspect of the olfactory bulb. A summary of the literature is available in the Ariëns Kappers, Huber and Crosby text ('36). For the rabbit it has been described by von Kölliker (1896), Ramón y Cajal ('11), McCotter ('12), and Winkler and Potter ('11). The accessory olfactory bulb is lacking in some mammals, for example in the bat (Humphrey, '36).

The accessory olfactory bulb (figs. $3,4,18,28$ ) is a small oval body lying on the dorsomedial aspect of the olfactory bulb and peduncle in the rabbit. Its cephalic extreme is deeply placed (in relation to the external surface), where it lies between the receding edges of the olfactory formation and rests upon the pars dorsalis of the anterior olfactory nucleus, occupying the distinct dorsal concavity of the latter. Its caudal two-thirds lies in a crescentic furrow or groove on the dorsal surface of the olfactory peduncle. Its caudal third is overlapped dorsally by the neopallium (fig. 4). Hence the caudal one-third of the accessory olfactory bulb appears wedged in between the olfactory peduncle below and the overlying neopallium, both surfaces of which it indents, and in this relation it finally disappears a little rostral to the plane of the caudal extreme of the olfactory formation. The general structure of the accessory olfactory bulb (fig. 3) resembles closely that of the olfactory bulb proper. Its dorsal or outermost layer is formed by the fibers of the vomeronasal nerves which spread out over the surface to form a definite fiber layer and then turn inward to terminate in the glomeruli. The glomeruli form a distinct layer deep to the outer fibrous layer. There is a narrow external granular layer immediately inside the glomerular layer. Next is a distinct molecular or external plexiform layer, and deep to this is a broad, diffuse mitral cell layer. The cells of this layer are not as characteristically mitral or triangular in shape as are the homologous cells in the main bulb. In some planes of cross section this layer is much broader medially than it is laterally. There is a relatively broad internal plexiform layer-in fact the mitral cells might be considered as being embedded in the center of a broad plexiform layer which extends from the 
internal to the external granular layers of the accessory bulb. The internal granular layer is a very narrow layer of medium sized granule cells overlying the medullated efferent fibers of the accessory bulb, and forming the deepest layer of the latter. This medullated layer lies dorsal to the cells of pars dorsalis of the anterior olfactory nucleus and extends lateralward as the dorsal peduncle of the lateral olfactory tract. The vomeronasal nerves (figs. 2 and 3 ) can be traced from the place at which they form the dorsal fibrous layer of the accessory bulb, rostrally and ventrally along the medial aspect of the olfactory bulb. In sagittal series of the rabbit's head, stained with chrome-silver, the vomeronasal nerves have been followed from Jacobson's organ to the accessory bulb, as has been done by McCotter ('12) by dissection methods and by Huber and Guild ('13) in the series here under consideration.

\section{Nucleus olfactorius anterior}

There seems to be no unanimity of opinion as to what should be included under the term nucleus olfactorius anterior. Herrick ('10, p. 497 ; '24, p. 324) regarded it as undifferentiated olfactory gray closely associated with the bulb. A literal application of Herrick's definition to the corresponding region in the rabbit is not possible, for much of the region belonging to the nucleus olfactorius anterior shows very considerable differentiation, as was also noted in Orycteropus by Sonntag and Woollard ('25). Herrick pointed out that the undifferentiated gray of the anterior olfactory nucleus extends caudalward in amphibian embryos to include the regions occupied by more specialized areas such as tuberculum olfactorium and anterior pyriform cortex in the same adults. These latter centers are subsequently differentiated from this undifferentiated gray in the course of the development of the embryo, proceeding from behind forward. It appears, therefore, that in phylogeny as well as in ontogeny, this process of differentiation of secondary olfactory gray proceeds caudo-rostrally and hence in higher mammalian forms the nucleus olfactorius anterior is differentiated practically to its rostral extreme, 
while in amphibians and lower forms its rostral part remains undifferentiated. The present writer must therefore agree with Sonntag and Woollard ('25, p. 1196) that the statement that defines the anterior olfactory nucleus as undifferentiated needs qualification. It is with such implied qualification that the name nucleus olfactorius anterior is used in the following account.

The nucleus olfactorius anterior (figs. 3 to $6,17,18,19$ ) begins well forward in the olfactory bulb, inside of the olfactory formation (fig. 3). It appears first as a group of small and medium sized cells lying dorsal to the olfactory ventricle and inside of the internal granular layer, in a transverse plane slightly rostral to the cephalic extreme of the accessory olfactory bulb. Solely on the basis of its topographical position it is designated the pars dorsalis of the anterior olfactory nucleus. It is homologous to the superior peduncular nucleus of Ramón y Cajal ('11). The morphology and variety of the cells, as well as their arrangement into indistinct laminae, resemble very closely those of the internal granular layer of the olfactory formation and the two areas are closely associated immediately cephalad to the accessory bulb. Only this portion of the anterior olfactory nucleus satisfies the definition of 'undifferentiated gray' in the rabbit. Even in the cell preparations fibers are evident among the cells of the rostral part of the pars dorsalis. These fibers extend dorsalward to enter the dorsal peduncle of the lateral olfactory tract along with the efferent fibers from the accessory olfactory bulb. Pars dorsalis soon assumes a crescentic outline (in cross section) with the accessory bulb lying in the dorsal concavity. Farther caudally this concavity becomes less marked and the cell group assumes a more linear outline (fig. 4). It acquires an obliquely transverse position in the olfactory bulb, lying along the ventral aspect of the accessory olfactory bulb and dorsal to the olfactory ventricle. Near the rostral extreme of the ventrolateral portion of the pars dorsalis of the anterior olfactory nucleus there appears a small oval patch of large, deeply staining, oval and polygonal cells (L, fig. 3). A few 
sections (50 $\mu$ each) farther caudally a similar group appears at the medial angle of pars dorsalis (M, fig. 3). These circular patches of cells at the medial and lateral extremes of pars dorsalis are quite prominent in the toluidin blue material due to their large and deeply staining cells. They extend over six to eight sections and assume at some levels the outline of a ' $U$ ' with its concavity directed dorsally and peripherally. From this concavity fibers appear to stream outward; those from the lateral group enter the lateral olfactory tract while those from the medial group course peripherally between the olfactory and the accessory olfactory formations to enter the medial olfactory tract. There are two such cell groups or patches placed one behind the other at the medial and lateral extremes of the pars dorsalis. The medial and lateral groups are placed somewhat alternately so that usually both groups do not occur in the same cross section. These cell patches might be considered as detached bits of the pars medialis and the pars lateralis of the anterior olfactory nucleus which have become separated from the cephalic extreme of this nucleus, particularly since they resemble its rostral extreme very closely in cell structure. As the sections are traced caudal to the second of these cell patches, what is apparently a third such group appears in the cross sections and joins the medial and lateral extremes of the pars dorsalis. The lateral group joins it at an acute angle and elongates ventromedially and thus forms the lateral limb, or pars lateralis, of the anterior olfactory nucleus. The medial group joins the pars dorsalis in a straight line as a medial extension of the same, and a little caudal to this junction extends ventrally to enclose the medial border of the olfactory ventricle. It thus forms the medial limb or pars medialis of the anterior olfactory nucleus (fig. 5). As the sections are traced caudally the medial and lateral limbs extend ventrally and finally unite in the ventromedial angle of the peduncle, thus completely surrounding the olfactory ventricle. The extension of the medial and lateral limbs of the anterior olfactory nucleus to surround the ventricle follows closely on the disappearance of the olfactory formation from the medial aspect of the peduncle and the union of 
the two limbs occurs in the same plane in which the olfactory formation disappears from the ventromedial aspect of the peduncle. The gray of the peduncle also blends with the gray of the overlying neopallium in this same plane (fig. 17).

The anterior olfactory nucleus occupies the entire length of the olfactory peduncle, extending rostrally into the olfactory bulb. As the base of the peduncle is approached the cytoarchitecture of the nucleus olfactorius anterior changes to a more differentiated type. This is especially evident in the dorsolateral quadrant where the characteristics of the anterior pyriform cortex are assumed early.

The nucleus olfactorius anterior pars lateralis pars externa (figs. 4,5$)$ begins a few sections $(50 \mu)$ rostral to the cephalic extreme of the pars lateralis itself. Here it appears as an elongated group of small, deeply staining cells closely applied to the inner aspect of the lateral olfactory tract, some of its cells being interposed between the medial fascicles of this tract. With the appearance and enlargement of the pars lateralis, the pars externa diminishes in size for a few sections, then rapidly enlarges and elongates until it is almost equal in length to, but always narrower than, the pars lateralis, to which it lies parallel. The pars externa is now separated from the lateral olfactory tract by a narrow plexiform layer and a similar layer intervenes between it and the pars lateralis. This latter plexiform layer narrows ventrally, suggesting a continuity here between these two cell groups. A similar observation was made for Caenolestes by Obenchain ('25). The cells found in the pars externa are smaller and more compactly arranged than those in the pars lateralis. As the plane of the rostral extreme of the neopallium is approached, the pars externa beçomes thinner and more elongated, accompanying the spread of the lateral olfactory tract over the surface of the peduncle. In the plane of the caudal extreme of the accessory olfactory bulb, the pars externa divides into a dorsal and a ventral tailpiece (fig. 5). The smaller dorsal part continues caudally and dorsally to join a similar group of accessory cells which lies dorsal to the pars dorsalis of 
the anterior olfactory nucleus and finally disappears in the same plane as does the olfactory formation. The ventral part of the pars externa continues caudally and ventromedially for a greater distance than the dorsal part. It lies medial to the pars ventralis of the lateral olfactory tract and finally disappears at the ventral limit of the pyriform cortex (fig. 17).

It has been hypothecated by Obenchain ('25) that the pars externa is derived in phylogeny from a splitting of the pars lateralis under the neurobiotactic influence of the lateral olfactory tract. It is herein observed that the elongation and narrowing of the pars externa accompanies the spread of the lateral olfactory tract over a larger area of the lateral wall of the peduncle. The splitting of this nucleus into a dorsal and a ventral tailpiece might likewise be presumed to be the result of the aggregation of the particular fibers that exert this neurobiotactic influence into the dorsal and ventral parts of the lateral olfactory tract. This division of the nucleus occurs at the caudal extreme of the accessory olfactory bulb and at this level the lateral olfactory tract consists of fibers from the olfactory formation and the nucleus olfactorius anterior and fibers from the accessory olfactory bulb (p. 337). This nucleus has been described in the opossum by Herrick ('24), in Caenolestes by Obenchain ('25). The account given here for the rabbit agrees essentially with the description of the above authors, especially as regards the uneven swallowtail pennant shape found in the opossum. Obenchain stated that the pars externa is an accessory nucleus which serves the function of reenforcing or stepping up the olfactory stimuli by discharging its afferent fibers into the subjacent lateral part of the olfactory nucleus and the relations apparently justify such a conclusion. The pars externa has been labeled by Gurdjian ('25, fig. 2, p. 131). Such a pars externa has been described in the bat by Humphrey ('36). No mention of it has been found elsewhere in the literature. While the toluidin blue preparations permit the subdivision of the nucleus olfactorius anterior into the various parts described in the literature, further work is demanded before a more definite evaluation of their functional significance can be made. 
The nuclear groups in the ventromedial portion of the hemisphere

In its general relations the olfactory peduncle is completely separated from the rostral extreme of the overlying neopallium for a short distance by the rhinal fissure (figs. 6 to 15), which is continued caudally along the lateral surface of the hemisphere as a deep fissure which separates the pyriform lobe from the neopallium, and for a short distance along the medial surface of the hemisphere as a shallow groove. Where the olfactory peduncle joins the hemisphere, the nucleus olfactorius anterior completely surrounds the ventricle, as has been particularly emphasized by Herrick ('24), Obenchain ('25), and Humphrey ('36) in other forms. Caudal to this level lie the pyriform lobe, laterally; the medial and ventral areas of the hemisphere in those respective positions; and the anterior pole of the hemisphere dorsally. The nucleus olfactorius anterior likewise widens into these areas and becomes differentiated into several centers, the transition being accomplished for the most part very gradually by cell differentiation so that no sharp line of demarcation can be drawn between its caudal limits and the rostral extreme of the nuclear groups next to be described. It might be stated provisionally that the dorsal part of the anterior olfactory nucleus blends with the cortical gray of the overlying neopallium, the lateral part is continued into the pyriform cortex, the ventral part is replaced by the tuberculum olfactorium, and the medial part blends into the precommissural hippocampus and the septum. There is no direct cellular continuity between the nucleus olfactorius anterior and the caudate nucleus.

Precommissural portion of hippocampus. Near the base of the olfactory peduncle in the medial part of the anterior olfactory nucleus and on a level with the ventricle can be noted an aggregation of moderately large, oval and rounded cells. Scattered among these are a few smaller, elongated, fusiform or triangular cells which stain intensely and appear almost black in the tigroid preparations. These cells increase 
in number as the sections are followed caudally and they represent a cephalic extension of the precommissural hippocampus (figs. 6, 17), which, in the plane of the rostral extreme of the caudate nucleus, appears as a crescentic group of deeply stained cells at the ventromedial angle of the hemisphere. Some of the cells of this group continue dorsolaterally into the deepest cortical layer of the medial part of the hemisphere, scattered along the medial aspect of the hippocampocortical fibers (fig. 6). Caudally the precommissural hippocampus ascends in a steep curve (fig. 17) to the ventral aspect of the genu of the corpus callosum (fig. 7), where it extends caudally as the nucleus septo-hippocampalis. It also extends rostrally around the genu to reach the dorsal surface of the corpus callosum, where it can be followed caudally, near the midline, as the indusium (figs. 7 to 11,17 ) as far as the caudal aspect of the splenium, over which it passes to join the hippocampus proper.

Tuberculum olfactorium. In the rabbit the tuberculum olfactorium (figs. 6, 7, 8, 17, 20,21) is somewhat triangular in general outline, lying in the ventralmost part of the hemisphere with its apex directed rostrally toward the base of the peduncle and its base directed caudally to the plane of the optic chiasm. It consists of an internal or deep layer, and an external or cortical layer of crumpled and corrugated gray which is sharply bounded laterally by the pyriform cortex, medially by the precommissural hippocampus, in front and behind this by the septal nuclei, and still farther caudally by the diagonal band of Broca. Its rostral extreme lies in the same transverse plane in which the circular olfactory ventricle joins the vertical lateral ventricle. Here the cells are few in number and diffusely arranged and fiber tracts dominate the field in the ventral area of the hemisphere lying between the pyriform cortex laterally and the hippocampus medially. The cells of the caudal extreme of the ventral part of the anterior olfactory nucleus (the pars posterior of most authors) can here be traced into the deep layer of the tuberculum (fig. 6). A short distance caudal to this plane the cor- 
rugated outline of the cortical layer of the tuberculum enlarges at the inner boundary of the external plexiform layer. The two cellular layers are well shown in the tigroid series. The outer, ventral, or cortical layer (tuberculum olfactorium pars corticalis) lies nearer the ventral surface and in cross sections appears as a narrow band of cells presenting many corrugations and evaginations, some of which almost reach the ventral pial surface of the hemisphere. The inner or deeper layer (tuberculum olfactorium pars interna) is composed of more diffusely arranged cells, some of which, however, are clumped into nuclear groups varying in size and shape, while others form typical islands of Calleja (figs. 7, 17). The cells in the rostral extreme of this deep layer are larger, resembling neurons of the anterior olfactory nucleus, while those in the more caudal portions of the nucleus are smaller and similar to the cells of the cortical layer. The deep layer is very intimately associated with the ventral aspect of the nucleus accumbens septi, which lies immediately dorsal to it (fig. 7), and the two appear to blend at certain levels, especially in the more caudal planes. The cells of the cortical layer are rounded in outline but smaller and less deeply stained than those of the neighboring pyriform cortex and hippocampus. Some larger cells are scattered throughout the deeper layer, which otherwise is made up of neurons resembling those of the cortical layer. Both layers of the tuberculum are closely related to numerous cross cut and obliquely coursing fibers which are quite evident even in cell preparations. As the hippocampus curves dorsally toward the corpus callosum the tuberculum olfactorium extends medially and then turns dorsally in the medial hemisphere wall and thus comes to occupy the entire ventral and part of the medial surface of the hemisphere ventral to the nucleus medialis septi (fig. 7). In this plane of its greatest dimensions there occur along the medial border of the nucleus accumbens (in the zona limitans of Johnston, '13) three or four giant islands of Calleja which stain intensely (fig. 17). Caudal to this plane the tuberculum is gradually displaced from the field by the 
ventrolateral extension of the nucleus of the diagonal band of Broca (fig. 8), but its lateralmost part extends caudally to the plane of the optic chiasm. For purposes of description the tuberculum may be divided (in its widest part, which is caudal) into a medial, a lateral, and an intermediate part. The structural pattern of this area varies in different mammals; in the bat (Humphrey, '36) also only the caudal portion of the area shows these three parts. Ramón y Cajal ('11, p. 727) stated that this area corresponds to the anterior perforated space of man.

Nucleus accumbens septi. The nuclear groups of the septal area have been the subject of much controversy and dissention, probably due largely to a lack of agreement regarding their correct phylogenetic and ontogenetic anlagen. As a result a varied terminology has been applied to this area (the paraterminal body of Elliot Smith, '10 and earlier; the septum of Edinger, '08 and Herrick, '10 and elsewhere; the parolfactory area of Johnston, '13 and '15) and it has been divided into a varying number of cell groups. The terminology of Edinger and Herrick is employed here, realizing, of course, that the term 'septum' is used in a purely comparative sense and is not to be confused with the term 'septum pellucidum' as used in human anatomy, since only its most caudal portion falls within this latter area. Most of the American school of comparative neurologists now employ the term 'septum' as including the medial telencephalic wall ventral to the hippocampal formation and rostral to the anterior commissure (Hines, 29 ).

The nucleus accumbens (figs. 7, 8, 17, 21, 28) appears rostrally in the transverse plane in which the hippocampus turns dorsalward toward the corpus callosum. Apparently this nucleus is a medial expansion of the head of the caudate nucleus through the narrow area lying between the ventricle dorsally and the anterior limb of the anterior commissure ventrally, thus entering the medial area of the hemisphere. It extends around the ventral aspect of the lateral ventricle and forms the medial wall of the ventral part of the same. In some planes its cells almost completely surround the interbulbar component of the anterior commissure (fig. 8). The 
medial surface of the accumbens nucleus is convex and lies adjacent to the cell free zona limitans, which forms a sharp boundary between it and the septal nuclei. Ventrally it blends intimately with the internal layer of the tuberculum olfactorium (fig. 7). Caudally it extends as a narrow band of cells over the medial aspect of the interbulbar fibers nearly to the plane of crossing of the same, where it blends with the supracommissural part of the interstitial nucleus of the stria terminalis. Its cell structure resembles closely that of the caudate nucleus but the arrangement is less broken up by cross cut fibers than is the case with the caudate nucleus. Johnston ('13) has included this nucleus with his lateral parolfactory nucleus. Since the accumbens nucleus topographically and functionally occupies an intermediate position between the septum and the striatum, it has been described here but will be considered again with the striatum, of which it is actually a part.

Nucleus lateralis septi (figs. 7, 8). The cephalic extreme of the lateral septal nucleus lies slightly caudal to the plane of the rostral extreme of the genu of the corpus callosum. It lies ventral to the latter structure and between the septohippocampal nucleus medially and the lateral ventricle laterally. The cells are moderate in size, faintly stained, and triangular or fusiform in outline. The nucleus enlarges rapidly and extends medially to blend imperceptibly with the septohippocampal gray, and ventrally to become continuous with the medial septal nucleus without a sharp line of demarcation. Intimately blended with these neighboring groups, it continues caudally to the nucleus of the hippocampal commissure, where it can no longer be delimited as a special nuclear group.

Nucleus medialis septi (figs. 7 and 8). This group of cells extends a few sections farther rostrally, but in general outline is much smaller than the lateral group. Its cells are moderate in size, fusiform in outline, and more deeply stained than those of the lateral group; in general they are disposed in a dorsoventral manner. The medial septal nucleus makes its rostral appearance at the medial aspect of the accumbens nucleus; 
it enlarges toward the midline and extends dorsally along the medial border of the accumbens nucleus to blend with the ventral aspect of the lateral septal nucleus, with which it is continued caudally above the anterior commissure. The caudal part of this nucleus is composed of smaller and more compactly placed cells than the rostral part. The nucleus of the diagonal band passes in close relation to the ventrocaudal part of the medial septal nucleus.

Nucleus septo-hippocampalis (the so-called 'primordium hippocampi' and dorsal septal nucleus; figs. 7, 8, 17). Of the perplexing nuclear groups of the septum, the region described by Johnston ('13) as the primordium hippocampi has given rise to more differences of opinion and interpretation than all the associated septal nuclear groups. Johnston stated that the area intervening between his sulcus fimbriodentatus and sulcus limitans in reptiles was 'hypothetically identified' as the primordium hippocampi. He based his conclusions partly on the presence in this area of hippocampal commissure and fornix fibers and partly on its appearance, in his opinion, in the thickened portion of the lamina supraneuroporica. In the rabbit he carried this primordium ventralward to the zona limitans which outlined his nucleus parolfactorius lateralis, extended it forward into what is usually considered the rostral continuation of the hippocampus and caudalward into the bed nucleus of the hippocampal commissure and adjoining gray. Crosby ('17) recognized a lateral parolfactory nucleus comparable to the lateral septal nucleus of Herrick ('10), which included the lateral part of the primordium hippocampi as described by Johnston ('13), leaving a small area medial to the hippocampal commissure fibers and extending forward with the hippocampus toward the olfactory bulb region. Hines ('22) suggested that the primordium hippocampi might be the anlage of the fascia dentata. The anterior part is obviously the anterior extension of the hippocampus as seen in mammals. The part in the septal region is characterized by its intimate relation with the descending hippocampal commissure and fornix longus 
system and corresponds to the nucleus dorsalis septi of Loo ('31). This latter nucleus of Loo can be identified easily in the rabbit material available for study, but it is continuous there with the anterior extension of the hippocampus. It is thus a question of personal interpretation and of terminology as to where one should cease to call it hippocampus and begin to call it septum. From its position in relation to the anterior extension of the hippocampus, the nucleus extends caudalward to the bed nucleus of the ventral hippocampal commissure. Behind this level its caudal portion passes over into the bed nucleus of the dorsal hippocampal commissure and nucleus fimbrialis septi. This portion of the so-called primordium hippocampi, or, if preferred, the nucleus dorsalis septi, is seen as a commissural gray mass connecting the dorsal and ventral hippocampal (commissura fornicis) commissures, serving as an interstitial nucleus in the course of the descending hippocampal fibers. Its intimate association with the hippocampal paths and hippocampus is emphasized by the above account. The septo-hippocampal nucleus has been identified in the bat by Humphrey ('36).

The bed nucleus of the hippocampal commissure (fig. 9). Tigroid preparations show both small and medium-sized cells scattered among the decussating fibers of the hippocampus. These are especially evident in the commissura fornicis. These cells form a bed nucleus for the fibers and are apparently a specialization of the cells of the septal area immediately rostral to this level. They have been studied in detail in Golgi preparations by Ramón y Cajal ('11, p. 778). Triangular nucleus of the septum (fig. 9). Extending rostrally from the neuroporic recess is a triangular group of very small cells occupying the midplane above the anterior commissure. They apparently represent a condensation of the cells of the bed nucleus of the hippocampal commissure, but they are smaller, more compact, and more deeply stained than the latter. This group has been described by Ramón y Cajal ('11) and more recently by Loo ('31). 
Nucleus tractus cortico-habenularis medialis (fig. 9). This small group appears at the lateral aspect of the rostral extreme of the triangular nucleus of the septum. It is composed of moderately large fusiform cells which have a purple tinge in tigroid preparations. The cells for the most part have a dorsoventral arrangement at the lateral aspect of the fornix columns, where they are scattered among the fibers of the medial cortico- and septo-habenular tracts. They only extend caudally for a few sections among these fibers and are lost in the plane of the anterior commissure. They represent a specialization of a broad band of gray extending back into the diencephalon, termed the caudal extension of the bed nucleus of the hippocampal commissure in lower forms (Huber and Crosby, '26).

Bed nucleus of the anterior commissure (figs. 9 and 17). This nucleus is represented by an oval group of small cells surrounding the rostral and ventral aspects of the anterior commissure on either side of the midline. The cells are small like those of the surrounding area, but stain slightly deeper. Laterally the nucleus is bounded by the supracommissural part of the interstitial nucleus of the stria terminalis, and ventrally it passes into the preoptic region. This group of cells is not well defined nor sharply delimited in rabbit. A bed nucleus for the anterior commissure has been recognized in rodents by Gurdjian ('25) and Craigie ('25) and in the opossum by Loo ('31). It has long been recognized in lower forms.

The nucleus of the diagonal band of Broca (figs. 8 and 17). This band of gray and its associated fascicles have been recognized by various students (Broca, 1879; Johnston, '15, 23, for the rabbit; Craigie, '25, for the rat; Loo, '31; Humphrey, '36, for the opposum) of the mammalian telencephalon (although sometimes under other names), and for reptilian (Johnston, '15; Crosby, '17 ; Cairney, '26 ; and others) and avian forms (Huber and Crosby, '29). The nucleus of the diagonal band of Broca is well shown in our cross and sagittal series of tigroid preparations. It is composed of 
medium sized, well stained, oval cells, some of which are elongated and packed in between the fibers of this band. There are also many larger cells present in this nucleus that will be separately considered below. In the sagittal series this nucleus forms a bow-shaped mass near the midplane, with its shallow concavity directed caudally and its vertex directed rostrally as far as the plane of the giant islands of Calleja (fig. 17). The dorsal limb of the bow begins in the septal region a little rostral and dorsal to the anterior commissure (fig. 8) and extends ventrally, medially, and rostrally as a broad band of cells through the septal region to the ventrocaudal border of the medial septal nucleus. From this point it extends caudalward and ventralward (as the ventral limb of the bow) to the medioventral aspect of the hemisphere, where it turns lateralward and crosses the ventral area of the hemisphere to terminate in the anterior amygdaloid area in the pyriform region. In cross sections, a short distance in front of the anterior commissure, the diagonal band meets its fellow in the midline and gives a conspicuous triangular outline to the midventral part of the sections (fig. 8). The rostral extreme of the nucleus of the diagonal band is intimately associated with the medial septal nucleus. The ventral limb of the diagonal band passes beneath the anterior commissure; it also passes ventral to and partly through the medial forebrain bundle in the lateral preoptic area where it is designated as the nucleus preopticus magnocellularis (figs. $9,10,16)$. The lateral course of the diagonal band from the midplane along the ventral aspect of the hemisphere to the pyriform area displaces the tuberculum olfactorium and forms its caudal limits. It also establishes a cellular continuity between the septum medially and dorsally and the pyriformamygdaloid area laterally and ventrally. Accompanying this cellular group are fibers of the precommissural fornix system (the tract of the diagonal band) to the lateral hemisphere areas (p. 343), for which it forms an interstitial nucleus.

The presence of many large, oval and triangular cells has been noted above in relation to the diagonal band. These have 
a very distinct nucleus, a clear perinuclear area, and many large Nissl bodies in their cytoplasm. These cells are diffusely scattered through the rostral extreme of the nucleus of the diagonal band, but farther caudally they tend to aggregate at its lateral border, and when the diagonal band turns lateralward across the ventral floor of the hemisphere they occupy a dorsal position in this nucleus. When the medial forebrain bundle is reached this large celled portion divides into a dorsal group and a ventral group. The latter group continues with the diagonal band lateralward toward the pyriform lobe, while the dorsal group extends dorsally and caudally to enter the rostral extreme of the medial segment of the globus pallidus. Johnston ('23, p. 377) apparently recognizes these as isolated clumps of large cells near the anterior commissure in his horizontal series, and he says: "The only cells with which these could be compared are the large cells of the globus pallidus, but these recede as the diagonal band advances in this region so that there is no doubt as to the limits of either." As yet it has not been possible to follow any fiber fascicles into special relation with these large cells, consequently no interpretation of their functional significance is offered.

Nucleus septalis fimbrialis (fig. 9). This group of cells may be considered as the caudoventral continuation of the more rostral groups of the septal area (the lateral septal nucleus and nucleus septo-hippocampalis). It lies lateral and somewhat ventral to the fornix fibers as they course caudally through the septal area to form the columna fornicis. It is bounded laterally by the lateral ventricle. The triangular nucleus of the septum may be said to separate this group of cells from its fellow of the opposite side. The cells of nucleus septalis fimbrialis, however, are larger than those of the triangular nucleus. Fibers enter its dorsal aspect from the fornix system and the septo-habenular fibers arise here to pass caudally with the fornix fibers. This nucleus might therefore be considered as a place of synapse for some fibers from the hippocampus to the habenular and hypothalamic centers. 
The basal centers of the lateral wall of the hemisphere

It is obvious to all familiar with the comparative neurological literature, that any attempt at a complete review of the literature dealing with these basal centers of the lateral wall would in itself far exceed the limits of the present paper. Consequently, the following list includes those articles which proved of particular value in delimiting the nuclear groups in the material studied or in interpreting its significance. On this basis special mention is made of the contributions of Völsch ('06, '10) on the ferret, de Vries ('10) on mammals, Winkler and Potter ('11, '14) on rabbit and cat, Johnston ('23) on various mammals, Obenchain ('25) on Caenolestes, Precechtel ('25) on elephant, Gurdjian ('28) on rat, Hines ('29) on Ornithorhynchus, Olive Smith ('30) on Tamandua, Loo ('31) on opossum and Humphrey ('36) on bat. Reviews of the literature on these centers in other forms are available in various research papers and in the reference book by Ariëns Kappers, Huber and Crosby ('36).

Caudate nucleus (figs. 6 to 15,20 to 26 ). In the rabbit the caudate nucleus extends rostrally approximately to the plane of the cephalic extreme of the tuberculum olfactorium. Just caudal to the plane of junction of the olfactory and lateral ventricles there appears at the lateral aspect of the latter a group of small, faintly staining cells interposed as a wedge between the ventricle and the fibers of the internal capsule, with its apex directed dorsally and its blunt extremity resting ventrally upon the interbulbar fibers (fig. 6). Here the cephalic extreme of the caudate nucleus appears to be a differentiation from the periventricular gray, for no definite cellular continuity can be established with nearby nuclear groups, from which it is separated on all sides by fiber bundles. Laterally is the internal capsule, ventrally the interbulbar component of the anterior commissure, medially the lateral ventricle, and dorsally the corpus callosum and corona radiata. Traced caudally the caudate nucleus enlarges rapidly and its lateral cells become interposed among the medial fascicles of the internal capsule. As the anterior limb of the internal 
capsule takes on its characteristic form, the caudate nucleus intervenes between it and the lateral ventricle; however, bands of gray extend laterally between the fascicles of the internal capsule to become continuous with the rostral extreme of the putamen, which in turn lies between the internal capsule medially and the external capsule laterally (fig. 8). No differentiation between these two cell groups can be made on a basis of cell morphology or arrangement and no evidence of their derivation from different anlagen is offered by the adult material. In some rodents (Gurdjian, '28 for the rat) they are considered together as a caudo-putamen complex. Medially the caudate nucleus extends around the ventral aspect of the lateral ventricle and into the medial wall of the hemisphere to form the nucleus accumbens septi, which has already been described with the septal area. The caudate and accumbens nuclei are continuous with each other through the slightly constricted area lying between the lateral ventricle and the interbulbar fibers (as shown in fig. 7). The cells of the accumbens nucleus appear to be somewhat more deeply stained and slightly more compactly arranged than those of the caudate, but this distinction is not marked. Near the plane of the giant islands of Calleja the internal capsule has assumed a more medial position and its fibers are aggregated into larger fascicles but there is still a distinct caudo-lenticular fusion of the gray between these fascicles. In the plane of figure 8 the ventral angle of the lateral ventricle and the interbulbar fibers have approached each other and thus constricted the connecting area between the caudate nucleus and the nucleus accumbens. Here the boundaries of the caudate are as follows: medially and dorsomedially the lateral ventricle, dorsally the corpus callosum, and laterally the internal capsule, which incompletely separates it from the putamen. Its narrow ventral extreme extends into the accumbens nucleus medially. As the sections are traced caudal to this plane the fibers of the internal capsule become aggregated into fewer but larger fascicles and it assumes a more medial position (fig. 9), this at the expense of the caudate nucleus which becomes gradually smaller. In the plane of the caudal extreme 
of the anterior commissure (fig. 10) the internal capsule apparently forms a complete boundary between the caudate nucleus and the ventrally lying putamen. Here the caudate is oval in outline and this level may be considered as marking the beginning of the tail of the caudate, although the transition between the head and tail takes place so very gradually that no sharp delimitation of either is possible. The stria terminalis courses along the ventrolateral boundary of the tail of the caudate. Maintaining these same relations, the tail of the caudate continues caudally over the dorsal surface of the internal capsule, gradually becoming smaller and more rounded in outline. The cell structure remains unchanged, but here and there small, patchy aggregations of deeper staining cells occur. In the plane of the rostral extreme of the nucleus geniculatus lateralis pars ventralis, the tail of the caudate turns sharply ventralward, along with the stria terminalis, over the caudal aspect of the internal capsule fibers to rejoin the putamen and the amygdaloid complex, and can be followed a short distance farther caudally, lying in the lateral wall of the lateral ventricle (fig. 15).

Putamen (figs. 7 to 15, 21 to 26). Cross section series of the toluidin blue material show that in the rabbit the putamen is roughly triangular in outline in its rostral half (fig. 9) and kidney-shaped in its caudal half, with the globus pallidus assuming the appearance of the hilus (fig. 12). Rostral to the plane of the anterior commissure the putamen is more or less continuous with the head of the caudate nucleus by means of cellular extensions between the fascicles of the internal capsule. This caudo-lenticular fusion results in a caudateputamen complex similar to that described in the rat by Gurdjian ('28). The cell structure of this area is uniform throughout. Accepting the internal capsule as the conventional boundary between the caudate and putamen, the boundaries of the latter rostral to the plane of the anterior commissure are; the external capsule laterally, the internal capsule medially, and the interbulbar fibers medioventrally. Ventrally the putamen is not sharply bounded and extends 
among the cells of the deep layer of the tuberculum olfactorium, and at some levels joins the accumbens nucleus ventral to the interbulbar fibers (fig. 8). Farther caudally this ventral extension is separated from the main mass of the putamen by the transverse fibers of the external capsule as they approach the anterior commissure (fig. 9). This ventral part stains slightly deeper than the rest of the putamen and is apparently the part given the designation of 'nucleus intermedius striati' by Loo ('31), who stated that in his material "It is continuous below and in front with the head of the caudate though partly separated from it by fascicles of the lateral forebrain bundle that lie below the anterior commissure." In the rabbit material it has not been possible to establish relations of this nucleus intermedius striati with the head of the caudate nucleus, while its relations with the putamen, as regards both cellular continuity and interfiber connections, are evident in the cell and fiber material studied. Consequently, it is regarded in the present contribution as belonging to the putamen complex, an interpretation in accord with the work of Livini ('08) and Dart ('20). A short distance caudal to the plane of the anterior commissure the globus pallidus appears at the medial aspect of the putamen, and, together with the internal capsule, forms the medial boundary of the latter (figs. 11 and 12). The lateral boundary of the putamen is now formed by the external capsule and by the pars anterior of the lateral amygdaloid nucleus, which is here wedged in ventrally between the putamen and the external capsule. The central amygdaloid nucleus lies ventral to the caudal part of the putamen and is closely associated with it (figs. 11, 13). The putamen decreases in size as it is followed farther caudally and terminates by blending with the amygdaloid nuclei and the tail of the caudate nucleus as the latter dips ventrally over the caudal aspect of the internal capsule to enter this area from above (figs. 14 and 15).

Intercalated mucleus of the internal capsule (figs. 9, 10; Nucl. intercal. L. F. B.). This name of intercalated nucleus has been applied to a large and prominent cell group scattered 
among the ventromedial fascicles of this capsule. At its rostral extreme the transverse fibers of the external capsule divide this nucleus into a dorsal and a ventral portion (fig. 9). Caudal to these transverse fibers the dorsal and ventral portions unite to form a single group (fig. 10), the cells of which intervene between the cross cut fascicles of the internal capsule, separating these fascicles and causing a marked enlargement of the area as a whole. The intercalated nucleus of the internal capsule continues caudalward in these relations to a plane through the rostral extreme of the globus pallidus, where the cells of this nucleus blend with those of the globus pallidus. Probably this nucleus is to be regarded as interstitial with respect to certain components passing through the internal capsule. Difficulty has been encountered in attempts to homologize it with certain accounts in the literature. It is neither the "noyau de la capsule interna" of Ramón y Cajal ('11), which is a diencephalic center, nor is it the entopeduncular nucleus of Gurdjian ('27), Olive Smith ('30), and others. Possibly it is the peduncular nucleus as labeled by Papez ('29, fig. 17) in the cat. The cells of this nucleus are moderately large, are triangular in outline, and stain relatively deeply. In some more caudal levels of this nucleus these cells are interspersed with very large triangular neurons of the type characteristic of the globus pallidus.

Globus pallidus (figs. 11 to 13). The globus pallidus in the rabbit is made up of large, and certain very large, cells. The large cells are continuous with those of the group described in the preceding paragraph. The globus pallidus attains its greatest dimensions in the plane of the caudal third of the optic chiasm, where it is seen as a roughly triangular group of cells closely applied to the medial aspect of the putamen, from which it is not sharply delimited by a medullary lamina. The cells extend among the more lateral fascicles of the internal capsule and the group as a whole is traversed by many fiber bundles coursing in various directions, which aids in giving it its characteristically pallid appearance in cell preparations. The large cells of the globus pallidus are triangular in outline and deeply 
stained. They are the largest individual cells found in the striatum and apparently the largest in the basal regions of the forebrain. Traced rostrally, these large cells separate into two small groups; a dorsal group which may be followed among the fibers of the internal capsule and its intercalated nucleus, and a ventral group which extends medially and ventrally to the nucleus of the diagonal band of Broca. Traced caudally the globus pallidus grows progressively smaller and disappears as the optic tract appears at its medial aspect. The relations of the globus pallidus to the entopeduncular nuclear group are discussed under the next heading.

The entopeduncular nuclear group (figs. 13 and 14). Certain of the cells in the caudal third of the globus pallidus extend ventromedially along the fibers of the ansa lenticularis (fig. 13). These neurons retain cellular characteristics comparable to those of the cells of the globus pallidus and constitute a nucleus for the ansa lenticularis which finds representation in the various entopeduncular nuclear groups. The term nucleus entopeduncularis has been applied to various nuclear groups, and in certain cases to groups of different functional significance. In birds Edinger and Wallenberg ('01) applied the name to what more recent observers have been calling the paleostriatum primitivum (Ariëns Kappers, '23, '28; Huber and Crosby, '29; and others) and which is believed to be the forerunner of the globus pallidus, and also applied the term to scattered groups along the course of the ventral peduncle of the lateral forebrain bundle which have been described in various submammals such as fishes (Ariëns Kappers, '21) and reptiles (Edinger, '08; de Lange, '11; Huber and Crosby, '26; and others) as entopeduncular nuclei, the various clusters of cells being designated as dorsal and ventral entopeduncular nuclei, or in some comparable way. These groups along the course of the ventral peduncle of the lateral forebrain bundle may be more or less continuous with the primitive anlagen of the globus pallidus, although showing regional enlargements as in certain birds (Huber and Crosby, '29, sparrow), or may appear as separate groups as is the case 
in certain reptiles. In mammals Olive Smith ('30) has considered that the inner segment of the globus pallidus is derived from the entopeduncular nuclear group, and the more caudal cells either scattered or compactly arranged are found "along the fibers of the lateral forebrain bundle (internal capsulepeduncle)." It must be remembered in this connection that the ventral peduncle of the submammalian lateral forebrain bundle is not represented in the internal capsule proper (except as the fibers cross it) nor in the cerebral peduncle proper, but in the ansa lenticularis of higher forms, and if its phylogenetic significance is to be retained, the term has application particularly to the scattered cell masses associated with the ansa lenticularis (Huber and Crosby, '29 a). Used in this way it is the homologue of the nucleus entopeduncularis of Rioch ('29) and the nucleus of the ansa lenticularis of Loo ('31). In addition to such cell groups, which are the direct. phylogenetic descendants of the entopeduncular groups of lower forms, there are cells associated with the efferent fibers from the cortex, which constitute the cortical projection paths of the internal capsule and form the fiber masses of the cerebral peduncle. These are evident in the rabbit material studied (fig. 14). So far as present evidence goes, these efferent cortical paths are new in mammals (although they may replace in part older efferent striatal paths). The cells associated with them through their relations with the globus pallidus show resemblance to the entopeduncular group, but their relations with these cortical fibers are secondarily acquired. If they are to be termed 'entopeduncular' (as Gurdjian, '27; Loo, '31, and others have done) it must be with full appreciation of the fact that they are not primarily representatives but secondary derivatives of the entopeduncular group of lower forms. Various other names have been given to these groups within the diencephalon, such as the intrapeduncular and suprapeduncular nuclei of Livini ('08).

Claustrum (figs. 7 to 14). There is still some question as to whether the claustrum is to be regarded as striatal or cortical. Thus Landau ('19) and Faul ('26) group it with striatum, 
while Brodmann ('09), Rose ('28, '31), and others have considered it as belonging with the insular cortex. De Vries ('10) regarded it as derived from the adjacent cortex and the studies of Elliot Smith ('19), Holmgren ('25), and others tend to support this view. The preponderance of evidence indicates at present that the claustrum is cortical rather than striatal; nevertheless it is discussed here because of its intimate topographical relations with the basal centers of the hemisphere. In the tigroid preparations the claustrum is seen as a group of deeply staining cells resembling cortical neurons in appearance, lying at the lateral aspect of the external capsule (fig. 9). This group is roughly dumb-bell shaped in outline in the cross sections, with its larger blunt extremity placed dorsally among the lateral fibers of the corona radiata and its smaller blunt or rounded extremity directed ventrally into the pyriform area. Its lateral boundary is formed by a narrow fiber layer of the cortex, the capsule extrema. This group extends from the anterior part of the hemisphere rostrally, to the temporal pole of the hemisphere caudally, blending at each extremity with the deep layer of the cortex. Throughout its extent it is rather sharply delimited ventrally within the confines of the pyriform lobe, while dorsally it is more closely associated with the deepest cell layer of the cortex among the fibers of the corona radiata.

The amygdaloid group. The amygdaloid nuclei have been described in the rabbit by von Kölliker (1896), but this author includes most of the amygdaloid complex with the lentiform nucleus. It was figured in part by Winkler and Potter ('11) for this rodent and has been studied by Johnston ('23) for various mammals including the rabbit. With the excellent description of Johnston the following account is in essential agreement, differing only in certain minor details. Consequently, the descriptions here are relatively brief.

The amygdaloid area in the rabbit (figs. 11 to 15, 26) occupies the medioventral part of the pyriform lobe from the caudal and lateral extreme of the nucleus of the diagonal band, in front, almost to the plane of blending of the gray of 
the dorsal and ventral limbs of the hippocampus, caudally. In this rather extensive area several nuclear groups may be outlined on the basis of their cell morphology and arrangement, as well as their fiber connections, especially with the stria terminalis. The tail of the caudate, the lateral amygdaloid nucleus, and the putamen blend intimately in the region of the caudal extreme of the latter. Loo ('31) believed that this fusion represents a remnant of the amygdaloid ridge of reptiles (Johnston, '23). The caudal extreme of the nucleus of the diagonal band of Broca extends to the rostral extreme of the amygdaloid area, and Gurdjian ('28) has designated this diffuse area of fusion as the anterior amygdaloid area. This is an area of scattered cells intermingled with the fibers of passage (fig. 10, unlabeled).

Nucleus of the lateral olfactory tract (figs. 12 and 25). In the plane in which the optic tracts turn lateralward from the optic chiasm there occurs a prominent rounded nucleus in the ventralmost part of the hemisphere between the pyriform cortex, laterally, and the preoptic area, medially. This is the nucleus of the lateral olfactory tract and represents the most sharply delimited group in the amygdaloid area. It is a duplex structure consisting of a medial and a lateral part. The latter is the larger and is oval in outline, composed of large cells which resemble those of the pyriform cortex, and is closely applied to the dorsal aspect of the lateral olfactory tract. The caudal part of this cell group is covered dorsally by the anterior commissure component of the stria terminalis, which arises (and apparently terminates also) in this nucleus. It disappears as a distinct group in the same transverse plane in which the optic tract reaches the medial border of the hemisphere, but caudal to this plane a few of its cells are scattered along the aforesaid component of the stria terminalis. The medial, small celled portion of the nucleus of the lateral olfactory tract is separated from the lateral part of the same nucleus by a narrow plexiform area. This cell group extends rostrally as a long, tongue-like projection at the medial and dorsal aspect of the lateral olfactory tract. Its cells are 
smaller and less deeply stained than those of the lateral part of this nucleus. It diminishes in size and finally disappears while the lateral part of the nucleus is still prominent in the field. The nucleus of the lateral olfactory tract is described as having dorsal and ventral parts in the rat (Gurdjian, '28) and also in Caenolestes (Obenchain, '25). This nucleus is apparently the same as that labeled ' $\mathrm{Ed}$ ' by Winkler and Potter ('11, figs. VII to IX). A very interesting variation of the usual mammalian pattern is found in the nucleus of the lateral olfactory tract in the bat (Humphrey, '36).

Lateral amygdaloid nucleus (figs. 11 to 15). The lateral nucleus is the largest of this amygdaloid group. It extends farther rostrally and caudally than any of the other amygdaloid nuclei. Throughout its extent it lies just medial to the external capsule, which separates it from the claustrum. In cross section it is roughly triangular in outline. On a basis of cell morphology and topographic relations it is divided in the present account into a pars anterior and a pars posterior, a subdivision not made by previous workers. The pars anterior of the lateral amygdaloid nucleus (figs. 11 to 15) is an elongated rostral extension from the main nucleus (or pars posterior). It is composed of moderately large, deeply staining, spindle-shaped cells. This group extends to the plane of the anterior commissure, and throughout its course is wedged in ventrally between the putamen, medially, and the external capsule, laterally. The fibers of the latter are seen to split at some levels and form a capsule for this nucleus (fig. 12). At its ventral aspect courses part of the posterior limb of the anterior commissure which is very prominent at these levels even in cell preparations-and it seems quite probable that this nucleus is more closely related to the two afore-mentioned fiber tracts than it is to the stria terminalis. Farther caudally, in the plane of the central amygdaloid nucleus, the pars anterior elongates and extends as a narrow, vertical band of cells at the lateral aspect of the putamen. In the plane of the rostral extreme of the medial amygdaloid nucleus, the pars anterior blends with the dorsal aspect of 
the pars posterior of the lateral amygdaloid nucleus which is distinguishable through its cellular character. In this plane the lateral nucleus now appears to be made up of a dorsal (pars anterior) and a ventral (pars posterior) portion. Johnston ('23, p. 425) undoubtedly refers to the pars anterior of the lateral nucleus which he described as a continuous plate of darkly staining cells extending from the anterior commissure to the caudal border of the corpus striatum. The caudal extreme of the pars anterior overlaps the rostral extreme of the pars posterior in the rabbit, and Gurdjian ('28) described the lateral amygdaloid nucleus in the rat as composed, in some planes, of a dorsal small celled portion and a ventral large celled portion. The cell morphology would therefore be the reverse in rat of that found in rabbit, if this homology can be established between the lateral amygdaloid nucleus of these rodents. Caudal to this level of overlapping in the rabbit the pars posterior enlarges as the pars anterior grows progressively smaller to disappear soon after the tail of the caudate joins the amygdaloid group.

The posterior part of the lateral amygdaloid nucleus (figs. 14 and 15) forms the bulk of this group, being much larger than the anterior part, and is composed of small, oval, and less deeply stained cells. It begins rostrally in the transverse plane of the cephalic extreme of the medial amygdaloid nucleus, where it is seen at the lateral aspect of the central amygdaloid nucleus, overlapped dorsally by the pars anterior of the lateral amygdaloid nucleus. It is triangular in outline and caudal to the nucleus centralis it enlarges to occupy the entire area between the lateral ventricle and the external capsule. The tail of the caudate joins it dorsally while the basal nucleus borders it ventrally. It is the most caudal member of the amygdaloid group but finally disappears in the lateral wall of the ventricle, lying dorsal and medial to the external capsule fibers.

Central amygdaloid nucleus (figs. 11, 13, 14). The central nucleus appears rounded or oval in outline. It is a large group placed medial to the lateral nucleus and ventral to 
the caudal part of the putamen. Its ventral boundary is formed by the basal nucleus. The cells of this group are medium sized, spindle and fusiform in outline, and not as compactly placed as those of the surrounding groups, giving to this area a more diffuse appearance in cell preparations. The rostral extreme of this nucleus is poorly delimited as it blends intimately with the overlying putamen. Caudal to the plane of appearance of the nucleus basalis, the central nucleus grows smaller as a result of the enlargement of the nucleus basalis and the nucleus lateralis pars posterior, and finally disappears in the plane in which the tail of the caudate joins the amygdaloid group. The lateral amygdaloid nucleus extends medially around the caudal aspect of the nucleus centralis, thus forming its caudal as well as its lateral boundary. The caudal third of the central amygdaloid nucleus is bounded on its ventromedial aspect by the two forks of a dense $\mathrm{Y}$-shaped group of cells (fig. 14), the stem of the $Y$ extending ventrally along the stria terminalis fibers. This group is composed of small, compactly placed cells which Völsch ('06) interpreted as glial cells, but it is more probable that they are neurons as Johnston ('23) has supposed. This group of cells serves as a boundary between the central and the underlying basal nucleus and hence corresponds to the 'intercalated masses' of Johnston ('23, p. 427).

Basal amygdaloid nucleus (figs. 13, 14, 15). The basal nucleus of the amygdaloid area is composed of two distinct parts, as was noted by Völsch ('06) in the ferret and by Johnston ('23) in the opossum and the rabbit. There is sufficient cellular differentiation to regard these as two separate nuclei, but in the present account they will be considered as the lateral large celled group and the medial small celled group of the basal amygdaloid nucleus. In the opossum (Johnston, '23 and Berkelbach van der Sprenkel, '26) and in Caenolestes (Obenchain, '25) the basal amygdaloid nucleus consists of a lateral small celled portion, termed the accessory basal nucleus, and a medial large celled portion, termed the basal nucleus. It seems wiser at present to attempt no direct 
homologies between the constituents of the basal nuclear groups in the rabbit and in marsupials, since the large and small celled groups occupy reverse positions in these two forms. In the bat, however, the accessory basal nucleus occupies a medial position. The lateral, large celled group of the basal amygdaloid nucleus (figs. 13 to 15) is composed of deeply stained, elongated cells which rememble those of the pyriform cortex. These cells are grouped into an almondshaped mass placed transversely at the ventral aspect of the lateral nucleus. The external capsule approaches the lateral extreme of this group and splits, sending some fibers dorsal and others ventral to this nucleus. The dorsal fibers separate it from the overlying lateral nucleus. Farther caudally all the fibers pass dorsal to the basal nucleus and a short distance caudal to this plane the cell group disappears as a distinct nucleus, its cells scattering among those of the pyriform area. Rostrally this nucleus can be traced as a small projection of scattered cells lying in the ventral angle between the lateral and central nuclei almost to the transverse plane of the optic chiasm. The medial small celled group of the basal amygdaloid nucleus (fig. 14) lies closely applied to the medial aspect of the lateral large celled group, but is delineated from it by a narrow area of fibers with a few intercalated cells. Its extent is not so great in any direction as is that of the lateral group, but it enlarges medially and causes a distinct convex bulge into the lateral ventricle. This medial group might be subdivided further into a dorsal part, of very small cells, and a ventral part of slightly larger cells. The entire group is bounded medially by the stria terminalis fibers as they course along the lateral border of the ventricle.

Cortical amygdaloid nucleus (figs. 11 and 13). This nucleus consists of a ventral grouping of the cells of the anterior amygdaloid area into a rather dense band of cells which resembles a medial extension of the pyriform cortex except for the fact that the cells of the cortical nucleis are smaller and less deeply stained than those of the pyriform cortex. It extends from the plane of the caudal extreme of the nucleus 
of the lateral olfactory tract to the plane of the tip of the temporal pole of the lateral ventricle. Rostrally this nucleus lies along the ventral border of the hemisphere medial to the pyriform cortex and farther caudally it extends medially along the medioventral border of the hemisphere at the lateral aspect of the ascending optic tract. It now has the outline of $a^{\prime}$ ' $\mathrm{V}$ ' in cross sections with its apex in the extreme medioventral angle of the hemisphere. One limb extends dorsolateralward into the pyriform area and the other limb extends dorsally along the medial border of the hemisphere. The whole nucleus assumes a more dorsal position as the sections are traced caudally and is overlapped at the medioventral angle of the hemisphere by the medial amygdaloid nucleus.

Medial amygdaloid nucleus (figs. 13 and 14). The medial nucleus of the amygdaloid complex occupies the medioventral angle of the hemisphere after the cortical nucleus assumes a more dorsal position. Its rostral extreme extends almost to the plane of the optic chiasm (fig. 13). It enlarges caudally, maintaining its same relations, and seems to blend with the gray of the ventral limb of the hippocampus. Its caudal third is overlapped ventrally by the pyriform cortex. This group is plainly related to the stria terminalis, even in cell preparations, and it is the only group included in the amygdala by von Kölliker (1896, figs. 716 and 717), who included the other amygdaloid nuclei with the lenticular nucleus. The medial nucleus of the present description corresponds to the area praesubicularis of Winkler and Potter ('11, z.pr.s., plates XI and XII). The cells of the medial and central amygdaloid nuclei cannot be traced dorsally into the stria terminalis to any appreciable extent in the tigroid material available, and hence no cellular continuity can be established between these groups and the interstitial nucleus of the stria terminalis, such as has been maintained to be the case by Johnston ('23).

Interstitial nucleus of the stria terminalis (figs. 9 and 10). This nuclear mass is shown best in the plane of the anterior commissure, where it appears among the fibers of the stria terminalis as this latter dips medially and ventrally toward 
the anterior commissure. Here the nucleus occupies the triangular area bounded ventrally by the lateral part of the anterior commissure, laterally by the internal capsule, and medially by the lateral ventricle. Its apex is directed dorsolaterally toward the caudate nucleus. The nucleus extends ventrally along the fibers of the stria terminalis, one part passing rostral to the anterior commissure, along with the supracommissural component of the stria terminalis, to become continuous with the caudal extreme of the accumbens nucleus. Caudal to the anterior commissure the interstitial nucleus extends ventrally and medially along the fibers of the preoptic component of the stria terminalis to blend with the medial preoptic gray. Medially the interstitial nucleus merges with the nucleus of the anterior commissure. The cells of this group are medium sized and are oval and elongated in general outline; the majority of them are interspersed between the fibers of the stria terminalis. At the level of the anterior commissure the cells extend dorsolateralward for a short distance among the fibers of the stria, to the place where it forms a compact bundle at the ventromedial aspect of the caudate nucleus. From this point caudally along the main bundle of the stria terminalis, very few cells are seen, and for many sections they are entirely absent. This is in contrast with the condition found in the opossum by Johnston ('23) and Loo ('31), but agrees with the findings of Gurdjian ('27) in the rat.

Among the cells of the preoptic part of the interstitial nucleus of the stria terminalis can be seen a special group of slightly smaller cells surrounded by a capsule of nerve fibers. Consequently this neuron group is quite distinct in the tigroid and silver series. It is somewhat oval in outline in the cross sections ; rostrally it gives off a dorsolateral cellular projection which extends among the dispersing fibers of the stria terminalis, a few sections caudal to the anterior commissure (p. 358). Hence it is club-shaped in the cross section series at this level. Caudally it inclines ventrally, surrounded by the fibers of the lateral olfacto-habenular and lateral 
cortico-habenular tracts. This nucleus appears to be an important synaptic center for the various fiber paths with which it is intimately associated. It has been termed here the encapsulated portion of the interstitial nucleus of the stria terminalis. It is apparently included with the anteromedial. nucleus of the thalamus by Münzer and Wiener ('02). It may be offered as a tentative suggestion that this cell group has certain resemblances in position and relations to the oval nucleus identified by Huber and Crosby ('26) in the alligator and later in the same year by Cairney ('26) in Sphenodon.

\section{Preoptic region}

In adult material there is no sharp boundary line between the hypothalamic and preoptic regions. Even among embryologists there is no exact agreement as to the di-telencephalic boundary, although most observers place it somewhere in the region of the optic chiasm or just in front of its rostral border; others place it at this border, slightly caudal to it where the optic tracts begin to turn dorsalward, or even at the caudal border of the chiasm. The preoptic region is carried forward to the caudal plane of the septum (also indefinite), which in general is occupied by the diagonal band of Broca. The region extends dorsalward to a horizontal plane through the ventral part of the anterior commissure. Laterally it reaches the amygdaloid area, thus including within itself the medial forebrain bundle. Within this somewhat indefinitely delimited area, for convenience of description, a lateral, a medial, and a periventricular preoptic area have been recognized, and within these areas certain nuclear groups are delimited.

Lateral preoptic area. This lateral area is composed largely of fascicles of the medial forebrain bundle, among the cross cut fibers of which are scattered medium sized oval and triangular cells, forming an interstitial nucleus for this bundle (figs. 9, 10, 16). They can be followed caudally among these fibers to the plane of the nucleus of the lateral olfactory tract, and rostrally to the medial septal nucleus and tuberculum olfactorium, whence arise the majority of the fibers of the 
medial forebrain bundle. This whole group of cells is homologous to Loo's ('31) nucleus preopticus interstitialis. The caudal and lateral part of the nucleus of the diagonal band enters the rostral part of the lateral preoptic area, and while in this position a group of cells from the diagonal band extends through the area dorsolateralward toward the globus pallidus. These were described previously (p. 317). Behind this level similar cells from the diagonal band can be traced caudalward intermingled with the lateral fascicles of the medial forebrain bundle. These larger cells are probably representative of the nucleus preopticus magnocellularis of Loo ('31) and are so labeled in figures 10 and 16 of the present description. These cells repeat in part the distribution of the nucleus magnocellularis interstitialis of chicken (Huber and Crosby, '29), which is associated with fibers of the septomesencephalic system, of which the diagonal band represents the ramus basalis frontalis.

Medial preoptic area. The medial preoptic area lies between the lateral preoptic area and the periventricular preoptic areas. It is composed of larger and more numerous cells than is the lateral area. It extends from the rostral to the caudal extreme of the preoptic region and is continuous with the same region of the hypothalamus without any line of demarcation. It is occupied chiefly by a large nuclear mass termed by Loo ('31) in the opossum the nucleus preopticus principalis. In the rabbit material in a plane through the cephalic extreme of the anterior commissure the nucleus preopticus principalis is an oval group of cells consisting of fairly large, rounded and triangular neurons (fig. 9). The nuclei of the two sides are separated from each other by a forward extension of the preoptic periventricular gray, termed the nucleus preopticus medianus (p. 335). Farther caudally the nucleus preopticus principalis increases in size and merges medially with the periventricular gray. It is joined at its dorsolateral aspect by the preoptic part of the interstitial nucleus of the stria terminalis. Nucleus principalis is now composed of two groups of cells, a ventral large celled group 
and a dorsal small celled group (fig. 10). These two groups represent the pars superior and pars inferior of the nucleus preopticus principalis of Loo ('31).

The nucleus of the anterior commissure is continued caudally at the ventral aspect of the anterior commissure into the dorsal part of the preoptic area as a small rounded group of small neurons on either side of the midline (fig. 9). This group can be traced to the caudal extreme of the anterior commissure, where it disappears. In the rabbit material available there is not sufficient cellular differentiation to justify the designation of this part as a separate nucleus, as is the case in the opossum where Loo ('31) has described it as nucleus preopticus anterior.

Periventricular preoptic area (figs. 9, 10, 16). This area lies between the medial preoptic area and the third ventricle. Rostral to the cephalic extreme of the preoptic recess of the third ventricle the midplane of the transverse series studied is occupied by a triangular group of small cells which appears to be a forward extension of the periventricular gray (fig. 9), with somewhat more special cellular differentiation. This group is bounded laterally by the nucleus preopticus principalis and dorsally by the anterior commissure, and extends ventrally to the lower border of the brain wall, but is soon split into two lateral halves ventrally by the rostral extreme of the third ventricle and becomes continuous with the periventricular gray caudal to this level. This group is here designated as the nucleus preopticus medianus, since it is homologous to a nucleus of the same name described by Loo ('31) in the opossum.

Nucleus preopticus periventricularis is the term applied to the narrow band of small cells on either side of the third ventricle in the preoptic area (fig. 10). These neurons are not very deeply stained and present a slight lamellar arrangement. Ventrally these cells follow the slightly lateral extension of the ventricle over the optic chiasm (fig. 16, unlabeled). Laterally the periventricular nucleus merges insensibly into the gray of the medial preoptic area, rostrally it is continuous with the nucleus preopticus medianus, and caudally it is con- 
tinued into the hypothalamic region as the hypothalamic periventricular gray.

FIBER CONNECTIONS OF THE TELENCEPHALON

Olfactory nerve, vomeronasal nerve, terminal nerve

These nerves have been discussed in early pages $(298,302)$ of the present account in order to establish the relations of the olfactory nerve to the layers of the olfactory bulb, of the vomeronasal nerves to the layers of the accessory olfactory bulb, and of these nerves to the nervus terminalis. They do not require further description here (McCotter, '12; Huber and Guild, '13).

\section{Olfactory tracts}

An account of the olfactory tracts in mammals, including man, is available in most of the standard texts on the anatomy of the nervous system and these tracts have been described by most workers on the mammalian forebrain. In view of these various accounts the present consideration of these tracts is relatively brief, emphasis being laid on certain phases of these connections about which there may be differences of opinion. It is generally recognized that while these tracts arise in part from mitral and certain large granule cells of the olfactory bulb, they are supplemented by neurons from secondary olfactory centers within the hemisphere, such as the nucleus olfactorius anterior. These tracts may in all probability also carry fibers entering the nucleus olfactorius anterior from lower centers, as Herrick ('24) has emphasized. The following accounts are based on rabbit material with the guinea pig material used to supplement. Unless specifically stated to the contrary, the descriptions apply to the rabbit.

The mitral and large granule cells (cellulae a houpette) in all parts of the olfactory bulb send their neuraxes centrally to form the internal medullary lamina of the bulb from which the majority of the olfactory tracts may be said to arise, 
since they are but the caudal continuation of these fibers. On the basis of their topographical relation the tracts are usually designated as lateral, medial, and intermediate olfactory tracts. Rostrally all these tracts are placed central to the olfactory formation, while caudal to the fissura circularis the medial and lateral tracts assume a superficial position in the crus, peripheral to the nucleus olfactorius anterior, but the intermediate tract retains its central position in relation to this nucleus and is in close proximity to the olfactory ventricle.

Lateral olfactory tract (figs. 3 to 10,18 to $22,24,25,28$ ). This tract, in both the rabbit and the guinea pig, begins rostrally as two major peduncles, one of which is situated dorsal to the olfactory ventricle and is composed largely of efferent fibers from the accessory olfactory bulb (the majority of which enter the lateral tract); the other bundle is situated ventral to the olfactory ventricle and is formed by fascicles from the internal medullary lamina of the bulb (figs. 3 and 18; also Winkler and Potter, '11, fig. I). The dorsal bundle begins at the rostral extreme of the accessory bulb and extends to the caudal extreme of the same. The ventral bundle begins a short distance behind the plane of the rostral extreme of the pars lateralis of the anterior olfactory nucleus (which separates the lateral olfactory tract from the internal medullary lamina of the bulb) and extends to the caudal extreme of the olfactory formation. The lateral olfactory tract enlarges rapidly from its rostral extreme to the caudal plane of the accessory bulb due to the constant addition of fibers by way of its dorsal and ventral peduncles. Caudal to the fissura circularis the lateral tract assumes a superficial position, spreading over the lateral surface of the crus. The pars lateralis of the anterior olfactory nucleus lies at its medial aspect, appearing here coincidentally with the disappearance of the olfactory formation from the lateral aspect of the tract. In the cross section series the lateral olfactory tract, caudal to the plane of the accessory olfactory bulb, can be divided into the following three parts: a thin dorsal part, which spreads along the dorsolateral surface of the crus and joins with fibers from the 
medial side of the same; a ventral part, which spreads along the ventrolateral aspect of the crus to the fascicles of the medial olfactory tract; and a pars intermedia, lying between the two above stated portions which is particularly massive in the rabbit and forms the bulk of the lateral olfactory tract. The ventral and intermediate parts are more nearly the same size in the guinea pig. A similar division has been noted in the lateral olfactory tract of the opossum by Herrick ('24) and Loo ('31). It is noteworthy that coincident with this division of the lateral tract at the plane of the caudal extreme of the accessory olfactory bulb, there is a similar division of the pars externa of the lateral limb of the anterior olfactory nucleus (p. 306) into dorsal and ventral tailpieces (fig. 5), which in their further caudal course parallel that of the respective parts of the lateral tract. Obenchain ('25, p. 194) believed that the pars externa is formed in phylogeny as a result of the neurobiotactic action of the lateral olfactory tract fibers upon the cells of the pars lateralis of the anterior olfactory nucleus. This caudal splitting of the pars externa would then seem to indicate that the particular fibers of the lateral tract, under the influence of which the pars externa is formed, have become aggregated in the dorsal and ventral portions of the tract, effecting the splitting of the nucleus, and the caudal course of the dorsal and ventral tailpieces (of the nucleus) would then suggest the course of distribution of these particular fibers. It is suggested here that the particular fibers in question are the efferents from the accessory olfactory bulb. Herrick ('21) traced these fibers in the frog from the accessory bulb to a ventrolateral group of cells which he believed to be the anlagen of the amygdaloid nucleus, but their specific distribution in higher forms has not been determined.

The dorsal limb of the lateral tract (figs. 18 and 19) continues caudally and medially to blend with the medial tract fibers in the dorsal part of the crus. It distributes to the rostral part of the pyriform cortex within the crus and caudal thereto. Caudal to the base of the crus it occupies the lateral aspect of the pyriform lobe between the rhinal and endorhinal 
fissures. The ventral limb (figs. 18 and 19) of the lateral tract continues caudally and medially and blends with the fascicles of the medial olfactory tract near the pial surface of the ventral aspect of the crus, forming thus the ventral olfactory tract of some authors. This ventral part continues caudally in the external plexiform layer of the tuberculum olfactorium and supplies this structure. The ventral part of the lateral olfactory tract also gives fibers to the pars posterior of the anterior olfactory nucleus and the pyriform cortex. The intervening portion of the lateral tract (figs. 18 to $22,24,25$ ) forms the main bulk of this tract; it lies ventral to the endorhinal fissure and continues to contribute fibers to the dorsal limb of the tract. As the sections are followed caudally, the lateral olfactory tract gradually grows smaller as it contributes fibers to the pyriform cortex and spreads over a large area of the lateral surface of the pyriform lobe. It also gives off fibers medially to the tuberculum olfactorium. The majority of observers have agreed that the tuberculum is the recipient of olfactory tract fibers from the olfactory formation, although Beceari ('10) was not able to trace olfactory fibers to this area. The lateral olfactory tract gives fibers to the nucleus of the lateral olfactory tract and the anterior amygdaloid area, and, caudal to this plane, cannot be recognized as a definite tract.

Medial olfactory tract (figs. 19 and 27). The medial olfactory tract is the smallest of the three tracts in both the rabbit and the guinea pig. It is represented by somewhat loosely scattered fascicles along the medial and ventral aspects of the crus. Ventrally it approximates the ventral part of the lateral tract and enters into the formation of the so-called ventral olfactory tract described above. At certain levels through the crus the fibers of the medial tract swing dorsalward toward the more medial fascicles of the dorsal part of the lateral olfactory tract (fig. 19). Thus it can be seen that these olfactory tract fibers practically encircle the crus just within its pial surface, and any division of the same on a topographic basis is largely academic. The remaining fibers 
of the medial olfactory tract continue caudally along the medial and ventromedial aspect of the crus and into the medial septal area for an undetermined distance. This medial tract contributes fibers to the anterior olfactory nucleus, the precommissural hippocampus, the medial septal nucleus, and the medial aspect of the tuberculum olfactorium (the medial rolled portion of the tuberculum olfactorium is labeled the nucleus of the medial olfactory tract by Livini, ' 08 , and others). Whether or not any of the axons of this tract continue caudally into the medial forebrain bundle without synapse cannot be stated from a study of the material at hand.

Intermediate olfactory tract (figs. 19, 20 and 28). This tract is composed of fibers which surround the olfactory ventricle of the bulb. In the crus they accumulate at the lateral aspect of the ventricle and hence they lie central to the anterior olfactory nucleus in contrast to both the above described tracts. The intermediate olfactory tract receives many fibers from this nucleus, and, as the tract is traced caudal to the olfactory formation, it continues to increase in size as a result of the constant accessions of fibers from this nucleus. Caudal to the base of the olfactory crus the intermediate olfactory tract forms a distinct, oval bundle of fibers which has successively the following relations; ventral to the anterior horn of the ventricle, then ventral to the head of the caudate nucleus, a little farther caudally forming the constriction between the caudate and the accumbens nucleus, and gradually approaching the midline to cross as the most rostral component of the anterior commissure. In its course through the forebrain it is joined at its lateral aspect by fibers from the pyriform lobe and from the anterior part of the external capsule, which collectively comprise the anterior limb of the anterior commissure. As has been demonstrated by the degeneration experiments of Löwenthal (1897; see also Edinger, '11, fig. 291) and Ramón y Cajal ('11), the interbulbar fibers terminate in a similar area on the opposite side from which they arise. Hence each interbulbar tract contains both afferent and efferent fibers. 
Tertiary olfactory connections within the hemisphere

Olfacto-cortical fascicles. From those portions of the pars posterior and the pars medialis of the anterior olfactory nucleus which lie caudal to the crus many fibers arise and course dorsally into the deep fiber layer of the overlying medial cortex (the stratum sagittale externum of Winkler and Potter, '11, plate III; the stria lateralis of Johnston, '13). These fibers establish olfacto-cortical connections and have been described by Johnston ('13) and are designated as the "ventral radiations of the ganglion olfactorium of Luys" by Winkler and Potter ('11). There is no satisfactory evidence in the present material to determine whether these fibers continue caudally in the stria lateralis (dorsal to the corpus callosum) to the hippocampus or terminate in the cortex of the immediate overlying region, although the former relation seems more probably from a comparison with lower forms. The available material does not show any direct fiber connection between the bulbar formation or the anterior olfactory nucleus, on the one hand, and the frontal pole of the cerebral cortex on the other hand, such as was described by Haller ('00) as funiculus olfacto-corticalis superior, for mammals, and by Herrick ('24) and Loo ('31) for marsupials and Hines ('29) for Ornithorhynchus as the tractus olfacto-frontalis.

Hippocampo-cortical fibers (figs. 6, 20). Throughout the greater part of the entire extent of the precommissural hippocampus, fibers arise from its lateral aspect and course dorsally into the deepest fiber layer of the overlying cortex (the stratum sagittale externum of Winkler and Potter, '11). This connection may represent a vestige of the association bundle connecting the rostral and caudal parts of the hippocampus in marsupials. In the rabbit these fibers appear to course with the lateral stria Lancisii to the retro- and sub-splenial portions of the hippocampus, but of this connection the present author is uncertain.

Septal connections. The fiber connections of this area are numerous and complex, and have never been completely analyzed and homologized throughout the various forms. 
Numerous contributions on submammalian forms have been made (Ariëns Kappers, Huber and Crosby, '36). The phylogenetic relations of the septal areas, together with certain fiber relations, have been discussed by Ariëns Kappers ('21), Young ('26), Ariëns Kappers, Huber and Crosby ('36) and others. There have been many studies of this region in mammals by Zuckerkandl (1888), von Kölliker (1896), Elliot Smith (1897), Ramón y Cajal ('11), Johnston ('13), Hines ('22), Loo ('31), and others. Part of these studies were concerned with acallosal brains, and this increases the difficulty of attempting homologies with higher forms where the development of the corpus callosum has altered the relations of this area to a very considerable extent. Crosby ('17) suggested that there is a division of labor between the medial and lateral septal nuclei in reptiles; the medial nucleus being a way station for ascending impulses going toward the hippocampus, and the lateral nucleus a similar station for descending impulses coming from the hippocampus. Loo ('31) accepted this interpretation and divided the septal area into a medial, a lateral, and an intermediate zone on the basis of its myeloarchitecture. The following is a brief description of the fiber relations as observed in this area in the rabbit, especially as regards the principal nuclear groups of this area. Other fibers course through this region with a synapse in these nuclei. As a general statement, it may be said that the fibers are more numerous near the midline and are fewer and more scattered in the lateral part of this area, and the total fibers of this area are relatively fewer than in the same region of lower forms.

Tuberculo-septal and septo-tubercular tracts (figs. 21 and 27). Caudal to the plane of the olfacto-cortical fibers described above, fascicles are seen arising from the rostral extreme of the tuberculum olfactorium and passing dorsally and caudally over the medial surface of the nucleus accumbens (along the zona limitans) to enter the septal area, where they disperse among the cells of the septal nuclei. These fibers constitute a tuberculo-septal pathway; conduction probably also 
occurs in the opposite direction, giving a septo-tubercular connection. They have been drawn but not labeled by Johnston ('13, fig. 66) in rabbit. Accompanying the tuberculo-septal fibers are found certain fibers which arise farther lateralward from the medial pyriform area and swing medially and dorsally; these have been labeled the "medial radiations of the ganglia olfactoria" by Winkler and Potter ('11, plate III). Running through the septal area are also numerous small fibers which connect the medial part of the tuberculum with the precommissural hippocampus.

Tract of the diagonal band of Broca (figs. 22 and 27). This tract has been variously designated by different authors. It appears to be a part of the precommissural fasciculus of Elliot Smith (1897) and the posterior part of the 'Riechbündel des Ammonhornes' of Zuckerkandl (1888) and of Ramón y Cajal ('11). Zuckerkandl considered it as efferent with respect to the hippocampus, while Ramon y Cajal ('11, p. 789-791) thought it to be afferent, although he stated that various authors have considered this pathway as being composed of both descending and ascending fibers. The concensus seems to regard it as a descending pathway. The tract of the diagonal band is shown best in the sagittal series of the available silver preparations of rabbit (fig. 27). The majority of the fibers emerge from the ventral psalterium and course ventrally and slightly forward through the nucleus of the diagonal band, which likewise begins in the dorsal part of the septum (p. 316) ; it receives additional fibers from the neurons of this nucleus and possibly forms synapses here. It follows this nuclear group through the septal area, receives fibers from the medial septal nucleus, and passes caudally beneath the anterior commissure, turning lateralward and caudalward across the ventral area of the brain (just caudal to the tuberculum olfactorium) to terminate in the region of the anterior amygdaloid area and the nucleus of the lateral olfactory tract. A few fibers of this tract probably continue to enter the pyriform area, and certainly many fibers from this latter area pass medially to the anterior amygdaloid area and the nucleus of 
the lateral olfactory tract. In its lateral course the diagonal band passes through and ventral to the medial forebrain bundle and contributes fibers to the same. The tract of the diagonal band, therefore, follows the general course of the nucleus of the same name and serves in general to connect the hippocampus and septal areas with the ventrolateral olfactory areas. The relations and connections as here observed in the rabbit agree essentially with those described by Johnston ('23) for this rodent.

Cortico-septal and septo-cortical connections (see figs. 8, 24 and 27, unlabeled). Fibers of the fornix arise in hippocampal cortex and course forward in the fimbria and superior fornix and some of them make connections with the septal nuclei, forming thus a cortico-septal pathway. It is very probable that many of the smaller and deeper staining fibers that accompany these conduct in the opposite direction, constituting a septo-cortical path. However, the connections specifically with the medial and lateral septal nuclei cannot be determined in the rabbit as Crosby ('17) has done in the alligator. The development of the corpus callosum has doubtless disturbed these primitive relations. Loo ('31) has described these tracts in the acallosal marsupial brain. In addition to the superior fornix fibers mentioned above, many of the fibers of the medial stria Lancisii course around the rostral aspect of the genu of the corpus callosum (figs. 21 and 27) and terminate in the lateral septal nucleus, affording another pathway between the cortex and the septum. Johnston ('13) has shown that the stria medialis Lancisii is not a vestige of the hippocampusas was formerly believed-since he has demonstrated it in marsupials which have a well-developed anterior hippocampus. He states that it is comparable to the reptilian fimbria. Some of the fibers accompanying the cortico-septal fibers from the hippocampus pass without synapse through the septal area and enter the medial forebrain bundle, thus representing a cortico-hypothalamic tract. 
Interconnections between olfactory centers of the hemisphere and lower centers

Medial forebrain bundle (figs. 9 to 12,21 to 26,28 ). This bundle has been recognized by many students of both the submammalian and the mammalian telencephalon. Among the workers on mammals may be mentioned Honegger (1890), Bischoff ('00), Wallenberg ('02), Dabrowski ('13), Tsai ('25), and Loo ('31). There are differences of opinion with regard to the details of both origin and distribution of this bundle. In part, these differences are due to the inclusion or exclusion of certain components within this system. Fascicles from fornix longus, fibers from the ventrolateral part of the striatum, and fibers of passage or bundles from regions through which the medial forebrain bundle courses may or may not be included in this fiber complex, depending upon the interpretation of the author considered. In the present account the bundle is regarded as an interconnection between the medial and ventral areas of the cerebral hemisphere and the tuberculum olfactorium, on the one hand, and hypothalamic and possibly tegmental regions on the other hand. This bundle may possibly carry ascending as well as descending fibers, bringing forward in this way visceral impulses from lower centers to the ventromedial part of the telencephalon, from which they may be relayed in part to the hippocampus. The following account of the medial forebrain bundle is based largely on a study of Weigert preparations of the guinea pig brain. As far as the material permitted, this system, which is not well impregnated in the silver preparations, has been checked in the rabbit. From the pars medialis of the anterior olfactory nucleus, fibers arise and course caudally in the ventromedial part of the crus to enter the medial forebrain bundle. They form the medial olfacto-hypothalamic tract (fig. 20), which is the most rostral component of the bundle. Whether or not fibers from the olfactory formation accompany these fascicles in rodents, as Herrick ('24) thought to be the case in opossum, is uncertain; at least they are not demonstrable in the material available. In the plane of the tuberculum olfactorium, caudal to the origin of the tuberculo-cortical 
and tuberculo-septal tracts, the fibers emanating from this nucleus are seen to take a more obliquely caudal course and soon appear cross cut in the transverse series as they enter the medial forebrain bundle, of which they represent a major constituent-the tuberculo-hypothalamic tract (fig. 21). At this rostral level the medial forebrain bundle is diffuse and is composed of three or four large fascicles lying for the most part between the cortical and deep layers of the tuberculum olfactorium. Farther caudally these fibers are collected into a more compact bundle and its size considerably increased as a result of the constant addition of fibers. From the ventromedial part of the caudate nucleus and from the nucleus accumbens, fibers arise to join the medial forebrain bundle constituting a strio-hypothalamic component (fig. 28). Joining the medial forebrain bundle at its ventrolateral aspect, but then running diagonally across its fibers, is the lateral olfactohypothalamic tract, which apparently is the ventral olfactory projection tract of Ramón y Cajal ('11), and which may be considered merely as accompanying the medial forebrain bundle or, as is sometimes done (Gurdjian, '27), as a part of it (fig. 24). Probably the largest component of the medial bundle is the septo-hypothalamic tract (fig. 28), which courses ventrally from the lateral septal nucleus in order to enter the bundle a little rostral to the anterior commissure. These are the most lateral of the fibers in this region, the more medial fibers belonging to the precommissural fornix system. Accompanying these fibers are some which seem to course through the septal area without synapse, and hence represent a corticohypothalamic path. The fibers contributed to the lateral aspect of the medial bundle from the tract of the diagonal band are probably of this nature. As the medial forebrain bundle is followed caudally beneath the anterior commissure it becomes somewhat smaller since many of its more medial fibers terminate in the preoptic area. The more lateral fibers become closely approximated to the ventral part of the lateral forebrain bundle and the two systems appear to be continuous in the transverse and sagittal series. The fibers of the medial 
forebrain bundle, in general, are smaller and less heavily medullated than those of the lateral bundle, hence they stain less deeply and appear lighter in Weigert preparations. However, this is not a cogent criterion for differentiating the two, since there is found an intermediate zone of fibers which may be considered as part of one or of the other systems. Caudal to the plane of the optic chiasm (fig. 26) the medial forebrain bundle assumes a more medial position and partly surrounds the descending fornix bundle, which lies at its medial aspect, and a few of its fibers accompany the fornix bundle into the mammillary body. The medial forebrain bundle grows progressively smaller and more diffuse as it proceeds caudally through the hypothalamic area, indicative of the termination of many of its fibers in this area. In the guinea pig series a few of the lateral fibers of the medial bundle can be followed caudal to the mammillary body into the interpeduncular region. These fibers course along with those of the mammillary peduncle and may be the homologue of such peduncular fibers as were described in lower forms by de Lange ('11) and others. It has not been possible in this study to follow the various components of the medial forebrain bundle throughout their individual course from origin to termination, and hence their specific anatomical terminology cannot be determined or applied at the present time.

Hippocampal commissure and fornix complex. The dorsal and ventral hippocampal commissures (figs. 9, 10, 17, 23, 25, 27,28 ). The dorsal hippocampal commissure (the dorsal psalterium of von Kölliker, 1896; the hippocampal commissure in the more restricted sense) and the ventral hippocampal commissure (ventral psalterium of von Kölliker, 1896; or commissura fornicis) have been generally recognized in mammals, though their spatial relations are somewhat different in acallosal as compared with callosal forms. The hippocampal commissures in the rabbit and the guinea pig consist of 1) fine, thinly myelinated fibers which in chrome silver preparations stain intensely, and 2) larger and more heavily myelinated fibers which stain lighter in the same series. Both types of 
fibers are represented in each division of the commissure but the former type predominates in the dorsal commissure while the latter type predominates in the ventral. The dorsal commissure lies dorsal to the subcallosal hippocampus and ventral to the corpus callosum; its fibers crossing the midline are plainly shown in sagittal series (figs. 27 and 28) as loosely arranged, cross-cut bundles. These extend from the dorsal aspect of the ventral psalterium forward around the rostral aspect of the hippocampus (subcallosal) and caudally, at its dorsal aspect, as far as the under part of the splenium of the corpus callosum, with the fibers of which it blends (fig. 27). This dorsal psalterium is composed almost wholly of the small, darkly stained fibers. In the rostral part of this crossing there is an exchange of fibers between the dorsal and ventral commissures.

The fibers from the caudal part of the hippocampus enter the alveus and course forward in the fimbria to the lamina terminalis (the lamina supraneuroporica of Johnston), where the majority of them cross to the opposite side, forming the conspicuous commissure of the fornix or ventral psalterium. These crossing fibers belong to the commissural system of the fornix and serve for coordination and correlation between the two sides of the hippocampus. However, all the fibers that course forward in the fimbria are not commissural in nature, many of them are projection fibers and continue forward (before or after crossing in the ventral psalterium) into the septal area as the fornix fibers. The hippocampus proper extends forward beneath the corpus callosum almost to the plane of the anterior commissure, and fibers from its rostral extreme project directly forward to the fornix system without coursing in the fimbria. The ventral psalterium lies a little dorsal and caudal to the anterior commissure in the midplane, and in midsagittal series there is an almost continuous cross-cut commissural system extending from the genu of the corpus callosum to the anterior commissure, embracing successively the genu, body and splenium of the corpus callosum, dorsal and ventral hippocampal commissures, and the anterior commissure (fig. 27). Such relations 
support the theory of the formation of the corpus callosum in phylogeny (Elliot Smith, 1897, '10) by the development of neopallial commissural fibers in the hippocampal commissure or dorsal psalterium. Johnston ('13), on a basis of degeneration experiments in the opossum, in which he removed an area of the dorsal cortex lateral to the hippocampus and followed the degenerated fibers through the hippocampal commissure, claims that this process (corpus callosum formation) has already been initiated in marsupials. Others doubt the existence of true callosal fibers in the dorsal commissure of these mammals. However, in the rabbit there is a restricted area at the caudal part of the dorsal psalterium which contains both hippocampal and corpus callosum fibers intimately intermixed, without any line of demarcation between the two systems. An intermingling of fibers of the hippocampal commissure and the corpus callosum occurs also in the telencephalon of the bat (Humphrey, '36). This fact, in addition to other relations of the commissural system and fornix fibers, would seem to indicate that the rabbit occupies an intermediate position in this respect between marsupial and primate types.

The fornix complex. The various parts of the fornix form the great efferent system of the hippocampal region. Consequently they have claimed the attention of many investigators. Anything like a complete review of the voluminous literature dealing with this subject in mammals is not only beyond the scope of the present article, but is quite unnecessary, since much of it has been reviewed and re-reviewed by various students of this fiber system. Among certain earlier contributions may be mentioned those of Honegger (1890), von Kölliker (1896), Elliot Smith (1896, 1896 a, 1897, '10, and elsewhere), Edinger and Wallenberg ('01), and Ramón y Cajal ('11). The appearance of the corpus callosum led to the splitting off of a part of the original fornix system from the main body of the fornix. Such fibers swing around the splenium of the corpus callosum and extend forward over its dorsal surface as the striae Lancisii. From the genu region fibers continue forward along the anterior extension of the 
hippocampus as the fasciculus marginalis (Elliot Smith, 1896 a). Others swing around the genu to distribute to the septum in front of the anterior commissure. The fornix ventralis of Elliot Smith (1897) constitutes those fornix fibers undisturbed by the developing corpus callosum. It is obvious that in acallosal forms the dorsal and ventral fornix will be combined as a single bundle. Loo ('31), working on the opossum, described precommissural and postcommissural fornix bundles; obviously this is the interpretation of Elliot Smith, since in acallosal forms the precommissural and postcommissural fasciculi of the dorsal fornix and ventral fornix would run together. Edinger ('11) has also utilized the terms preand postcommissural fornix, and precommissural and postcommissural fornix fibers have been recognized in the bat (Humphrey, '36). The precommissural fornix in the rabbit consists of perforating fibers which break through the corpus callosum and form a conspicuous bundle lying immediately ventral to the corpus callosum on either side of the midline (the fornix superior of von Kölliker, 1896), and course forward to the septal area and then course ventrally through this area near the midline. Certain of the fascicles of the precommissural fornix, however, pass directly forward with the main fornix bundle (or ventral fornix) and swing in front of the anterior commissure in their ventral course to form the most caudal part of the precommissural system; and a small minority of those fibers which swing around the genu also join this system. Contrary to the accepted accounts, many of the superior fornix fibers decussate in their ventral course through the precommissural septal region (fig. 22), crossing the midline as small fascicles alternating first from the right side and then from the left as the transverse sections are followed. The material available is not adequate for settling the long standing controversy concerning the origin of these perforating fibers; such evidence as is available from this study supports the opinion that they arise from the gyrus fornicatus. The fibers from the main fornix bundle are undoubtedly hippocampal in origin, and a few fibers are contributed by the anterior extension of the hippocampus. These fibers together form 
the precommissural fornix which sweeps ventrally and caudally through the precommissural septal region, intermingled somewhat with smaller, more deeply stained fibers (in chrome silver preparations) which constitute the tract of the diagonal band, which has been separately considered (p.343). Some of the fibers terminate, or at least synapse, in the septal region; others end in the preoptic area; while still others reach the region of the medial forebrain bundle and proceed candalward for an undetermined distance toward the mesencephalic region.

The fimbria contributes in large part to the formation of the postcommissural fornix (figs. 25 to 28 ), although there are extensive additions from the fibers perforating the corpus callosum and fibers coming directly from the hippocampal formation (subcallosal part). In its course through the septum it is joined by fibers arising in this area. The fibers constituting the posteommissural fornix pass rostrally and slightly ventrally immediately in front of the ventral psalterium, form a bend or knee by turning caudalward as two oval bundles of fibers, one on either side of the midline, and continue caudally, passing over to the dorsal aspect of the anterior commissure. Here the fornix columns form the anterior boundary of the interventricular foramen. At the lower border of the foramen (in the rostral part of the thalamic area) the fornix gives off laterally and dorsally the medial cortico-habenular and septo-habenular tracts, which enter into the formation of the stria medullaris. The main mass of the postcommissural fornix, carrying the cortico-hypothalamic and cortico-mammillary components, sweeps caudalward along the dorsal aspect of the preoptic area and then passes through the hypothalamus, where the cortico-hypothalamic fibers are given off, and continues to the mammillary body where the majority of the fibers terminate; a few fibers, however, enter the supramammillary commissure, beyond which they have not been traced.

Stria medullaris (figs. 11, 25, 26, 28). The stria medullaris is phylogenetically a very old pathway, having representation in all vertebrate forms, even in those in which the olfactory 
system is very greatly reduced, as in birds. As is to be expected, in view of its wide representation and its general recognition by students of this area, the literature which has grown up about its various components is enormous (Ariëns Kappers, Huber and Crosby, '36). The stria medullaris of both the rabbit and the guinea pig is made up of several components, most of which unite near the mediodorsal angle of the rostral extreme of the thalamus to form a single tract which courses caudally in the dorsomedial angle of the same, supplying the habenular nuclei of the same side, and sends its caudalmost fibers through the habenular commissure to terminate in the opposite side. The habenular commissure lies immediately dorsal to the posterior commissure at the base of the stalk of the epiphysis (fig. 27). The following components have been identified in the series studied.

Medial cortico-habenular tract (fig. 9). The fiber bundles of this tract arise in the hippocampal cortex (Ganser, 1882; Honegger, 1890; Lotheissen, 1894; Humphrey, '36; and others) and pursue an efferent course through the dorsal lamina terminalis along with the fibers of the postcommissural fornix, at the lateral aspect of which they can easily be recognized due to their smaller caliber and deeper staining in the chrome silver series. In the series of 1-day-old rabbit they appear to be unmyelinated. They are accompanied also by the septohabenular fibers. As soon as the fornix swings beneath the interventricular foramen and enters the rostral extreme of the thalamus, the medial cortico-habenular fibers leave the main fornix bundle and turn laterally and dorsally to enter the rostral extreme of the stria medullaris (fig. 25) which is just forming in the dorsomedial part of the diencephalon. Practically all investigators agree on the existence of this component with the exception of Ramón y Cajal ('11).

Septo-habenular tract (figs. 24 and 28). As the medial cortico-habenular fibers and the fornix column course through the septal region they are joined by fibers which arise from the caudal part of the septum (nucleus septalis fimbrialis). These fibers form the most lateral of the group in this area 
and accompany the medial cortico-habenular fibers into the stria medullaris.

Stria terminalis component (fig. 25, C). This component has been described by various authors (Johnston, '23; Gurdjian, '25; Berkelbach van der Sprenkel, '26; Loo, '31; Humphrey, '36). As the stria terminalis spreads out rostrally, some of the fibers from its ventral component swing medially and dorsally and some of these enter the stria medullaris near its rostral extreme. This amygdalo-habenular connection is quite small in the rabbit.

Connections with the bed nucleus of the stria terminalis. In addition to the connection between the stria terminalis and the stria medullaris mentioned above, there are many fine fibers which arise from the cells in the dorsomedial part of the interstitial nucleus of the stria terminalis and enter the rostral extreme of the stria medullaris, forming thus another pathway between these two fiber systems.

Medial olfacto-habenular tract. From the cells in the medial preoptic area near the floor of the hemisphere, fibers arise and course dorsally to enter the ventral aspect of the stria medullaris near its rostral extreme. These fibers are very fine and unmedullated and show best in the silver series. In their course dorsally they lie medial to the lateral olfactohabenular and lateral cortico-habenular tracts. Hines ('29) described a preoptic component of the stria medullaris in Ornithorhynchus, and Gurdjian ('27) and Humphrey ('36) found medial olfacto-habenular fibers in the rat and the bat, respectively. This tract is apparently homologous to the tractus olfacto-habenularis principalis described by Loo ('31). A few of the more caudal fibers of this tract in the rabbit seem to arise from the nucleus tangentialis (Gurdjian, '27), but their origin from this source is not definite. Apparently this small caudal component corresponds to the tractus olfactohabenularis supraopticus of Loo ('31).

Lateral olfacto-habenular tract (fig. 25). The fibers of this tract arise in the lateral preoptic area, possibly from the interstitial nucleus of the medial forebrain bundle and some 
may even represent stem fibers or collaterals of the latter tract. Gurdjian ('25) described these fibers as arising from the caudal part of the tuberculum olfactorium and rostral third of the preoptic area in the rat. Craigie ('25, p. 74) has quoted Herrick as having listed as the largest component of the stria medullaris in the rat, a tractus olfacto-habenularis anterior, which arises in the tuberculum olfactorium and passes backward with the medial forebrain bundle to the level of the optic chiasm, where they turn dorsally. The fascicles thus listed by Herrick probably fall within the bundle here described as the lateral olfacto-habenular tract, but this latter, taken independently, is not the largest component of the stria medullaris in either the guinea pig or the rabbit. In both these rodents the lateral olfacto-habenular fibers course dorsally from their position among the fibers of the medial forebrain bundle and join the lateral cortico-habenular fibers at an acute angle, and the two tracts pursue their further dorsal and rostral course together and enter the rostral extreme of the stria medullaris. In this course they lie lateral to the descending fornix columns and medial to the lateral forebrain bundle. They surround and form a fibrous capsule for a conspicuous group of cells lying lateral to the fornix which has been described (p. 332) as the encapsulated part of the interstitial nucleus of the stria terminalis.

Lateral cortico-habenular tract (fig. 25). The fibers of this tract arise from the deep layer of the pyriform area and course medially and dorsally through the interstices of the medial and lateral forebrain bundles, forming an imperfect boundary between the two fiber systems. Then they join with the lateral olfacto-habenular tract and continue their course into the stria medullaris with this bundle. Fascicles of this tract decussate in the habenular commissure, and it is altogether possible that this bundle carries in part commissural fibers between the lateral hemisphere regions, as is known to be the case with the homologous bundle of certain lower forms such as reptiles. Craigie ('25) listed a strio-habenular tract in some mammals, and if such exists in the guinea pig or rabbit 
it is closely associated with the lateral cortico-habenular system of fibers.

Summary of general relations of stria medullaris. From the foregoing description it is evident that the stria medullaris represents a very complex system of fibers. The hippocampus and septal areas are put in connection with it through the medial cortico-habenular and septo-habenular tracts. The lateral olfactory areas are connected with it through the lateral cortico-habenular tract and the stria terminalis. The medial olfacto-habenular tract forms a pathway between the medial olfactory area and the habenula while the lateral olfactohabenular tract probably transmits impulses from the tuberculum and the preoptic area. All these various components converge into a single tract which courses caudally at the mediodorsal angle of the thalamus; the majority of them terminate in the habenular nuclei, which are important correlation centers, while a few fibers cross in the habenular commissure and terminate on the opposite side.

Stria terminalis (figs. 9 to 15, 23 to 26). Von Kölliker (1896), Winkler and Potter ('11), and Johnston ('23) have contributed largely to the present knowledge of the stria terminalis in the rabbit. Gurdjian ('25, '28) and Craigie ('25) have described it for the rat. By far the most complete accounts of the stria terminalis thus far offered are for the opossum (Johnston, '23; Berkelbach van der Sprenkel, '26) and for the bat (Humphrey, '36) since in these forms the morphologic relations favor such an analysis. In the rabbit and guinea pig, as in other mammals, the stria terminalis serves essentially for connecting the lateral olfactory areas of the hemisphere (the amygdaloid complex) with the preoptic, the hypothalamic, and, in small part, the epithalamic areas. From these latter centers the impulses are discharged to centers lying farther caudalward through various efferent paths. While the direction of conduction in the stria terminalis cannot be determined in the available material, nor has it been done satisfactorily and completely for any form, the concensus is that in large part it is efferent with respect to hemisphere centers. In the region of origin and termination of 
this bundle the several components of the stria terminalis can be followed into relation with specific nuclear masses. However, in its course between these two extremes the several components are collected into a more or less compact bundle and with certain exceptions, cannot be individually identified and traced as specific components in the available series. Johnston ('23) arrived at the same conclusion with respect to the rabbit material which he studied, and a similar opinion is held by Obenchain ('25) and Olive Smith ('30) in regard to their series. Fortunately, several of the components are differentially stained in the guinea pig series studied, thus facilitating greatly their identification and study.

Supracommissural component of the stria terminalis (fig. 23). From the region of the basal and the cortical nuclei and the intercalated mass of the amygdaloid complex, relatively dark staining fibers arise and swing dorsalward toward the stria terminalis as it accumulates into a definite bundle on the under side of the internal capsule. These fibers form the most ventral component of this bundle in this position. As the stria terminalis swings around the caudal end of the internal capsule, these dark staining fibers form the outer or most caudal portion of the stria terminalis complex, and when the latter attains a position dorsal to the internal capsule these dark staining fibers attain a position along the ventricular wall forming the most dorsal component of this bundle. At the level of the anterior commissure, where the stria terminalis breaks up into its various components, these dark fibers swing ventralward around the anterior aspect of the anterior commissure forming the supracommissural component of the stria terminalis. These fibers in part reach the cephalic end of the preoptic area; some of them may pass farther caudalward with the fascicles of the medial forebrain bundle but there is no direct evidence of this distribution. The supracommissural component therefore supplies the gray in the medial part of the area rostral and ventral to the anterior commissure. The details of the course and relations of this component of the stria have been given for marsupials (Johnston, '23; Berkelbach van der Sprenkel, '26). The above ac- 
count is in essential agreement with their results, particularly those of the latter author. No account of this system as it passes through the stria or its relation to the amygdaloid areas has been given previously for rodents so far as the present writer is aware.

The commissural component of the stria terminalis (figs. 23 and 24). From the regian of the nucleus of the lateral olfactory tract a small, dark staining, rounded fascicle accumulates and swings dorsalward and caudalward toward the under side of the internal capsule, where it joins other bundles of the stria but is distinguishable from them throughout its entire course due to its deeper stain and rounded or oval outline. It forms a ventral component of the stria which can be followed around the caudal border of the internal capsule system and then forward to the plane of the anterior commissure. At this level this small, dark stained component swings ventrally and medially to enter the caudal part of the anterior commissure, in which it decussates. After decussation it swings dorsolaterally into the stria terminalis of the opposite side and follows back along this bundle to the nucleus of the lateral olfactory tract. Johnston ('23) described this component for the opossum and spoke of the stria terminalis component of the anterior commissure in the rabbit as being very small, but gave no details concerning it. Gurdjian ('25, contrary to Craigie's misstatement of this author, '25, p. 95) was unable to trace these fibers through their course in the stria terminalis of the rat. Recently this component has been carefully analyzed in the bat (Humphrey, '36).

Preoptic component of the stria terminalis (figs. 23 and 24). The preoptic component is the largest and most caudal component of the stria terminalis as it disperses anteriorly. Here these fibers leave the main strial bundle from a plane through the transverse limb of the anterior commissure to a plane through the most rostral fibers of the superior thalamic radiations. They course medially and ventrally over the medial aspect of the internal capsule and enter the dorsal aspect of the medial preoptic area. Some of the more caudal fibers 
enter the hypothalamus. As these fibers descend from the main bundle of the stria terminalis they are interspersed among the cells of the interstitial nucleus of this stria, which likewise merges with the gray of the medial preoptic area (fig. 16). The infracommissural bundle of Johnston ('23) is made up of the more rostral fibers of this component.

Stria medullaris component of the stria terminalis (fig. 25). This component was described under the components of the stria medullaris (p. 353).

Interstitio-hypothalamic tract (amygdalo-hypothalamic tract) (fig. 25). This component arises from the interstitial nucleus of the stria terminalis, caudal to the plane of the anterior commissure, and passes medially, caudally, and ventrally over the dorsal aspect of the fornix column and joins the medial cortico-hypothalamic tract, with which it disperses among the neurons of the periventricular preoptic area. No fibers were traced directly from the stria terminalis into this component in the guinea pig. In the rabbit there is a suggestion of added fibers direct from the stria terminalis. It seems probable that this interstitio-hypothalamic tract is comparable to the amygdalo-hypothalamic tract of the rat (Gurdjian, '27). In its course the fibers of this tract pass ventral to the rostral part of the stria medullaris and dorsal to the encapsulated part of the interstitial nucleus of the stria terminalis. The tract then passes over the dorsal aspect of the descending fornix column to reach its medial aspect, where it turns ventrally into the periventricular area. Winkler and Potter ('11, plate X) have shown but not labeled these fibers.

Connections of the bed nucleus of the stria terminalis. The bed nucleus of the stria terminalis is a place of synapse for many of the fibers of this stria, and here a number of its fibers originate or terminate. The fibers of this nucleus to the stria medullaris have been described under the discussion of this last-named system. The interstitio-hypothalamic tract is discussed in the previous paragraph and in addition to these, many small, short fibers are seen coursing from this nucleus around the ventral angle of the lateral ventricle (in the plane of the anterior commissure) into the nucleus fimbrialis septalis. 
These fibers outline the course of an arc with its concavity directed laterally toward the ventricle and serves to interconnect the bed nucleus of the stria terminalis and the septal nucleus.

Summary of the general relations of the stria terminalis. The stria terminalis arises from various nuclear groups of the amygdaloid complex - the basal, the cortical, the medial, and possibly other amygdaloid nuclei and the nucleus of the lateral olfactory tract. The various bundles converge on the caudoventral border of the internal capsule. From here the fibers swing around the caudal end of the internal capsule system as a broad, flattened band to reach the dorsal side of this system. This occurs in a plane through the rostral end of the lateral geniculate nucleus (fig. 26). It now continues forward, roughly in a horizontal plane close to the floor of the lateral ventricle at the medial aspect of the tail of the caudate nucleus and dorsal to the internal capsule. Through this part of its course the fibers of the superior thalamic radiation course transversely at its medial and ventral aspect. There are very few cells associated with the stria terminalis in this part of its course, a very few being scattered here and there along its lateral aspect, adjacent to the caudate, but these could hardly be considered as constituting an interstitial nucleus for this tract. As the stria reaches the plane of the anterior commissure its relations are slightly altered, for at such a level it is bounded dorsally by the lateral ventricle, medially by its interstitial nucleus, ventrally by the internal capsule, and laterally by the caudate nucleus (figs. 23 and 24). In this region it turns medially and ventrally and breaks up into its various components. As has been indicated in the earlier descriptions, these components distribute to the gray in the region of the anterior commissure, to the preoptic and possibly anterior hypothalamic areas, and in small part to the epithalamus through the stria medullaris component, while interamygdaloid connection is provided by the commissural bundle. Primarily, then, the stria terminalis relates the amygdaloid complex with its fellow of the opposite side and with the medial basal centers of the telencephalon. 


\section{Anterior commissure}

Practically all workers on the forebrain have given more or less consideration to this, its oldest commissure, and all textbooks on nervous anatomy devote some space to its description. However, the literature reveals a lack of agreement concerning the origin and termination of the various systems that compose this commissure. The following account of the components of the anterior commissure is based primarily on the silver preparations of the rabbit brain available for the present study. However, many of the details have been documented in the guinea pig material. Viewed in sagittal section the anterior commissure appears as a rounded (almost circular) band of fibers just beneath the ventral psalterium (figs. 17, 27, 28), bulging slightly backward into the cavity of the third ventricle. By virtue of differential staining the components of the anterior commissure (figs. 9, 10, 20 to 24, $27,28)$ are easily distinguishable from each other. These components are considered as follows:

Anterior limb of the anterior commissure (figs. 20 to 22, 28). The fascicles making up the anterior limb of the anterior commissure form the most rostral component of that commissure as it crosses the midline and are distinguishable in silver preparations by reason of their darker staining. The anterior limb is ' $U$ ' shaped in general outline, with the extremities of the ' $U$ ' extending forward into the olfactory bulbs while its convex part occupies the rostral part of the anterior commissure proper. It is composed largely of interbulbar fibers (p. 340) accompanied by fibers from the nucleus olfactorius anterior, the tuberculum olfactorium, the anterior pyriform area (Röthig, '09), and joined at its lateral aspect by many fibers from the external capsule. The interbulbar fibers constitute the intermediate olfactory tract and are largely, if not wholly, commissural (Ramón y Cajal, '11) ; that is, they interconnect the two olfactory bulbs. It is of interest that the intertubercular fibers form a separate bundle in the bat (Humphrey, '36). The external capsule component interconnects the lateral and ventral neopallial areas of the two sides. 
Röthig ('09) regarded the connections from the olfactory areas behind the bulb (prepyriform cortex) as possibly constituting a lobolobar commissure, but this needs further proof, although such a relation seems probable. Some of the fibers accompanying the anterior limb of the anterior commissure are probably not commissural in nature but association tracts, connecting cortical areas on the same side.

Transverse limb of the anterior commissure (figs. 9 and 22). The transverse limb of the anterior commissure crosses the midline between the anterior and posterior limbs, and might logically be considered as a middle limb of this commissure. It extends farther laterally than the other limbs and then spreads out fan-shaped into the external capsule and hence extends over a much greater area here than it occupied in its compact crossing in the commissure proper. The transverse limb is composed largely of these external capsule fibers, the cells of origin of which lie in the lateral and ventrolateral areas of the general neopallial cortex. As stated in the preceding paragraph, some external capsule fibers from the anterior part of the cortex join the lateral aspect of the interbulbar fibers and course caudally as a component of the anterior limb of the anterior commissure to cross with it in the commissure. In a similar manner, the external capsule fibers from the posterior regions of the neopallium course with the posterior limb of the anterior commissure to cross the midline in this commissure. However, the majority of the external capsule component of the commissure belongs to the transverse limb of the anterior commissure. These fibers stain lighter in the chrome silver series than do those of the anterior limb. As the transverse limb courses medially from the ventral aspect of the external capsule to the commissure proper, it passes across the ventral part of the internal capsule, some fibers of which course between the fascicles of the transverse limb in order to reach its ventral aspect. However, no additions of internal capsule fibers to the commissure are evident in the material studied. Such a connection has been said to exist exclusively in diprotodonts (Elliot Smith, '02), but such a 
component is also found in the bat (Humphrey, '36). Numerous vertically coursing fibers are seen passing between the fascicles of the transverse limb interconnecting the putamen proper with its ventral part (figs. 21 and 22 ; the nucleus intermedius striati of Loo, '31) but again it has not been possible to follow any of the fibers from the putamen into the transverse limb and across the midline in the preparations studied, as Loo ('31) did in the opossum. There are, however, fibers from the pyriform area that join the transverse limb and are undoubtedly commissural in nature.

Posterior limb of the anterior commissure (figs. 12, 23, 24). The posterior limb of the anterior commissure outlines the course of a ' $U$ ' as does the anterior limb, but the extremities of the ' $U$ ' extend caudalward rather than rostralward. In its caudal course the posterior limb extends along the ventrolateral aspect of the putamen to its caudal extreme, and then along the lateral aspect of the lateral amygdaloid nucleus almost to the caudal extreme of the amygdaloid area. Throughout its course it receives fibers from the pyriform area and external capsule in addition to those from the amygdala. A small basal and a large lateral interamygdaloid component are described by Humphrey ('36) in the bat. This component continues forward to the plane of the transverse limb of the anterior commissure with which it turns medialward to cross the midline in the posterior part of the anterior commissure. The commissural fibers of the stria terminalis lie at the posterior dorsal aspect of the posterior limb in the anterior commissure.

A general consideration of the anterior commissure. From the foregoing account it is evident that the anterior commissure carries various systems of fibers. In its anterior limb pass fibers of the intermediate olfactory tract, which constitute the interbulbar component found in mammals in general, including man. In its posterior limb, particularly, and to less extent in its anterior and transverse limbs, are interconnections between the pyriform lobe of one side and the corresponding regions of the opposite side. The posterior 
limb serves also to interconnect the amygdaloid nuclei of the two sides (especially the lateral nucleus of this group). These connections correspond to the intertemporal component, which also is found in mammals in general, including man. The commissural fibers of the stria terminalis as described for the rabbit are comparable to similarly described fibers in other mammals and man. In the transverse limb of the anterior commissure, and to a small extent in the anterior and posterior limbs, there are fascicles which run through the external capsule and swing medially at its ventral aspect to cross in the commissure, thus providing a commissural pathway for the lateral and ventral neopallial regions of the hemisphere. Thus they form a neopallial commissure which is the largest component of the anterior commissure in the rabbit. It supplements the relatively small corpus callosum of this rodent. In the bat likewise (Humphrey, '36) the largest component of the anterior commissure is neopallial, but includes a few fibers entering by way of the internal capsule in addition to the great mass of fibers entering by way of the external capsule. In the opossum, with the exception of a very few fibers which cross in the dorsal hippocampal commissure (Johnston, '13, Ariëns Kappers, '21), all the neopallial commissure fibers decussate as components of the anterior commissure, reaching it by way of external capsule fibers. In the other marsupials (Elliot Smith, '02; Obenchain, '25) similar relations maintain, except that Elliot Smith found that in the diprotodont brains studied by him part of the neopallial fibers reach the lateral border of the anterior commissure by way of the internal rather than by the external capsule. He termed such fibers the fasciculus aberrans. In most higher mammals the majority of the neopallial commissural fibers cross as a dorsal corpus callosum, and a neopallial component of the anterior commissure has not been generally recognized, although van Valkenberg ('11) is of the opinion that a remnant of this neopallial component of the anterior commissure persists. At all events, with respect to the development of the corpus callosum and the anterior commissure the rabbit oc- 
cupies an intermediate position between that of the marsupials, on the one hand, and higher mammals on the other hand, since it presents a well-developed corpus callosum as well as a massive neopallial component of the anterior commissure.

\section{Intrahemispheric connections of striatum (exclusive of amygdaloid complex)}

Cortico-striate fascicles (figs. 21, 22, 23). The greatest interest with regard to intrahemispheric connections of the caudate and lentiform nuclei centers at present around the possibility of connections of these centers with the cortex. About such connections there has been great difference of opinion. Thus von Gudden (1870), Flechsig (1876), Wilson ('14), C. and O. Vogt ('20), and others could not establish connections between the cortex and the striatum. Bianchi and d'Abundo (1886) and Marinesco (1895), after experimentation with dogs, reached the conclusion that corticostriate fibers were present. Economo ('10), Ramón y Cajal ('11), and others have favored these connections by way of collaterals of internal capsule fibers. Von Gudden (1881), Sachs ('09), von Monakow ('25), Kodama ('27), and Coenen ('27) believed that they could establish connections between the cortex and the caudate nucleus, usually as accompaniments of association fibers. Connections of the putamen and cortex have been described by Economo ('10) and Kodama ('29). Minkowski ('24), Riese ('27), and others have described fibers to the globus pallidus.

In the rabbit material studied, just rostral to the plane of the accumbens nucleus (fig. 20) fibers were seen coursing from the medial part of the head of the caudate nucleus medially and dorsally around the ventral aspect of the lateral ventricle to enter the deep fiber layer of the general cortex, beyond which they could not be traced. These fibers, which are very few in number in the rabbit material, resemble in general relations certain fibers described by Loo ('31) in the opossum. In this latter animal they were carried to the septum and 
the hippocampus. These medial fibers have been termed the tractus cortico-caudatus medialis, and the lateral connections between the cortex and caudate have been called the tractus cortico-caudatus lateralis. This latter tract (figs. 21 and 22), which is presumably the same as the fasciculus described by Loo ('31) under that name, consists of delicate fibers which enter the dorsolateral angle of the anterior third of the candate nucleus and course along its dorsolateral aspect (in a somewhat medial direction) for a short distance before entering the gray of this nucleus. These fibers arise from the temporal and lateral cortex and cut through the converging fibers of the internal capsule system at the lateral aspect of the corpus callosum to reach the caudate nucleus. They correspond to the cortico-caudate connections described by Minkowski ('24) and Coenen ('27) for rabbits. Accompanying the fibers of the internal capsule along the ventrolateral border of the same are fine fibers which swing into the dorsal tip and the medial side of the putamen. They are relatively few in number (figs. 21 and 22), but appear to constitute a cortico-putamal path, although they require further experimental verification to prove that they terminate in this nucleus and are not merely aberrant fascicles of the internal capsule which rejoin this system farther caudally. Such a connection has not been recognized in the rabbit by Coenen ('27). As the internal capsule passes between the caudate and lentiform nuclei, small, dark staining, unmyelinated fibers can be seen to leave the capsule and enter the gray of the globus pallidus (figs. 22 and 23). In part these may be collaterals of internal capsule fibers such as have been described by Ramón y Cajal ('11) and in part they may represent direct corticopallial connections such as were described by Coenen ('27) through the internal capsule.

Internuclear connections. There are numerous connections between the caudate nucleus and the putamen by means of cellular and fibrous bridges passing through the interstices of the internal capsule which forms the imperfect boundary between these two structures. These connections are more 
evident and more numerous in the rostral part of the putamen where the boundary is less complete than it is farther caudally. Fibers arise in the lateral part of the putamen and course medially into the globus pallidus. In some of the cross section planes, particularly near the caudal extreme of the nucleus, these fibers give to the putamen a striated appearance as they stream medially through it (figs. 11, 12, 23 to 25). Whether these fibers terminate in the globus pallidus or continue through it into the ansa lenticularis cannot be stated definitely. Wilson ('14) favored the former point of view. These fibers do not form a well-defined lamina separating the putamen from the globus pallidus (lateral medullary lamina of general description), but the two areas blend without sharp line of demarcation. Likewise there is no medial medullary lamina dividing the globus pallidus, and the latter is represented by a single segment triangular in outline, with its base directed laterally and apposed to the medial surface of the putamen and its apex directed medially toward the internal capsule. As the fibers of the external capsule course medially to enter the anterior commissure they separate the most ventral part of the putamen from the main mass of the same (this small ventral segment has been designated the nucleus intermedius striati by Loo, '31). However, these two parts of the putamen are intimately associated with each other by numerous fine, short internuclear fibers (fig. 22). A study of the present material leaves some doubt concerning possible connections between the claustrum and the putamen, although certain of the chrome-pyridine-silver sections show fibers that are suggestive of such a connection.

Interconnections between the striatum (exclusive of the amygdaloid complex) and lower centers

Interconnections between the dorsal thalamus and striatum. In normal material it is exceedingly difficult to distinguish between striatal and cortical connections of the thalamic nuclei. There is rather general agreement that such connections are present for the medial nucleus of rodents, where they have 
been studied experimentally in the rat (Clark and Boggon, '33). For the anterior nucleus of rodents there is more doubt with regard to connections with the striatum. Clark and Boggon ('33) have been unable to obtain evidence for such connections in their experimental work on the rat, although von Monakow (1895) described a connection between the striatum and the nucleus anteroventralis by way of the inferior thalamic peduncle. Olive Smith ('30) believed that she could trace fibers in Tamandua from the lenticular nucleus through the internal capsule and suggested a possible connection with the anterior nucleus. In the guinea pig material available for study, fibers of the inferior thalamic peduncle cut through the internal capsule fibers and swing dorsalward fairly near the midline. Certain of such fibers reach the nucleus anteroventralis. Presumably such fibers correspond to those described by von Monakow and Smith, but their striatal origin has not been established in the material studied for this report.

Ansa lenticularis (figs. 13, 25, 26). The chief afferent pathway of the striatum is the ansa lenticularis, and this system has been the object of a considerable amount of work, particularly in experimental and clinical fields. The major interest has centered to a considerable extent around the location of the cells of origin of the ansa fibers as well as their exact distribution. Thus Wilson ('14), in his study of the ansa lenticularis, reached the conclusion that this fiber bundle took origin only from the globus pallidus. Spatz ('21, '22) emphasized that the globus pallidus was the portion of the striatal complex most closely related to the red nucleus, the substantia nigra, and the nucleus subthalamicus, thus apparently substantiating Wilson's point of view. Riese ('24, '24 a) emphasized particularly fibers from the globus pallidus by way of the lenticular fasciculus of Forel to the medial longitudinal fasciculus, although he obtained connections also between the head of the caudate and the substantia nigra. Muskens ('22) stressed the connection of the globus pallidus with the gray associated with the medial longitudinal fasciculus. Morgan 
('27), by injuries to the lenticular nucleus in the cat, obtained degenerated strio-fugal fibers to various subthalamic nuclei and certain hypothalamic nuclei, to the interstitial nucleus of Ramón y Cajal, and the nucleus of Darkschewitsch, to various motor nuclei of cranial nerves of the brain stem (nucleus ambiguus and nucleus hypoglossi), to reticular nuclei, and various other centers. Apparently, he also regarded them as arising only from the globus pallidus. The more ventral and medial portions of the globus pallidus, he considered, gave rise to subthalamic fibers, the more dorsal and lateral portions to fibers to the various efferent centers of the brain stem. Many years ago, von Monakow (1895) divided the ansa lenticularis into three divisions, depending upon the course of the fibers. Of these three divisions, which for convenience may be designated as dorsal, middle, and ventral bundles, the first two reach the subthalamic region by cutting directly through the internal capsule, while the last named runs ventral to the lentiform nucleus and enters the diencephalon largely ventral to the internal capsule system. Some of the differences of opinion with regard to the components of the ansa may depend on whether or not this bundle is included in that fasciculus. It seems probable that Wilson ('14) did not so include it; von Monakow (1895, '25, and elsewhere), Tilney and Riley ('21), Foix and Nicolesco ('25), Kodama ('29), and others have regarded certain fascicles of the ansa lenticularis as arising from other parts of the striatum as well as from the globus pallidus. The ventral bundle of von Monakow (figs. 25 and 26) can be seen in the guinea pig as fascicles of fine fibers which swing along the ventral border of the globus pallidus. Some of the fascicles lie among the bundles of the globus pallidus; others swing along the under border to about the line between globus pallidus and putamen, where they turn into the gray. The material suggests that certain of these fibers may be in relation with the putamen, but the evidence for this is inconclusive. Some of them certainly appear to arise from the globus pallidus. After leaving the putamen, these fibers swing under and to some extent through 
the ventral edge of the internal capsule. Others of them turn directly ventralward over the optic chiasm toward the region of the dorsal supraoptic decussation of Meynert, where they appear to decussate (Probst, '05; Kodama, '29). Some of the fibers continue caudalward between the optic and supraoptic fibers and the peduncle (fig. 26), and turn dorsalward at its medial border to reach the nucleus subthalamicus, the substantia nigra, and possibly other neighboring groups. The dorsal and medial bundles of the ansa cut through the cerebral peduncles to enter the subthalamic region (fig. 26) where they distribute to various subthalamic centers, including the red nucleus, the substantia nigra, the nucleus subthalamicus, the field of Forel, and the zona incerta. The details of this distribution must be left for a later report.

\section{Internal capsule}

The intimate topographic relations of the internal capsule system (figs. 6 to 15, 20 to 26 ) to the striatal areas of the forebrain necessitate some account of its course in relation to these areas, even though the details of its cortical and thalamic connections are outside of the scope of the present account. In the frontal part of the cerebral hemisphere, fibers form a core of white matter, in the center of the gray, which is easily distinguished in cross sections (fig. 19). In this white core are represented all three types of cortical fibers; that is, association, commissural, and projection fibers. In the plane in which the olfactory and lateral ventricles join, the projection fibers have accumulated at the lateral aspect of the lateral ventricle as a vertical column of cross cut fibers, intermingled with the fibers of the external capsule and lying dorsal to the anterior limb of the anterior commissure (fig. 20). The further addition of fibers to the internal capsule is from the cells of the dorsal and dorsolateral areas of the neopallium by way of the corona radiata. These additional fibers are applied to the dorsal aspect of the accumulated group of internal capsule fibers lying at the lateral aspect of the lateral ventricle. Hence it is evident that the more ventrally placed 
fibers of the internal capsule arise farther rostrally than the more dorsally placed fibers. The combined internal and external capsules form the lateral boundary of the rostral extreme of the caudate nucleus. The fibers of the internal capsule are cross cut in the transverse series and can be distinguished from those of the external capsule which are cut more obliquely in this series. In the plane of the rostral extreme of the accumbens nucleus it will be noted that the scattered fascicles of the internal capsule have become separated from those of the external capsule and have assumed a more medial position; the gray lying between these two fiber systems represents the rostral extreme of the putamen (fig. 7). The internal capsule fibers assume a more medial position and form larger fascicles as the tract is followed caudally, while the external capsule retains its lateral position and forms the lateral border of the putamen throughout (figs. 8, 22). Fibers are continually being added to the dorsal aspect of the internal capsule from the corona radiata, and its fascicles become aggregated into fewer but larger bundles which serve as an incomplete boundary between the caudate and the putamen (fig. 9). As the external capsule fibers swing medially to cross in the anterior commissure, they pass directly through the ventral part of the internal capsule and separate the ventral fibers of the same from the main part of the bundle (figs. 9 and 22). In the plane of the anterior commissure the intercalated nucleus of the internal capsule is evident among the ventromedial fibers of this bundle, and its fascicles thus become spread over a larger total area (figs. 9 and 10). Caudal to this plane, the internal capsule appears as a single, compact fiber mass forming practically a complete boundary between the putamen and the caudate. This fiber complex now occupies an obliquely transverse position in the cross sections in contrast to its almost vertical position farther rostrally. Ramón y Cajal ('11) has described collaterals from the fibers of the lateral forebrain bundle into the globus pallidus, and such were recognized in the material here studied, and in addition certain stem fibers appear to enter the lenticular nucleus from this 
fiber system (p. 365). Minkowski ('24) and others have also described such connections. Many fibers from the cortex course in the internal capsule and turn medially and dorsally to enter the dorsal part of the diencephalon. These fibers form the thalamic radiations and probably conduct in both directions. The ventrolateral fibers of the internal capsule course among the cells of the globus pallidus and give to this region its 'pallid' appearance. In the plane of the caudal third of the anterior commissure the internal capsule assumes a more medial position and approaches the medial forebrain bundle, and the two systems appear to be continuous. However, the fibers are larger and more heavily myelinated in the former than in the latter. The additional fibers from the corona radiata are now applied to the dorsolateral aspect of the internal capsule, since the latter occupies an almost horizontal position in the series. It passes immediately dorsal to the ascending optic tract and as the latter turns dorsally to enter the lateral geniculate nucleus it also forms the lateral boundary of the internal capsule (figs. 15 and 26). In the same plane in which this occurs the stria terminalis dips ventrally over the caudal aspect of those internal capsule fibers coursing from the cortex into the main bundle, and no further additions are received by the internal capsule caudal to this plane. It now becomes the cerebral peduncle. Some cortical fibers arising caudal to this plane course forward in the cortex to enter the internal capsule just rostral to the descending stria terminalis, but none are added caudal to the latter. The internal capsule contributes stem fibers and collaterals to the various subthalamic nuclei, but the material at hand is not favorable for an analysis of these fibers. The relation of the peduncle fibers to the entopeduncular nuclear group has already been discussed earlier in the present account (p.323).

\section{A hypothalamo-hypophyseal tract}

Although the hypothalamo-hypophyseal tract has no connection with the telencephalon, attention is called here to this diencephalic tract, particularly well stained in the silver prepa- 
rations of the rabbit (fig. 27). This tract arises a short distance caudal to the optic chiasm from a distinct nucleus lying in the midline ventral to the third ventricle near the pial surface of the brain. This cell group has been designated as nucleus hypothalamicus ventralis pars centralis. From this group of cells fibers arise which course caudalward along the midplane of the floor of the hypothalamus, just within the pial surface and sometimes projecting dorsalward as a ridge in the floor of the third ventricle. These fibers are evident even in cell preparations, but are best seen in the sagittal silver series. They course caudally over the dorsal aspect of pars oralis of the hypophysis and into the infundibular stalk, and thus enter pars neuralis of the hypophysis, where the fibers disperse among the cells and on the blood vessels of this region. The tract as given here differs in certain particulars from various connections of the hypophysis described in the literature. Thus Krieg ('32) described a somewhat similar tract, which he said beyond doubt runs from the optic chiasm to the hypophysis, while the tract here described is believed to take origin from the hypothalamic gray, distinctly caudal to the chiasm. Greving ('28) and Loo ('31) described connections from the supraoptic nucleus to the hypophysis-the tractus supraoptico-hypophyseos-but this tract is somewhat lateral to the midline in contrast to the one herein described. In the fasciculus supraopticus of the opossum (Loo, '31, fig. $93)$, fibers are shown that resemble in some respect the tract now being considered in rabbit. In the opossum these fibers appear to arise from a differentiation of the midline gray, which Loo has termed the nucleus epichiasmaticus. In the rabbit also these fibers arise from a midline group, distinetly caudal to the chiasm. Because of uncertainty with regard to its homologies the tract is labeled here as tractus hypothalamo-hypophyseosus.

\section{GENERAL SUMMARY}

The olfactory sense is highly developed in the rabbit and this specialization is reflected centrally in the high degree of differentiation of the primary, secondary, and tertiary olfactory 
centers of the telencephalon. This specialization is indicated in the first place by the presence of a highly developed olfactory bulb and an accessory olfactory bulb, with the arrangement of its layers and the morphological characteristics of the neurons indicating a high degree of differentiation, and by the appearance of a greatly specialized nucleus olfactorius anterior, showing all the differentiated portions which up to the present time have been described in detail only for marsupials (Herrick, '24; Obenchain, '25). The nucleus in rodents differs from that in marsupials in having a more specialized rostral extent. The tuberculum olfactorium is also well developed, with typical islands of Calleja, although it is not quite so highly differentiated as in certain mammalian forms. The septal areas show a differentiation comparable to that described for lower mammals in general. Emphasis has been laid on the particularly clearly developed nucleus of the diagonal band and certain of its secondary relations and on the nucleus septo-hippocampalis. For this latter nuclear group certain interesting relations have been established. It has been seen to be directly continuous in front with the anterior extension of the hippocampus, to extend caudally beneath the corpus callosum in company with fornix fibers to the region of the dorsal hippocampal commissure, where, through its bed nucleus, it becomes continuous with the hippocampus. Just as the induseum griseum is a band of gray connecting the anterior extension of the hippocampus with the hippocampus proper by passing dorsal to the corpus callosum, so the nucleus septo-hippocampalis in the rabbit establishes a similar relation ventral to the corpus callosum. In this sense, then, this part of the area merits the name of the primordium hippocampi, a term applied to it and the adjoining gray by Johnston ('13). The amygdaloid complex has been resolved into the various nuclei described for it in the rabbit by Johnston, and further division of the lateral amygdaloid nucleus into an anterior and a posterior portion has been made on the basis of the cytoarchitectonic structure. 
Correlated with the development of clearly demarked primary, secondary, and tertiary olfactory telencephalic centers is the appearance in these forms of a wealth of associated fiber tracts. The entering olfactory fila, the nervus terminalis, and the vomeronasal nerves have been identified. The olfactory tracts have been described in considerable detail, and their specialization related to the nuclear masses. The relations of the ventromedial portions of the hemisphere with the overlying hippocampal areas have been established through the identification of cortico-septal and septo-cortical connections and tuberculo-cortical and cortico-tubercular tracts. These centers of the ventromedial wall have been related with amygdaloid and pyriform lobe areas through the diagonal band of Broca, and with lower centers through the medial forebrain bundle. The connections of the amygdaloid complex have been described in detail, for the various components have been traced from specific amygdaloid nuclei via the stria terminalis to various preoptic and hypothalamic areas, or as commissural fibers to the amygdaloid region of the other side. The various components of the stria medullaris, providing connections of basal and cortical olfactory centers of the hemisphere with the habenular regions, have been identified and described. The commissural connections of the hemisphere, dorsal and ventral hippocampal commissures, and the anterior commissure have received due attention. For convenience of description the fornix bundle has been separated into precommissural and postcommissural portions as Elliot Smith (1897), Edinger ('11), and others have done. Each portion was found to consist only in part of fibers directly from the hippocampus, although the latter predominate in the postcommissural fornix.

The non-olfactory centers here considered include the caudate and lentiform nuclei and the claustrum. The caudate and putamen were found to be interconnected by broad bands of gray which extend between the fascicles of the internal capsule, especially at more rostral levels. Fiber connections were also established between these two cell groups. Apparently there is a wider separation between the two nuclei 
caudally than was described by Gurdjian ('28) for the rat, but as in other mammals, their continuity at more frontal levels and their common cytologic character suggest their close relationship. The claustrum probably is cortical rather than basal, although morphologically it occupies an intermediate position in the adult mammal. The connections demonstrated for these non-olfactory centers consist of thalamo-striatal, interstriatal, and cortico-striatal fascicles, and efferent bundles by way of the ansa lenticularis. The three divisions of the ansa lenticularis (as used in the broader sense) were demonstrated. The normal preparations indicated that this bundle has origin to some extent from the putamen, although largely from the globus pallidus. In the material available it was not possible to demonstrate fascicles from the caudate into the ansa lenticularis. In addition to certain generally accepted connections, fibers of the most ventral division were carried through Meynert's commissure, a connection denied by Wilson ('14) and accepted by Kodama ('29). It is believed that the discrepancies here are due to differences of delimitation of the ansa lenticularis, the term as used by Wilson ('14) not including certain of the more ventral fibers. The commissural connections for the non-olfactory cortical areas are provided for by two commissural systems in the rabbit and the guinea pig; a dorsal corpus callosum which serves to interconnect the more dorsal portions of the hemisphere, and a large neopallial component by way of the external capsule and the anterior commissure. Thus in this, as in certain other respects, the rabbit's telencephalon is intermediate between that of mammals such as the opossum, where the major neopallial commissure system is through the anterior commissure, and the corresponding regions of higher mammals, where this component is reduced to a minimum (or entirely absent) and the corpus callosum serves to interconnect all neopallial areas of the two hemispheres. 


\section{BIBLIOGRAPHY}

All references cited in the text which are not included in the following bibliography may be found in the bibliographies accompanying the appropriate chapters of the fourth reference listed below.

ARIËNS KAPPERS, C. U. 1914 The phenomena of neurobiotaxis in the central nervous system. XVIIth International Congress of Medicine. London. 1923 Le developpment ontogenetique du corps strié des oiseux en comparaison avec celui des mammiferes et de l'homme. Schweizer Areh. f. Neur. und Psych., Bd. 13, s. 348.

1928 Three lectures on neurobiotaxis and other subjects delivered at the Univ. of Copenhagen. Levin and Munksgaard, Copenhagen.

ARIËNs KapPERS, C. U., G. C. HUBRr aND E. C. CRosBX 1936 The comparative anatomy of the nervous system of vertebrates including man. New York, The Macmillan Company.

BALOGH, C. 1860 Über das Jacobson'sche Organ des Schafes. Sitzungsb. d. Kais. Akad. d. Wissensehaften in Wien, Bd. 42, S. 280 und 449.

BARKER, L. F. 1899 The Nervous System. New York, Appleton \& Co.

BecCari, N. 1910 Il lobo parolfattorio nei mammiferi. Arch. Ital. Anat. e di Embriol., vol. 9, p. 173.

BERKELBACH VAN DER SPRENKEL, H. 1926 Stria terminalis and amygdala in the brain of the opossum (Didelphis virginiana). J. Comp. Neur., vol. 42 , p. 211.

BIANCHI, L. AND G. D'ABUndo 1886 Die ins Gehirn und Rückenmark herabsteigenden experimentalen Degenerationen als Beitrag zur Lehre von den cerebralen Lokalisierungen. Neurol. Centralbl, Bd. 17, s. 385.

BROCA, P. 1879 Recherches sur les centres olfactifs. Revus d'anthropologie, p. 385 .

BRODMANA, K. 1909 Vergleichende Lokalisationslehre der Grosshirnrinde in ihren prinzipien dargestellt auf grund des Zellenbaues. Leipzig, Barth.

CAIRNeY, J. 1926 A general survey of the forebrain of Sphenodon punctatum. J. Comp. Neur., vol. 42 , p. 255.

ClaRK, W. Le Gros AND R. H, Boggon 1933 On the connections of the anterior nneleus of the thalamus. J. Anat., vol. 67, p. 215.

CoENEN, L. 1927 The connection of the cortex with the neostriatum and paleostriatum in rabbits. Proc. Kon. Akad. v. Wetens. te Amsterdam, vol. 30, p. 811.

Crataie, E. H. 1925 Finer anatomy of the central nervous system based upon that of the albino rat. Philadelphia, Blakiston's Son \& Co.

Crosst, Elizabetri C. 1917 The forebrain of Alligator mississippiensis. J. Comp. Neur., vol. 27, p. 325.

DART, R. A. 1920 A contribution to the morphology of the corpus striatum. J. Anat., vol. 55, p. 1.

Economo, C. J. 1910 Beitrag zur Kasuistik und zur Erklärung der posthemiplegischen chorea. Wien Klin. Wochenschr., Bd. 23, S. 429.

EdNaer, L. 1908-1911 Vorlesungen über den Bau der nervösen Zentralorgane des Mensehen und der Tiere. Leipzig, Vogel.

Edingme, L. AND A. W ALLENBerat 1901 Untersuehungen über den Fornix und das eorpus mammillare. Archiv f. Psychiatr., Bd. 35, s. 1. 
Elliot Sмiтh, G. 1896 The morphology of the limbic lobe, corpus striatum, the reptilian septum pellucidum and the fornix. J. Anat. and Physiol., vol. $30, \mathrm{pp} .157$ and 185.

1896 a The fornix superior. J. Anat. and Physiol., vol. 31, p. 80. 1897 The relation of the fornix to the margin of the cerebral cortex. J. Anat. and Physiol., vol. 32, p. 23.

1902 On a peculiarity of the cerebral commissures in certain Marsupiala not hitherto recognized as a distinctive featuro of the Diprotodontia. Proc. Roy. Soc. of London, vol. 70, p. 226.

1910 Some problems relating to the evolution of the brain. The Arris and Gale Lectures I, II, and III. Lancet, vol. 1, pp. 1, 147 and 221.

1919 The morphology of the corpus striatum and the origin of the neopallium. J. Anat., vol. 53, p. 272.

FAUL, J. 1926 The comparative ontogenetic development of the corpus striatum in reptiles. Kon. Akad. v. Wetens. te Amsterdam. Proc. sect. Sci., vol. 29, p. 150 .

Gehuchiten, A, van 1906 Anatomie du Systéme Nerveux de l'homme. IVth ed. Louvain.

Gehuchten, A. van and I. MaRtin 1891 Le bulbe olfactif. La Cellule, vol. 7, p. 205.

GoLGI, C. 1875 Sulla fina anatomia dei bulbi olfatorii. Reggio-Emilia.

Greving, R. 1928 Die zentraien Anteile des vegetative Nervensystem. Möllendorff's Handb. d. Mikros. Anat. d. Menschen., Bd. 4, Nervensystem. Berlin, J. Springer.

GUDDEN, B. vON 1870 Experimentaluntersuchung über das peripherische und centrale Nervensystem. Arch. f. Psych., Bd. 2, S. 699.

1881 Beitrag zur Kenntniss des Corpus Mammillare und der sogenannten Schenkel des Fornix. Arch. f. Psychiat., Bd. 11, S. 428.

GuRDJIAN, E. S. 1925 Olfactory connections of the albino rat with special reference to stria medullaris and anterior commissure. J. Comp. Neur., vol. 38, p. 127.

1927 The diencephalon of the albino rat. Studies on the brain of the rat. No. 2. J. Comp. Neur., vol. 43, p. 1.

1928 The corpus striatum of the rat. J. Comp. Neur., vol. 45, p. 249.

Haller, B. 1900 Vom Bau des Wirbelthiergehirns. Morph. Jahrb., Bd. 28, S. 347.

HERRICK, C. J. 1910 The morphology of the forebrain in Amphibia and Reptilia. J. Comp. Neur., vol. 20, p. 413.

1921 The connections of the vomeronasal nerve, the accessory olfactory bulb and the amygdala in Amphibia. J. Comp. Neur., vol. 33, p. 213.

1924 The nucleus olfactorius anterior of the opossum. J. Comp. Neur., vol. 37, p. 317.

HGRRICK, C. L. 1892 The cerebrum and olfactories of the opossum, Didelphis virginiana. J. Comp. Neur., vol. 2, p. 1. 
HINES, MARIoN 1922 Studies in the growth and differentiation of the telencephalon in man. The fissura hippoeampi. J. Comp. Neur., vol. 34, p. 73. 1929 The brain of Ornithorhynchus anatinus. Phil. Trans. Roy. Soe. of London, series B, vol. 217, p. 155.

HONEGGRR, J. 1890 Vergleichende anatomischen Untersuchungen über den Fornix. Recueil. Zool. Suisse, vol. 5.

Huber, G. Carl and Elizabeth C. Crosbr 1926 On thalamie and tectal nuclei and fiber paths in the brain of the American alligator. J. Comp. Neur., vol. 40 , p. 97 .

1929 The nuclei and fiber paths of the avian diencephalon. J. Comp. Neur., vol. 48, p. 1.

1929 a Somatic and viseeral connections of the diencephalon. Arch. Neur. and Psychiat., vol. 22, p. 187.

HubER, G. CART AND S. R. GUIL 1913 Observations on the peripheral distribution of the nervus terminalis in Mammalia. Anat. Rec., vol. 7, p. 253.

HuMphrex, T. 1936 The teleneephalon of the bat. I. The non-cortical nuclear masses and certain pertinent fiber connections. Huber Memorial Volume, J. Comp. Neur., vol. 65, p. 603.

Johnston, J. B. 1913 The morphology of the septum, hippocampus, and pallial commissures in reptiles and mammals. J. Comp. Neur., vol. 23, p. 371.

1915 The cell masses in the forebrain of the turtle, Cistudo carolina. J. Comp. Neur., vol. 25, p. 393.

1923 Further contributions to the study of the evolution of the forebrain. J. Comp. Neur., vol. 35 , p. 337 , and vol. 36, p. 143.

Konama, S. 1927 Über die sogenannte Basalganglien, morphogenetische und pathologische anatomisehe Untersuehungen. Schweiz. Arch. f. Neur. und Psych., Bd. 19, S. 152, and Bd. 20, S. 209.

1929 Ửber die sogenannte Basalganglien, Morphogenetische und pathologische anatomische Untersuchungen. Schweiz. Areh. f. Neur. und Psych., Bd. 23, S. 179.

KölLtKer, A. voN 1896 Handbuch der Gewebelehre des Menschen, 6. Auf., Bd. 2. Leipzig, W. Engelmann.

KRIEG, W. J. S. 1932 The hypothalamus of the albino rat. J. Comp. Neur., vol. 55 , p. 19 .

LANDAU, E. 1919 The comparative anatomy of the nucleus amygdala, the claustrum and the insular cortex. J. Anat., vol. 53, p. 351.

Livini, F. $1908 \mathrm{Il}$ proencefalo di un Marsupiale (Hypsiprymuus rufescens). Areh. di Anat. e Embriol., vol. 6, p. 549.

Loo, Y. T. 1931 The forebrain of the opossum, Didelphis virginiana. II. J. Comp. Neur., vol. 53 , p. 1.

Lowenthat, N. 1897 Über das Riechhirn der Saugetiere. Festseh. z. 69 Versammlung Deutscher Naturforscher und Arzte. Braunschweig.

Marinesco, M. G. 1895 Les connexions du corps strié avec le lobe frontal. C. $R$. Soc. Biol., p. 771.

MaCotrper, R. E. 1912 The connections of the vomeronasal nerves with the accessory olfactory bulb in the opossum and other mammals. Anat. Rec., vol. 6, p. 299. 
Mrnkowskr, M. 1924 Étude sur les connexions anatomiques des circonvolutions rolandiques, parietales et frontales. Sehw. Areh. f. Neur. und Psych., Bd. 14, S. 255 und Bd. 15, S. 97.

Monakow, C. voN 1895 Experimentelle und pathologische-anatomische Untersuchungen über die Haubenregion, den Sehhügel und die Regio subthalamica, nebst Beiträgen zur Kenntniss früh erworbener Gross- und Kleinhirn defecte. Archiv f. Psychiat. u. Nervenkrank., Bd. 27, S. 1. 1925 Experimentelle und pathologische-anatomische, sowie entwicklungsgeschichtliche Untersuchungen über die Beziehungen des Corpus striatum und des Linsenkernes zu den übrigen Hirnteilen. Schw. Arch. f. Neur. und Psych., Bid. 16, S. 225.

MüNzer, E. AND H. WIENBR 1902 Das Zwischen- und Mittelhirn des Kaninchens und die Beziehungen dieser Teile zum übrigen Centralnervensystem. Monatseh. f. Psychiat. und Neur., Bd. 12, S. 241.

Obenchais, J. B. 1925 The brains of the South American Marsupials, Caenolestes and Orolestes. Field Mus. Nat. Hist., pub. 224, Zool. Ser., vol. 14, p. 175.

OwsIannIKow 1860 Über die feinere Structure der Lobi olfactorii der Saugethiere. Arch. f. Anat., Physiol. u. wissensch. med. (Müller), Jahrg. 1860, S. 469 .

PaPez, J. 1929 Comparative neurology. New York, T. Y. Crowell Co.

Probst, M. 1905 Über die commissur von Gudden, Meynert und Ganser und über die Folgen der Bulbus atrophie auf die Zentrale Sehbahn. Monatsch. f. Psychiat., Bd. 17, S. 1.

RAḾ́N, PmDRo 1890 Notas preventivas sobre la estructura de los centros nerviosos. Gaceta sanitaria de Barcelona, Anno III, p. 10.

RAMON Y CAJAL, S. 1890 Origen y terminacion de las fibras nerviosas olfatorias. Gae. san, de Bareelona.

1911 Histologie du systéme nerveux de l'homme et des vertebres. Paris, A. Maloine

RIESE, W. 1924 Zur vergleichenden Anatomie der strio-fugalen Faserung. Anat. Anz., Bd. 57, S. 487.

1924 a Über faseranatomische Verbindungen im 'striären System' der Wasserlebenden Säuger. Zeit. f. d. gesam. Neur. und Psychiat, Bd. 90 , S. 591 .

Rroch, D. MCK. 1929 Studies on the diencephalon of Carnivora. II. Certain nuclear configurations and fiber connections of the subthalamus of the dog and cat. J. Comp. Neur., vol. 49, p. 121.

Röтнig, P. 1909 Reichbahnen, Septum und Thalamus bei Didelphis marsupialis. Abhandl. d. Senckenb. Nat. Gesellsch. Frankfurt am Main, Bd. 31, S. 1.

Smith, G. EluroT See Elliot Smith, G.

SMITH, LESLIE A. 1928 A comparison of the number of nerve cells in the olfactory bulbs of domesticated albino and wild Norway rats. J. Comp. Neur., vol. $45, \mathrm{p} .483$.

Smith, OuIve C. 1930 The corpus striatum, amygdala, and stria terminalis of Tamandua tetradactyla. J. Comp. Neur., vol. 52, p. 65.

SONNTAG, O. F. AND H. H. WoomaARD 1925 The brain of Orycteropus afer. Proc. Zool. Soc. of London, p. 1185. 
Spatz, H. 1921 Zur Anatomie der Zentren des Streifenhügels. Münch. Med. Wochensch., Bd. 69, S. 1441.

1922 Über Beziehungen zwischen der Substantia Nigra des Mittelhirnfusses und des Globus Pallidus des Linsenkerns. Verh. d. Anat. Gesellsch., Bd. 31, S. 159.

Trlney, F. AND H. RiLey 1921 The form and functions of the central nervous system. New York, P. Hoeber.

VoGT, C. AND O. VoGT 1920 Zur Lehre der Erkrankungen des striären Systems. J. f. Psych. und Neur., Bd. 25, s. 631.

VöLSCH, MAX 1906 Zur vergleichenden Anatomis des Mandelkerns und seiner Nachbargebilde. Pt. I, 1906 Arch. f. mikr. Anat., Bd. 68, S. 573, Pt. II, 1910 Areh. f. mikr. Anat., Bd. 76, S. 373.

VRIES, E. DE 1910 Das Corpus striatum der Säugetiere. Anat. Anz., Bd. 37, S. 385 .

Ward.gnberg, A. 1902 Das basale Riechbündel des Kaninchens. Anat. Anz., Bd. 20, S. 175 .

WILson, K. 1914 An experimental research into the anatomy and physiology of the corpus striatum. Brain, vol. 36, p. 427.

WINkLeR, G. AND A. POTTER 1911 An anatomical guide to experimental researches on the rabbit's brain. Amsterdam, W. Versluys.

1914 An anatomical guide to experimental researches on the cat's brain. Amsterdam, W. Versluys.

Zuokerkand, E. 1888 Das Riechbündel des Ammonshorns. Anat. Anz., Bd. 3, 8. 425 . 


\section{ABBREVIATIONS FOR ALL FIGURES}

A. hyp. ant., area hypothalamica anterior A. preop., area preoptica

Alv, alveus

Amyg., amygdala

Ansa lent., ansa lenticularis

Bulb. olf., bulbus olfactorius

Bulb. olf. ace., bulbus olfactorius accessorius

C., stria terminalis component of the stria medullaris

C. pyr., cortex pyriformis

Cap., capsula

Cap. ext., capsula externa

Cap. extr., capsula extrema

Cap. int., capsula interna

Cel. mit., cellulae mitrales

Cent. semiov., centrum semiovale

Cer., cerebellum

Cer. ped., cerebral pedunele

Ch. op., chiasma opticum

Cing., cingulum

Claus., elaustrum

Col. fx., columna fornicis

Col, inf., colliculus inferior

Col. sup., colliculus superior

Com. ant., commissura anterior

Com. ant. nuel. com.ant., commissura anterior, nucleus commissurae anterioris

Com. ant. 1. ant., commissura anterior, limbus anterior

Com. ant. 1. post., commissura anterior, limbus posterior

Com. ant. 1. trans., commissura anterior, limbus transversus

Com. hip. dors., commissura hippocampi dorsalis

Com. hip. vent., commissura hippocampi ventralis

Corp. cal., corpus callosum

Corp. cal. f. a., corpus callosum, forceps anterior

Corp. mam., corpus mamillare

Cor. rad., corona radiata

Dec. fx. precom., decussatio fornicis precommissuralis
Dec. suprop. dors., decussatio supraoptica dorsalis (commissure of Meynert)

Ep., epiphysis

F. circ., fissura circularis

F. rhin., fissura rhinica

Fase. ass., association fibers

Fase. lent, fascieulus lenticularis of Forel

Fib, intern., fibrae internucleares

Fib. vomeronas., fibrae vomeronasales

Fil. olf., fila olfactoria

Fim., fimbria

For. interv., foramen interventrieulare

Form. olf., formatio olfactoria

Fx. posteom., fornix posteommissuralis

Fx. precom., fornix precommissuralis

Fx. sup., fornix superior

Genu corp. cal., genu corporis callosi

Gl. pal., globus pallidus

Hab., habenula

Hip., hippocampus

Hip. p. ant., hippocampus pars anterior

Hyp., hypophysis

In. C., Island (insula) of Calleja

In. m. C., giant island of Calleja

Ind. gr., induseum griseum

L., lateral large-celled group of the nucleus olfactorius anterior

Lam. cel. mit., lamina cellularum mitralum

Lam. fib., lamina fibrosa

Lam. glom., lamina glomerulosa

Lam. gran. ext., lamina granulosa externa

Lam. gran. int., lamina granulosa interna

Lam. med. int., lamina medullaris interna

Lam. mol., lamina molecularis

Lam. plex. int., lamina plexiformis interna

Lem. med., lemniscus medialis

M., medial large-celled group of the nucleus olfactorius anterior

M. intercal., massa intercalata

Med. obl., medulla oblongata 
M. F. B., medial forebrain bundle

N. III., nervus oculomotorius

N. opt., nervus opticus

N. vomeronas., nervus vomeronasalis

Neopal., neopallium

Nucl. ace, nucleus accumbens

Nuc. ans. lent., nucleus ansae lenticularis

Nucl. ant. dors., nucleus anterior dorsalis

Nucl. ant. med, nucleus anteromedialis

Nucl. ant. vent., nucleus anteroventralis

Nuel. bas. amyg., nueleus basalis amygdalae

Nucl. bas. amyg. p. lat., nucleus basalis amygdalae pars lateralis

Nucl. bas. amyg. p. med., nucleus basalis amygdalae pars medialis

Nuel. eaud., nueleus caudatus

Nucl. cent. amyg., nucleus centralis amygdalae

Nucl. com. ant., nucleus commissurae anterioris

Nuel. com. hip. dors, nueleus commissurae hippocampi dorsalis

Nucl. com. hip. vent., nucleus commissurae hippocampi ventralis

Nucl. cort. amyg., nucleus corticalis amygdalae

Nucl. d. b. B., nucleus of the diagonal band of Broca

Nucl. endopyr., nucleus endopyriformis

Nucl. entoped., nucleus entopeduncularis

Nucl. gen. lat. p. dors., nucleus genicu. latus lateralis pars dorsalis

Nucl. intercal. L. F. B., nucleus interealatus lateral forebrain bundle

Nucl. interst. M. F. B., nucleus interstitialis medial forebrain bundle

Nucl. interst. st. term., nucleus interstitialis striae terminalis

Nucl. interst. st. term. p. encap., nucleus interstitialis striae terminalis pars encapsulata

Nucl. lat. amyg. p. ant., nucleus lateralis amygdalae pars anterior

Nucl. lat. amyg. p. post., nucleus lateralis amygdalae pars posterior

Nucl. lat. thal., nucleus lateralis thalami

Nucl. med. amyg., nucleus medialis amygdalae
Nucl. olf. ant. p. dors., nucleus olfactorius anterior pars dorsalis

Nucl. olf. ant. p. ext., nucleus olfactorius anterior pars externa

Nucl. olf. ant. p. ext. a, nucleus olfactorius anterior pars externa $a$

Nucl. olf. ant. p. ext. b, nucleus olfactorius anterior pars externa $b$

Nucl. olf. ant. p. lat., nucleus olfactorius anterior pars lateralis

Nucl. olf. ant. p. med., nucleus olfactorius anterior pars medialis

Nucl. olf. ant. p. post., nuclens olfactorius anterior pars posterior

Nucl. parat., nucleus parataenialis

Nucl. paravent., nucleus paraventricularis

Nucl. preop. magnocell., nucleus preopticus magnocellularis

Nucl. preop. med., nucleus preopticus medianus

Nucl. preop. perivent, nucleus preopticus periventricularis

Nucl. preop. prin., nucleus preopticus prineipalis

Nucl. preop. prin. p. inf., nucleus preopticus principalis pars inferior

Nucl. preop. prin. p. sup., nueleus preopticus principalis pars superior

Nuel. ret., nucleus reticularis

Nucl. sept. fimb., nucleus septalis fimbrialis

Nucl. sept. hip., nucleus septo-hippocampalis

Nucl. sept. lat., nucleus septalis lateralis

Nucl. sept. med., nueleus septalis medialis

Nucl. supraop. (Nucl. tang.), nucleus supraopticus (nucleus tangentialis)

Nucl. tr. cort. hab. med, nucleus tractus cortico-habenularis medialis

Nucl. tr. olf. lat., nucleus tractus olfactorii lateralis

Nucl. tr. olf. lat. p. lat., nucleus tractus olfactorii lateralis pars lateralis

Nucl. tr. olf. lat. p. med., nucleus tractus olfactorii lateralis pars medialis

Nucl. tr. sept. hab., nucleus tractus septo-habenularis 
Nucl. triang., nucleus triangularis septi

Ped. thal. inf., pedunculus thalamiei inferior

Ped. thal. inf. assoc. fib., pedunculus thalamici inferior, associated fibers

Perivent. gr., periventrieular gray

Put., putamen

Put. a., putamen, ventral extension

Rad. thal. sup., radiatio thalamici superior

Sept., septum

Sept. precom., septum precommissurale

sept. posteom., septum postcommissurale

Splen. corp. cal., splenium corporis eallosi

St. L., stria Lancisii

St. med., stria medullaris

St. term., stria terminalis

St. term. p. com., stria terminalis, pars commissuralis

St. term. p. preop., stria terminalis, pars preoptica

St. term. p. supracom., stria terminalis, pars supracommissuralis

Tap. corp. cal., tapetum corporis callosi

Thal., thalamus

Tr., transitional area between the amygdala and pyriform cortex

Tr. cort, caud. lat., tractus corticocaudatus lateralis

Tr. cort. caud. med., tractus corticocaudatus medialis

Tr. cort. hab. lat., tractus corticohabenularis lateralis

Tr. cort. hab. med., tractus corticohabenularis medialis

Tr. cort. put., tractus cortico-putamenalis

Tr. d. b. B., tract of the diagonal band of Broca

Tr. hab. ped., tractus habenulo-peduncularis

Tr. hip. cort., tractus hippocampo-corticalis

Tr. hyp. hypop., tractus hypothalamohypophyseosus
Tr. interst. hyp., tractus interstitiohypothalamieus

Tr. mam. thal., tractus mamillo-thala. micus

Tr. olf. hab. lat., tractus olfacto-habenularis lateralis

Tr. olf. hyp., tractus olfacto-hypothalamicus

Tr. olf. hyp. lat., tractus olfacto-hypothalamicus lateralis

Tr. olf. hyp. lat-assoc. fib., tractus olfacto-hypothalamicus lateralis, associated fibers

Tr. olf. hyp. med., tractus olfacto-hypothalamicus medialis

Tr. olf. interm, tractus olfactorius intermedius

Tr. olf. lat., tractus olfactorius lateralis

Tr. olf. lat. p. dors., tractus olfactorius lateralis, pars dorsalis

Tr. olf, lat. p. interm., tractus olfactorius lateralis, pars intermedia

Tr. olf. lat. p. vent., traetus olfactorius lateralis, pars ventralis

Tr. olf. lat. ped. dors., tractus olfactorius lateralis, peduneulus dorsalis

Tr. olf. lat. ped. vent., tractus olfactorius lateralis, pedunculus ventralis

Tr. olf. med., tractus olfactorius medialis

Tr. olf. sept., tractus olfacto-septalis

Tr. op., traetus opticus

Tr. sept. hab., tractus septo-habenularis

Tr. sept. hab. med., tractus septo-habenularis medialis

Tr. sept. hyp., tractus septo-hypothalamicus

Tr. st. hyp., tractus strio-hypothalamicus

Tr. tub. cort., tractus tuberculo-corticalis

Tr. tub. sept., tractus tubereulo-septalis

Tub. olf., tuberculum olfactorium

Tub. olf. p. cort., tuberculum olfactorium, pars corticalis

Tub. olf. p. int., tuberculum olfactorium, pars interna

V. III., ventriculus tertius

V. lat., ventriculus lateralis

V. olf., ventriculus olfactorius 

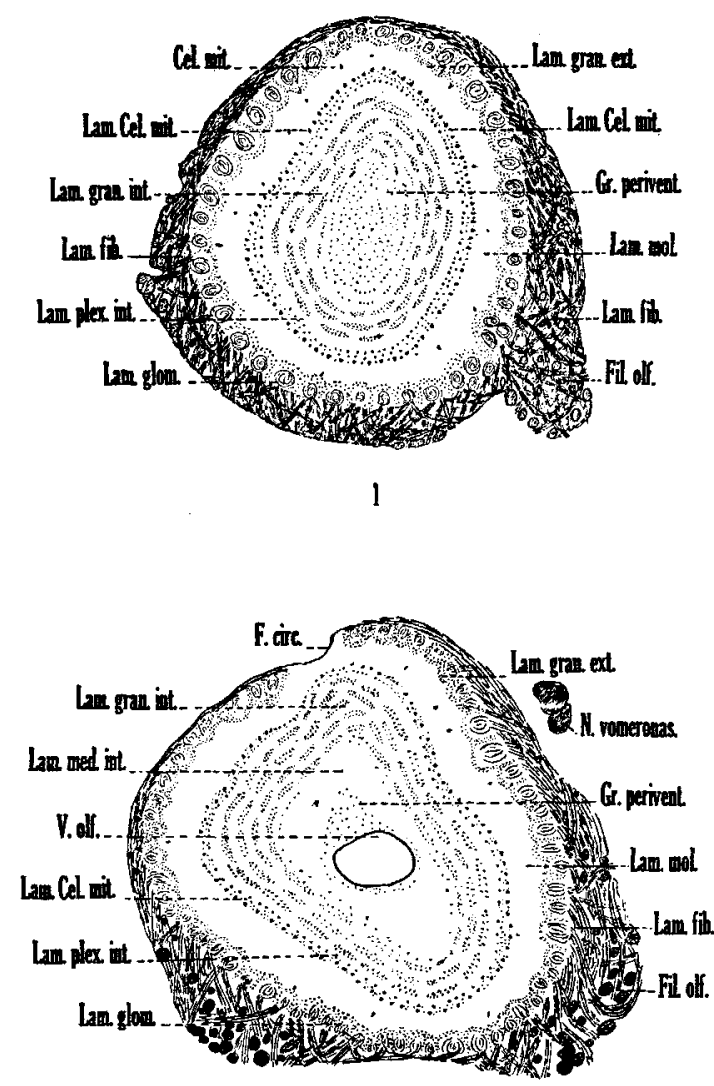

2

Fig. 1 Transverse section through the rostral extreme of the olfactory bulb of the rabbit, showing the laminae. Toluidin blue preparation, $\times 10$.

Fig. 2 Transverse section of the olfactory bulb of the rabbit at a plane cutting the anterior end of the olfactory ventricle. Toluidin blue preparation. $\times 10$. 

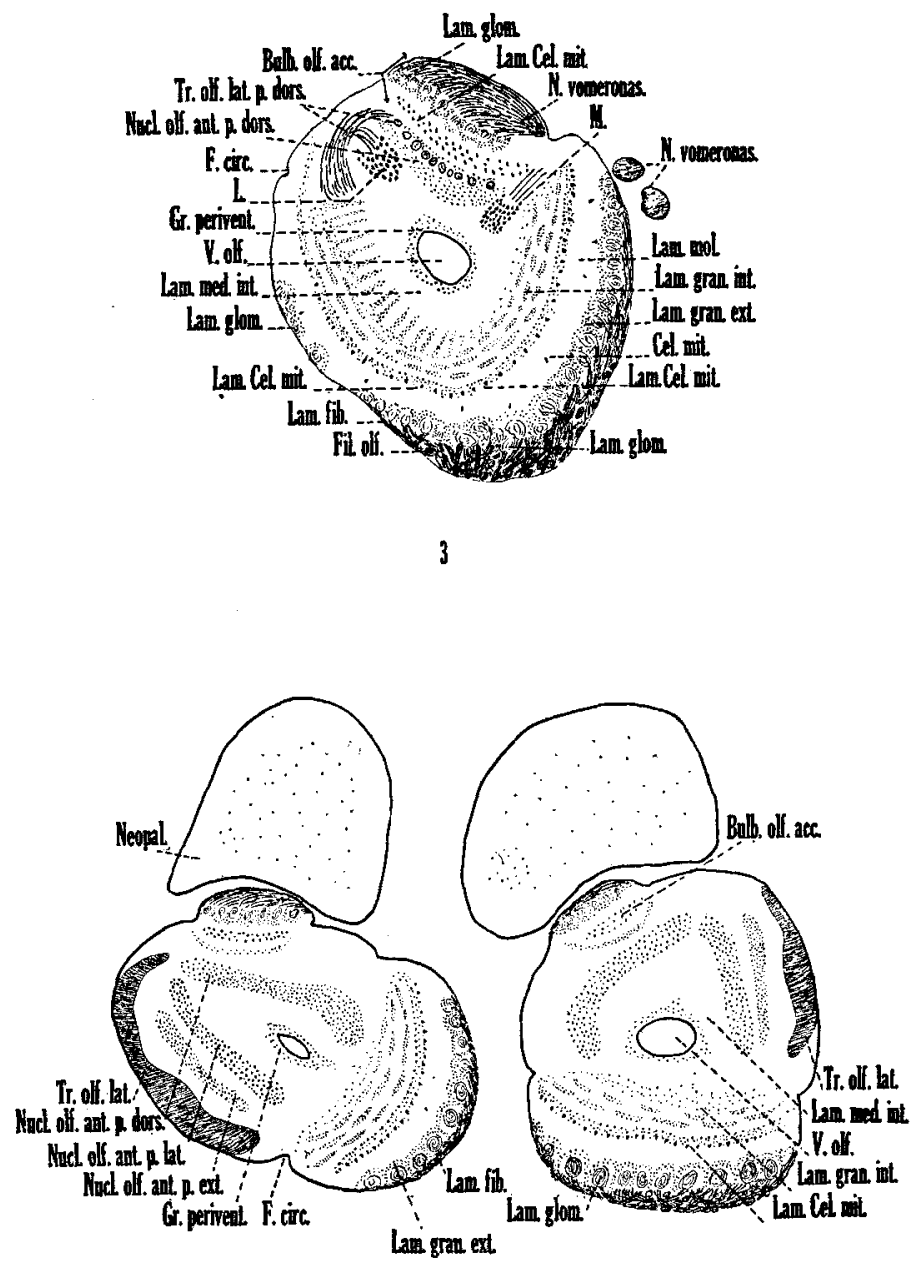

4

Fig. 3 Transverse section through the accessory olfactory bulb and the rostral extreme of the nucleus olfactorius anterior of the rabbit. Toluidin blue preparation. $\times 10$.

Fig. 4 Transverse section through the eaudal third of the accessory olfactory bulb and the pars externa of the anterior olfactory nucleus. Toluidin blue preparation. $\times 10$. 

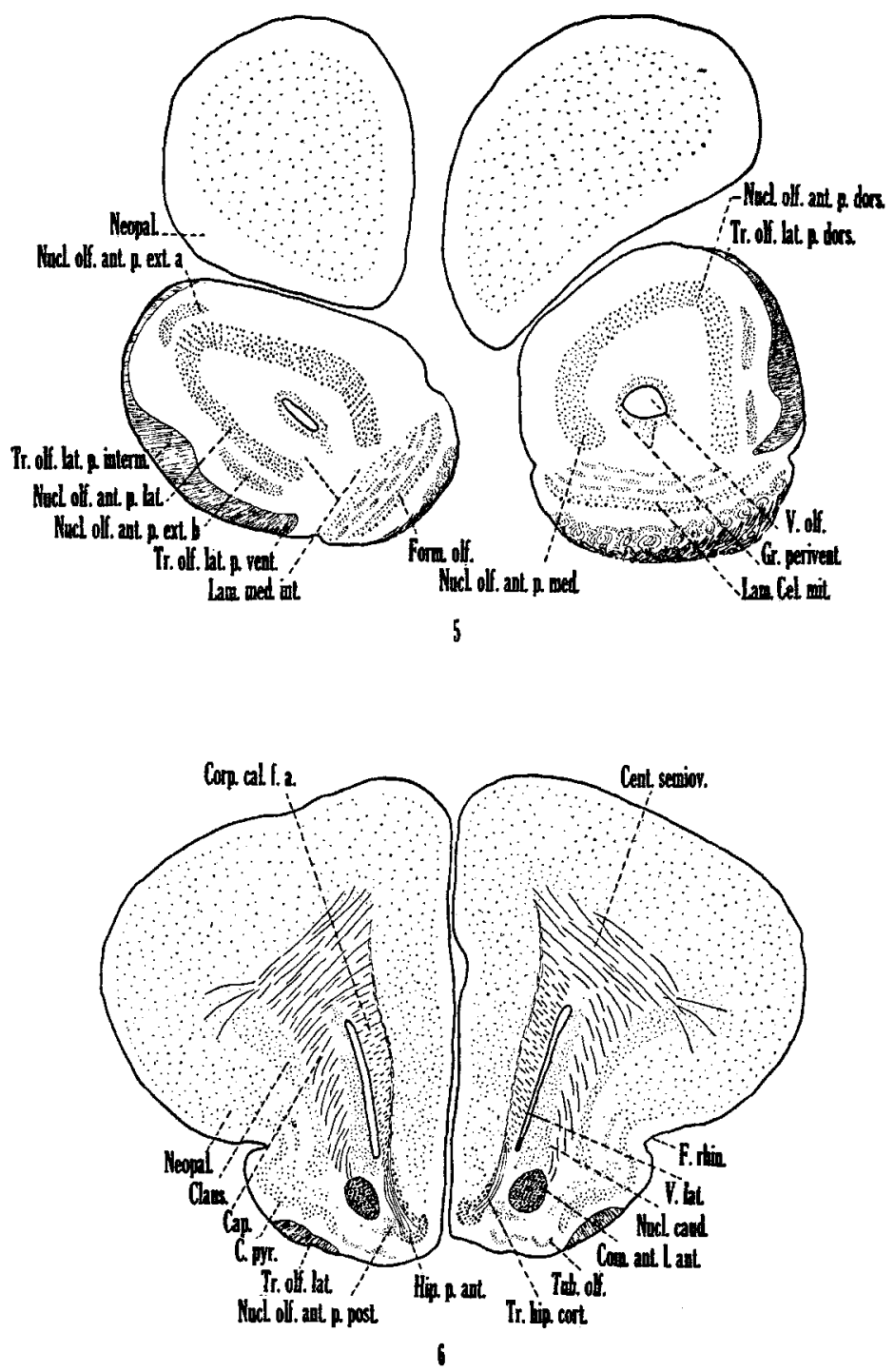

Fig. 5 Transverse section through the olfactory peduncle of the rabbit just caudal to the accessory olfactory bulb and showing particularly the dorsal and ventral tailpieces of pars externa of the anterior olfactory nucleus. Toluidin blue preparation. $\times 10$.

Fig. 6 Transverse section through the rostral extreme of the nucleus caudatus and tuberculum olfactorium of the rabbit. Toluidin blue preparation. $\times 5$. 

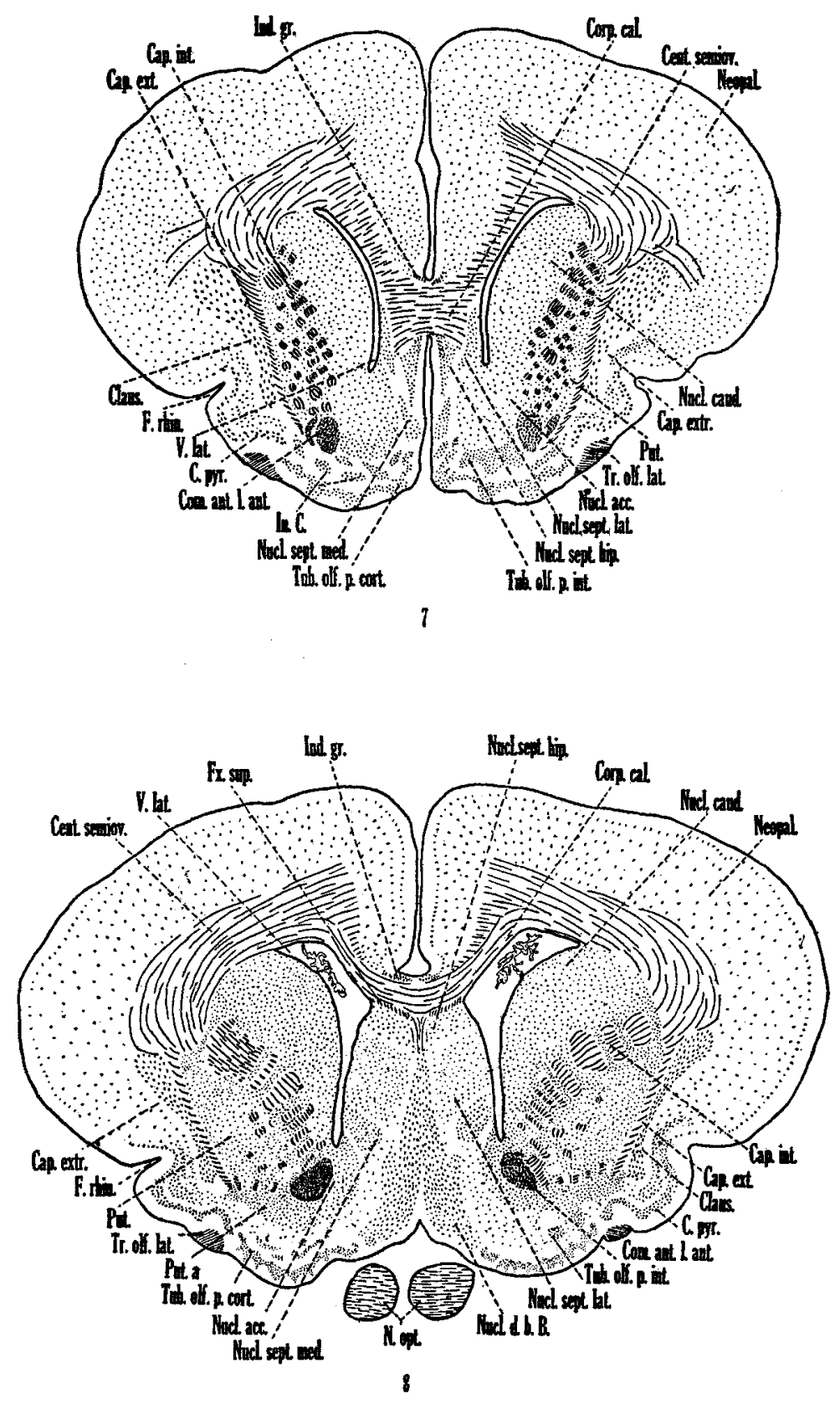


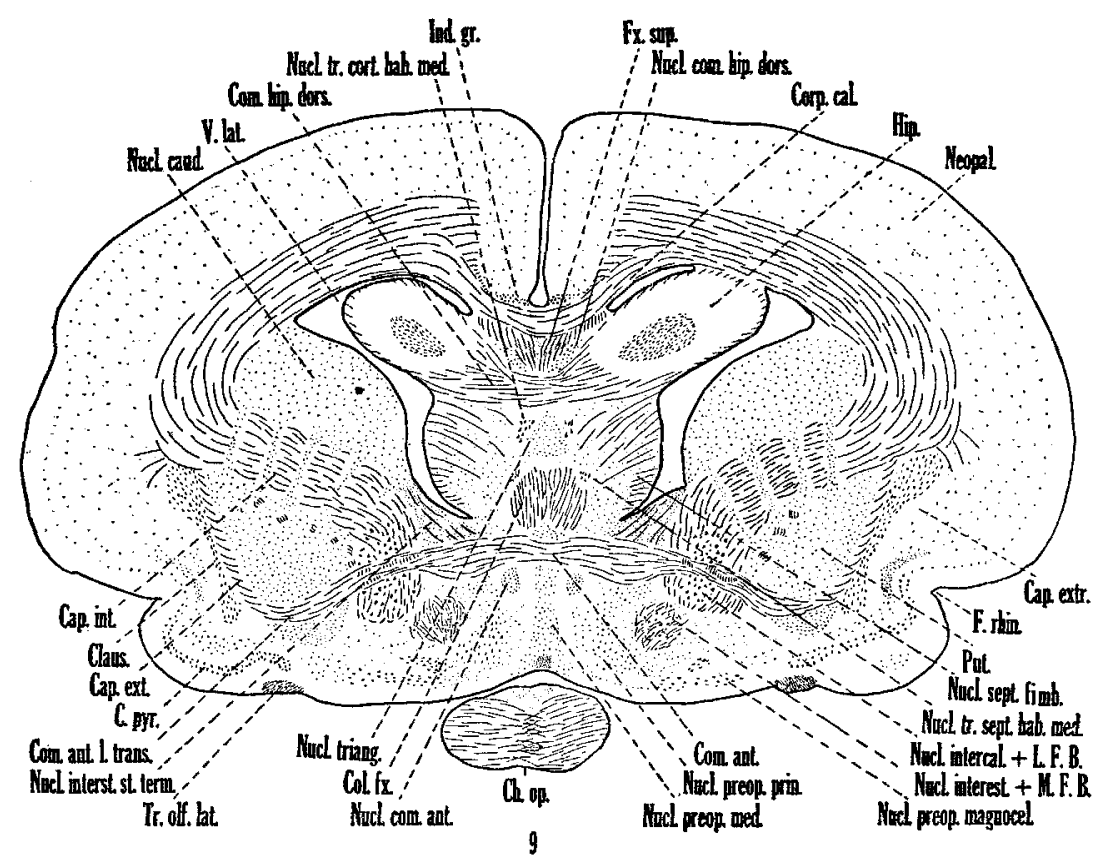

Fig. 7 Transverse section through the genu of the corpus callosum of the rabbit showing particularly the differentiation of the septal area at this level. Toluidin blue. $\times 5$.

Fig. 8 Transverse section slightly rostral to the crossing of the anterior commissure, showing the relations of the nucleus of the diagonal band and the striatum. Toluidin blue preparation. $\times 5$.

Fig. 9 Transverse section through the anterior eommissure of the rabbit showing the positions of the various nuclei at this level and particularly the relations of the external capsule to the anterior commissure. Toluidin blue. $\times 5$. 


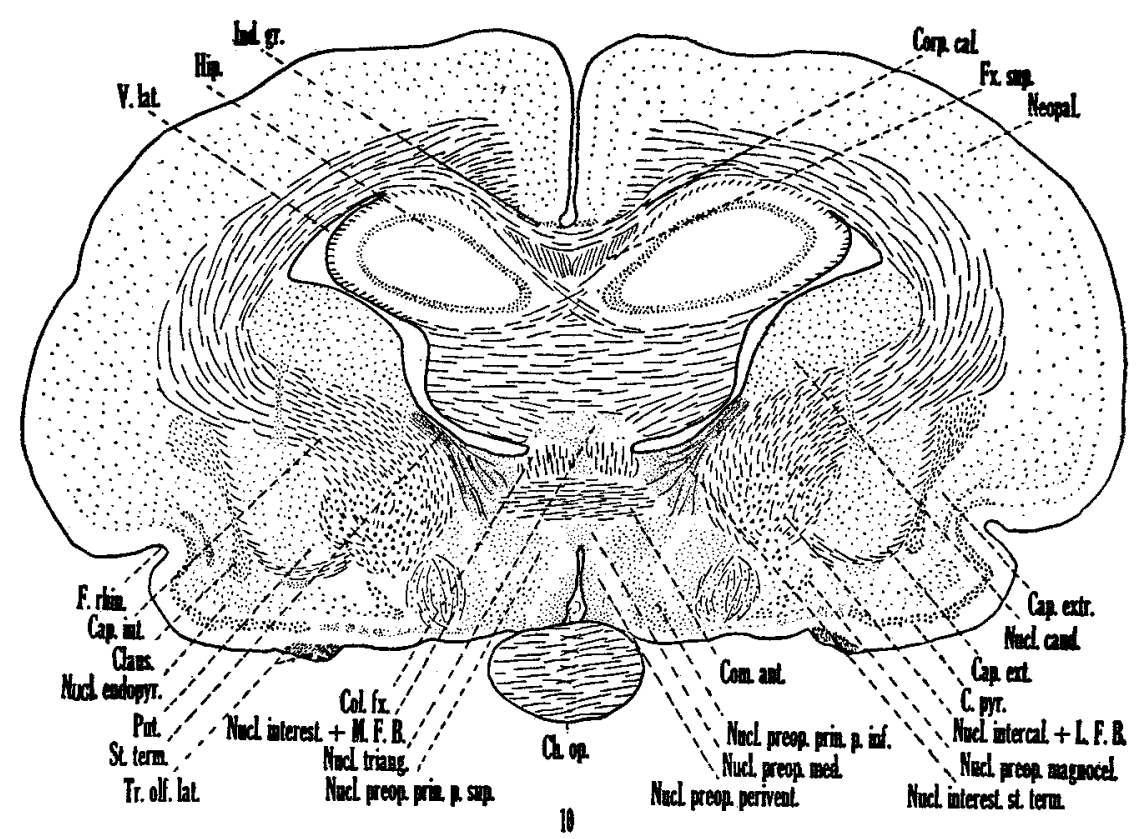

Fig. 10 Transverse section through the caudal third of the anterior commissure of the rabbit showing particularly the interstitial nucleus of the stria terminalis and the intercalated nucleus of the lateral forebrain bundle. Toluidin blue preparation. $\times 5$. 


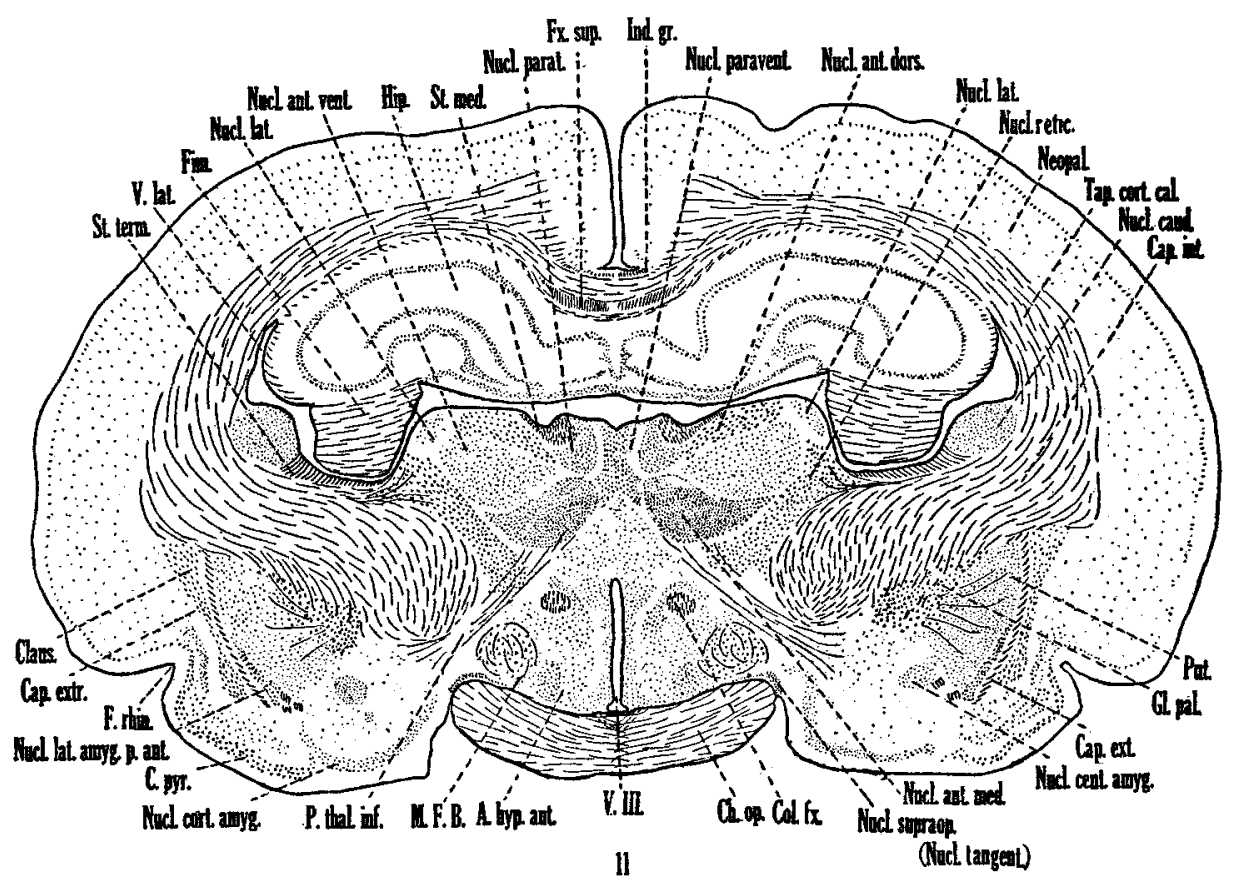

Fig. 11 Transverse section through the hemispheres and rostral end of the diencephalon of the rabbit showing particularly the relations of the striatal areas at this level. Toluidin blue preparation. $\times 5$. 
Figs. 12 to 15 These have been chosen to illustrate the various nuelear groups of the amygdaloid complex in the rabbit.

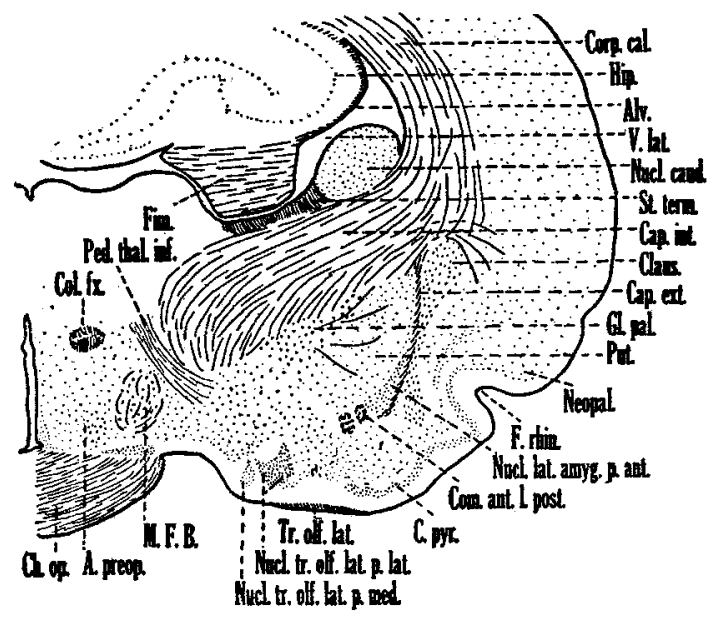

12

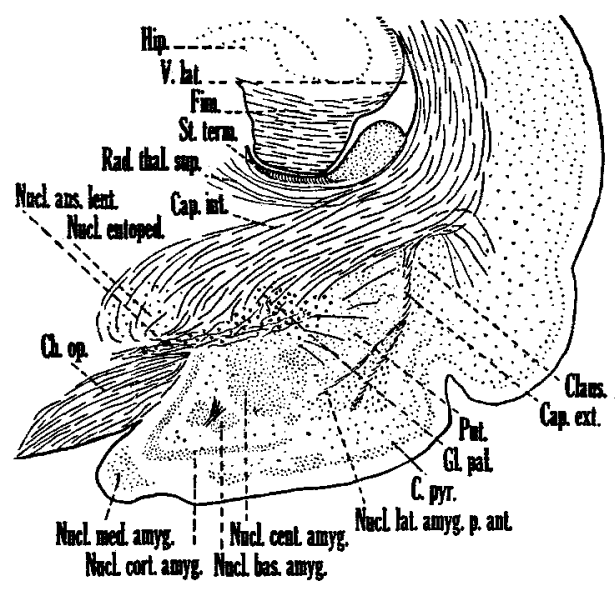

13

Fig. 12 Transverse section through the nucleus of the lateral olfactory tract. Toluidin blue. $\times 5$.

Fig: 13 Transverse section through the cortical amygdaloid nueleus. Toluidin blue preparation. $\times 5$. 

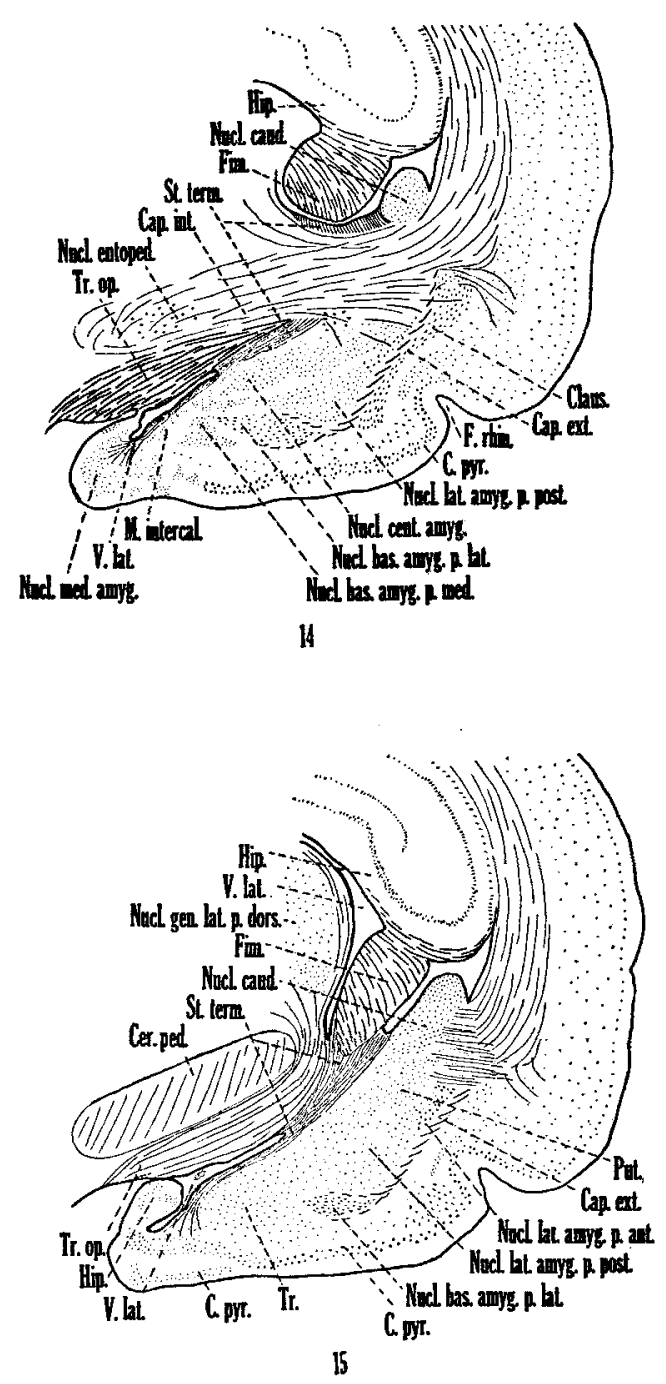

Fig. 14 Transverse section through the central, lateral, medial, and basal amygdaloid nuclei and the intercalated mass. Toluidin blue preparation. $\times 5$,

Fig. 15 Transverse section caudal to the plane of figure 14 showing the close interrelation of the amygdaloid complex to the putamen and tail of the caudate nueleus. Toluidin blue preparation. $\times 5$. 


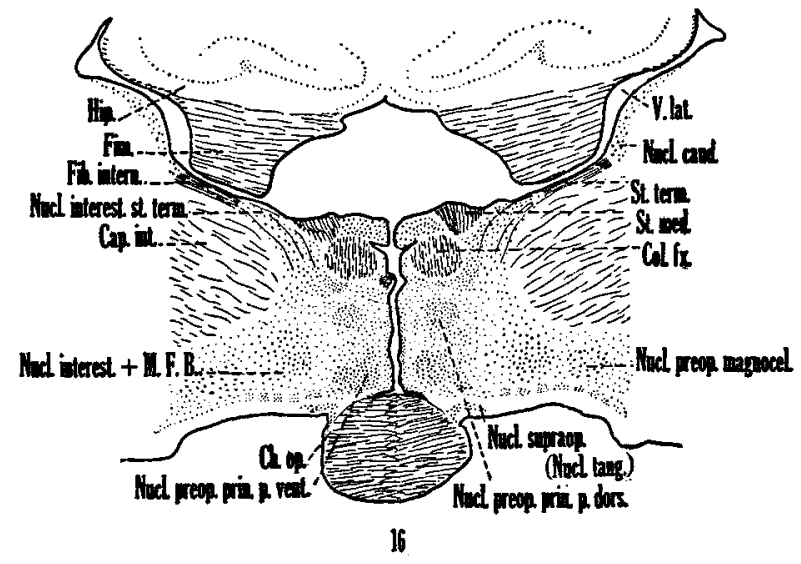

Fig. 16 Transverse section through the preoptic region of the rabbit. Toluidin blue preparation. $\times 5$. 


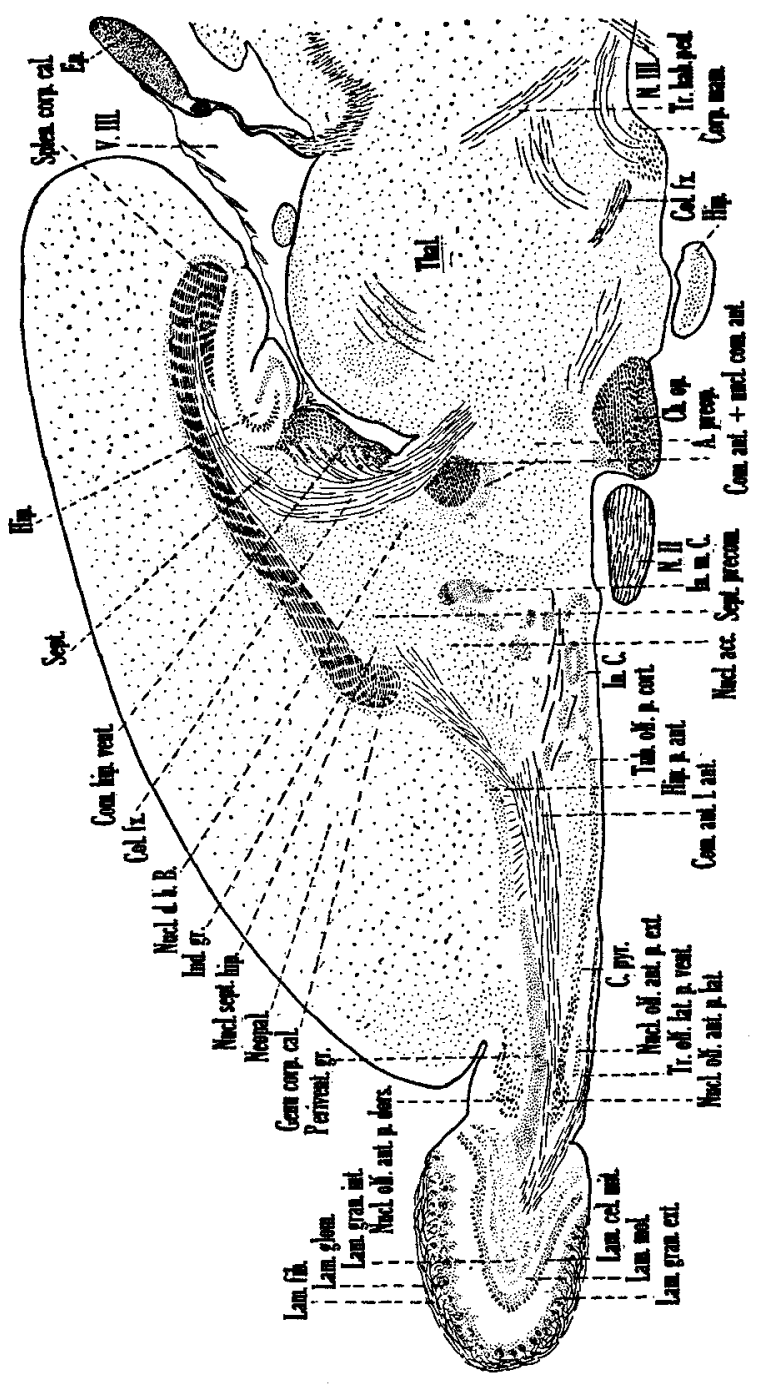

急总

更

\% 足年

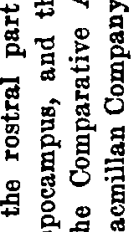
을 要

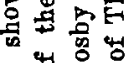
出

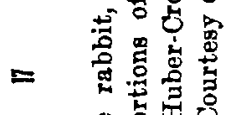
당 $\leftrightarrows$ 的 녕 罗 궁 造

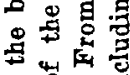
药 等

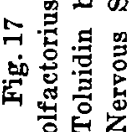



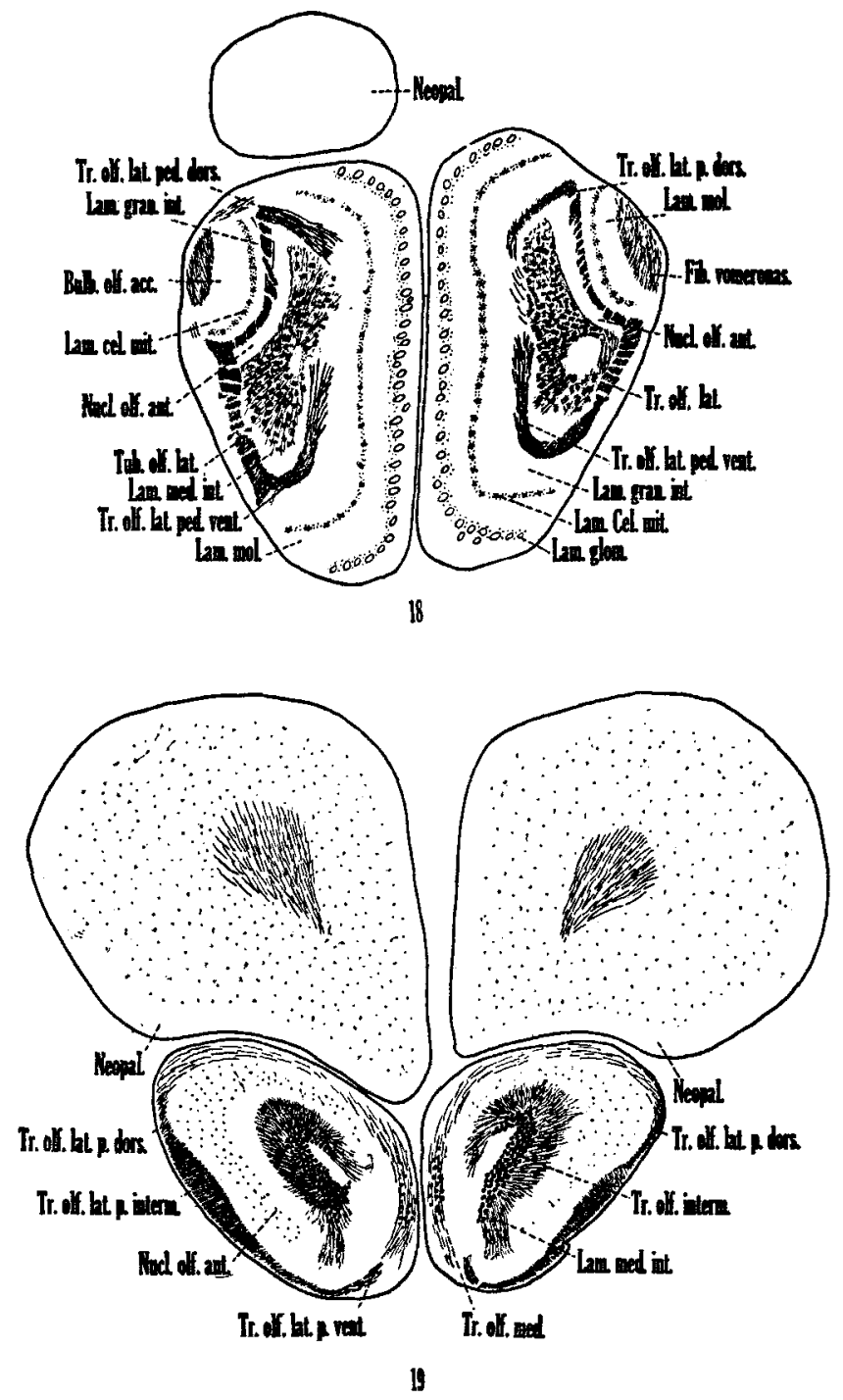

Fig. 18 Transverse section through the olfactory formation and accessory olfactory bulb of the guinea pig showing particularly the relations of the lateral olfactory tract (tub.olf.lat, on left. Pal-Weigert preparation. $\times 10$.

Fig. 19 Transverse section through the olfactory crus of the guinea pig showing the relations of the three major olfactory tracts and the secondary subdivision of the lateral olfactory tract. Pal-Weigert preparation. $\times 10$. 

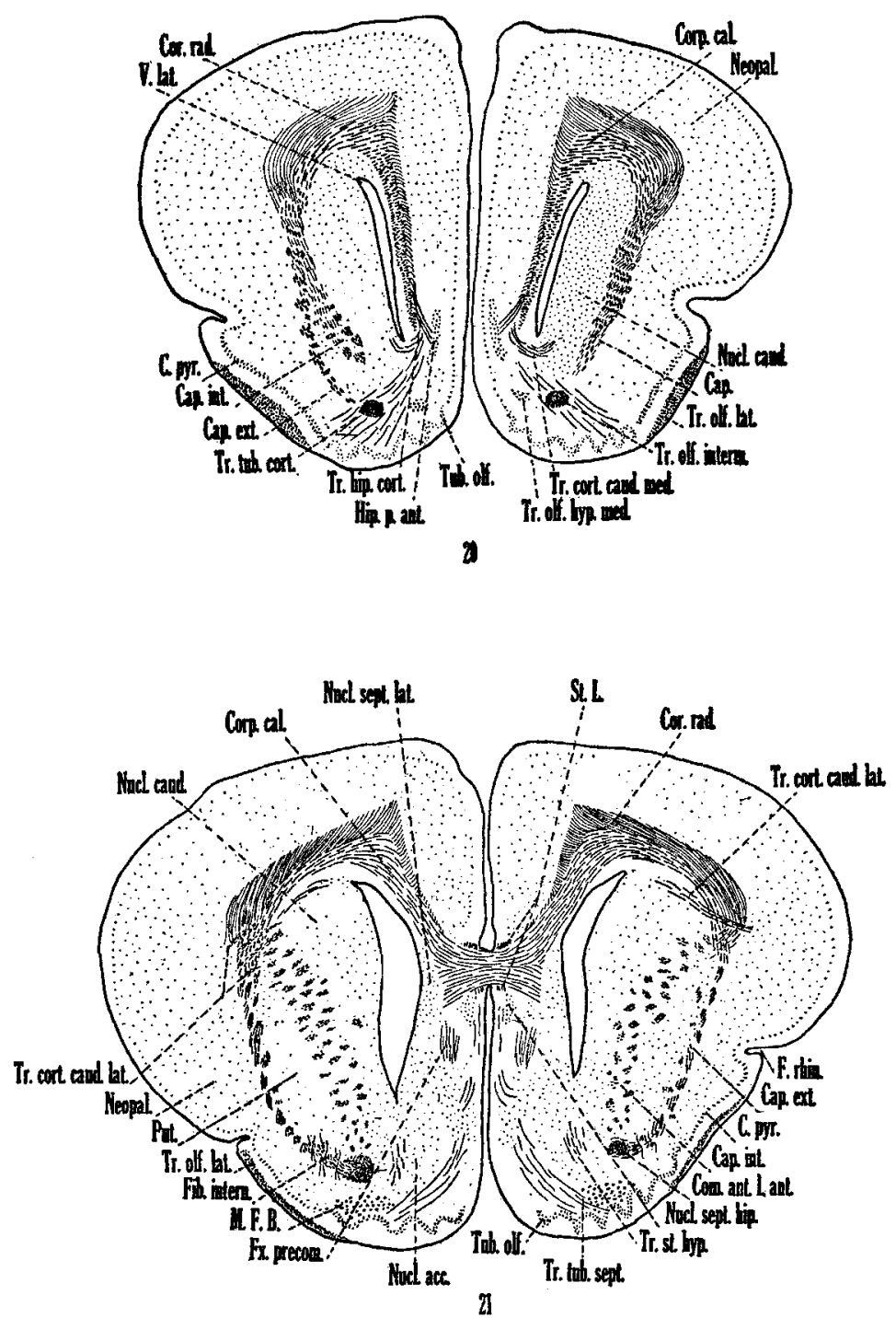

Fig. 20 Transverse section through the rostral region of the hemisphere of the rabbit showing on the left side the beginning of separation of the external and internal capsule systems. Chrome silver preparation. $\times 10$.

Fig. 21 Transverse section through the genu of the corpus callosum dorsally and the tuberculum olfactorium ventrally, showing particularly the relation of the external capsule to the forming anterior commissure. Rabbit. Chromo silver preparation. $\times 10$. 

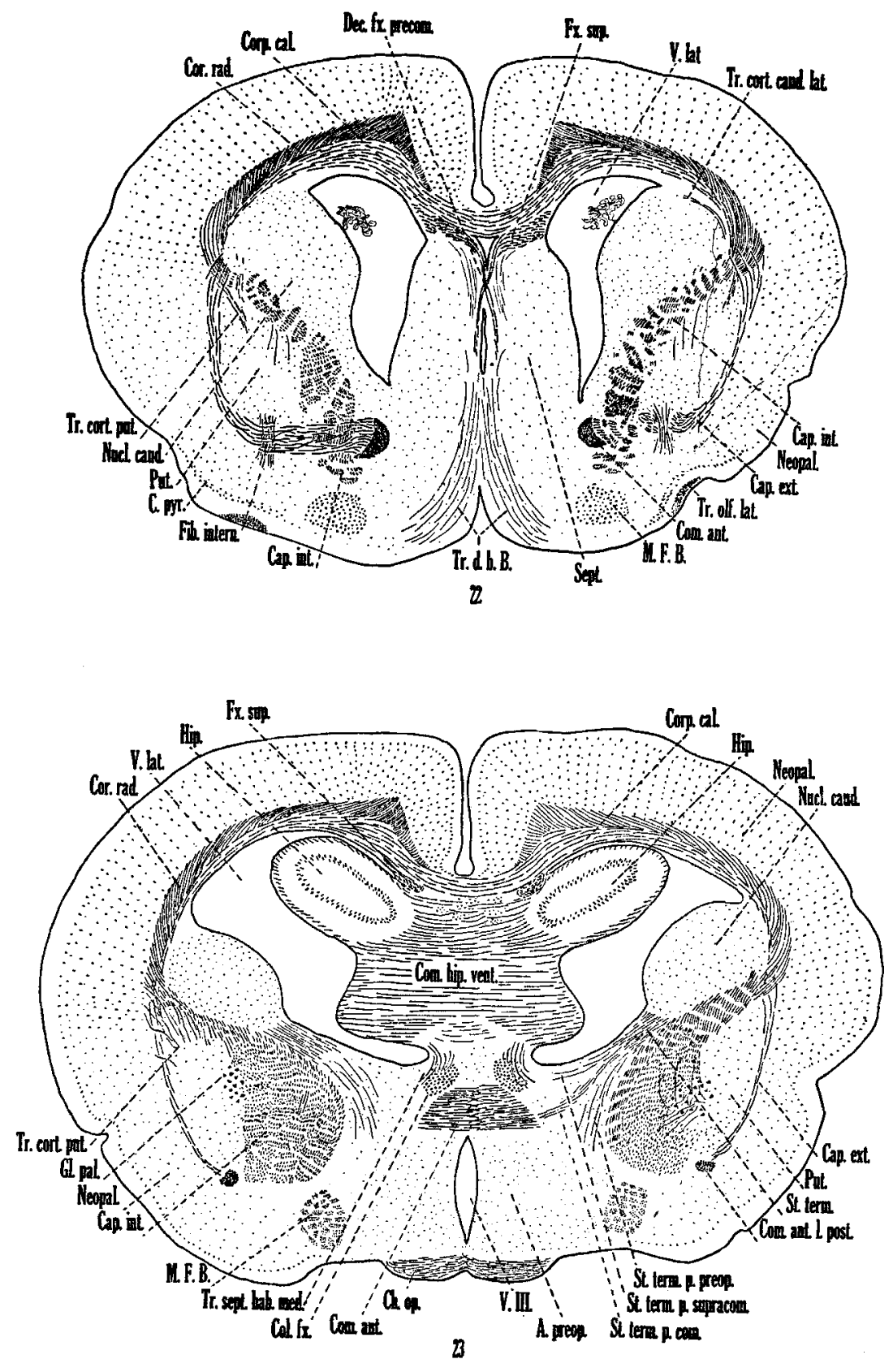


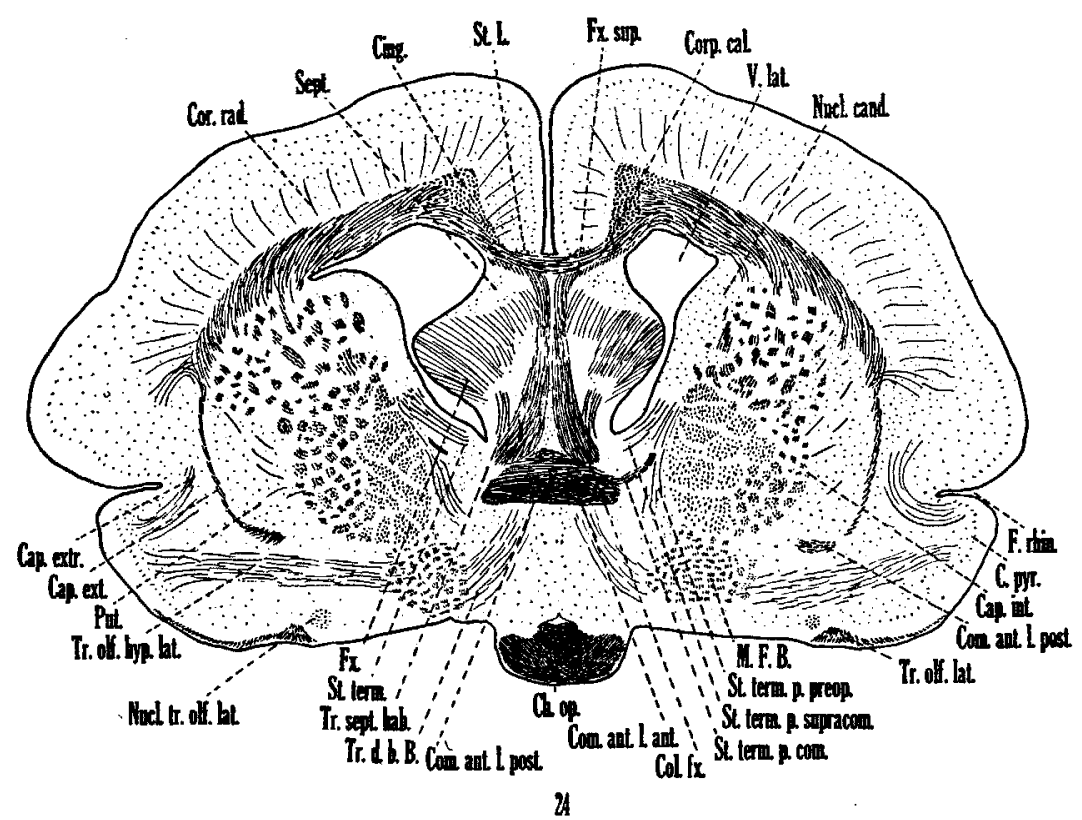

Fig. 22 Transverse section rostral to the anterior commissure of the rabbit showing the decussation of the precommissural fornix system. The relation of the external capsule system to the anterior commissure is also very evident at this level. Chrome silver preparation. $\times 10$.

Fig. 23 Transverse section through the ventral hippocampal and anterior commissures of the rabbit, illustrating particularly the three major subdivisions of the stria terminalis. Chrome silver preparation. $\times 10$.

Fig. 24 Transverse section through the anterior commissure of the guinea pig illustrating in this rodent the subdivisions of the stria terminalis and the relations of the striatal areas and the internal and external capsules. Pal-Weigert preparation. $\times 5$. 


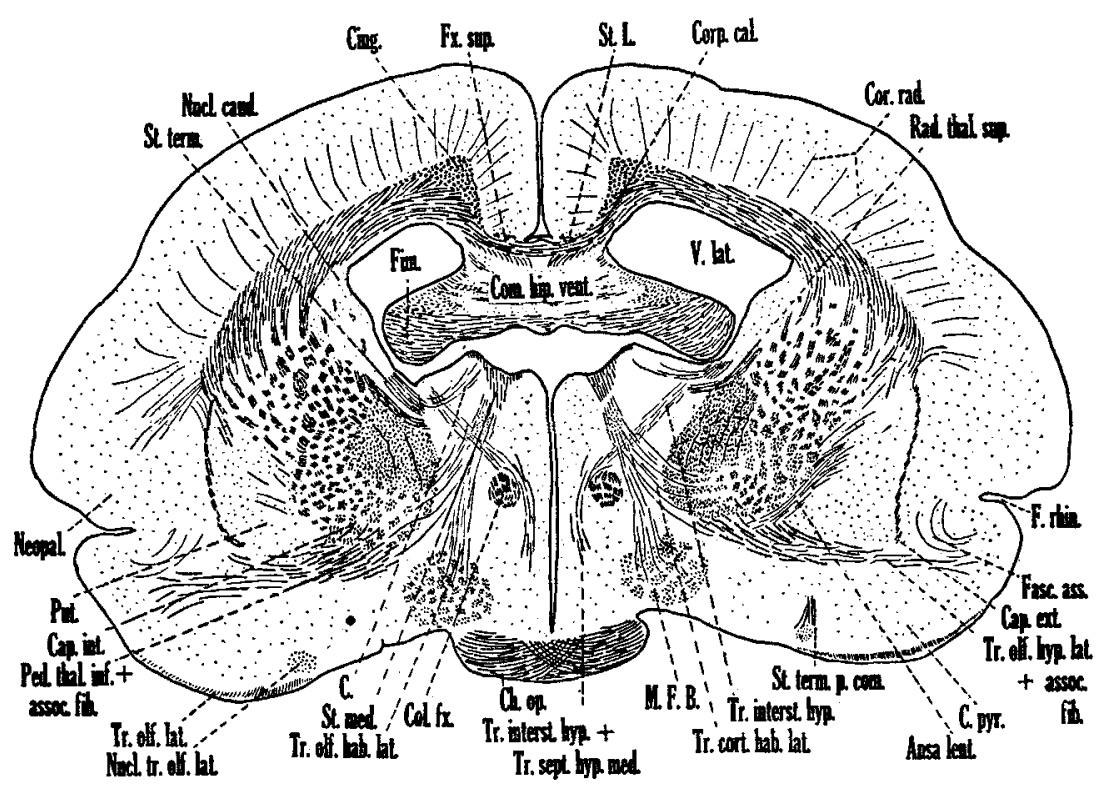

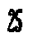

Fig. 25 Transverse section through the forebrain of the guinea pig in a plane eutting the ventral hippocampal commissure dorsally and the optic chiasm ventrally and showing certain components of the stria medullaris. Pal-Weigert preparation. $\times 5$. 


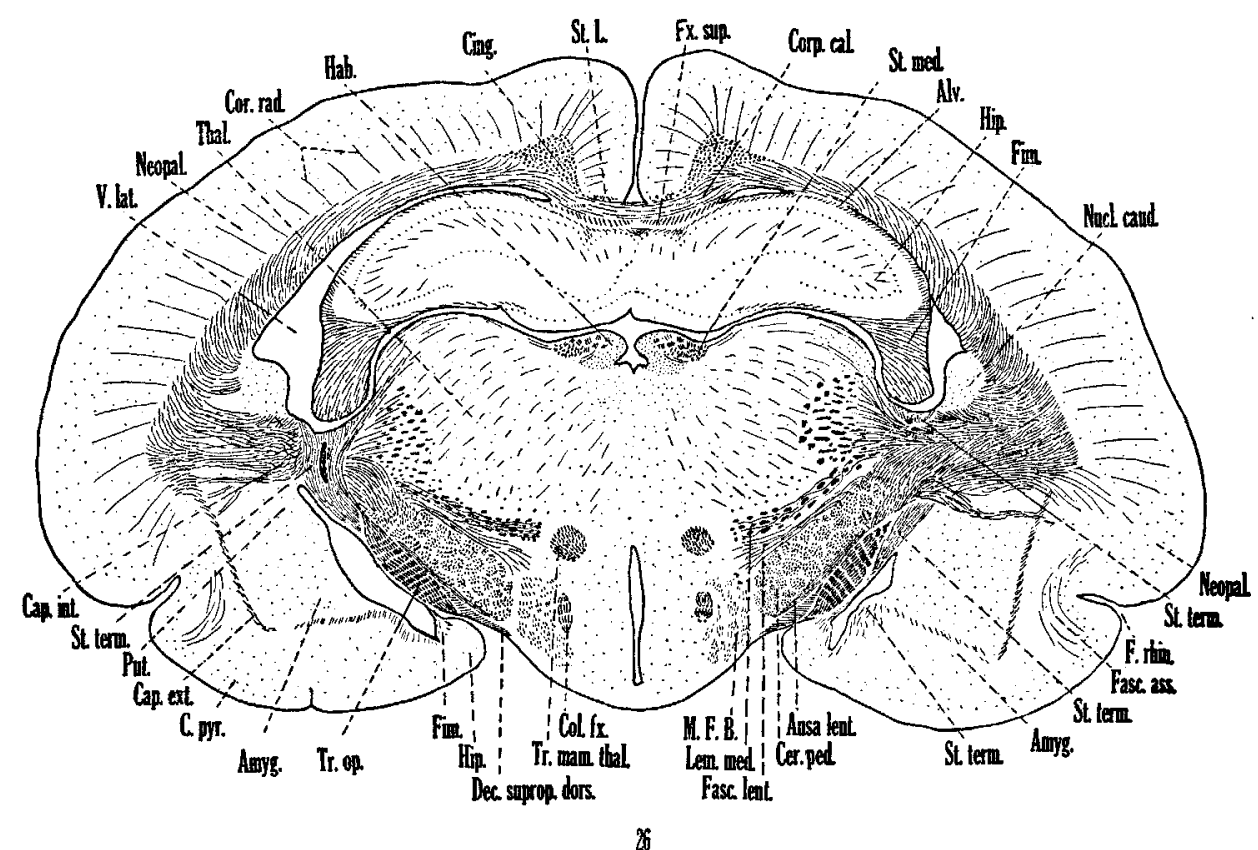

Fig. 26 Transverse section caudal to the plane of figure 25 and at the junction of the middle and caudal thirds of the amygdaloid complex of the guinea pig, illustrating especially the descent of the stria terminalis on the left side. Pal-Weigert preparation. $\times 5$. 

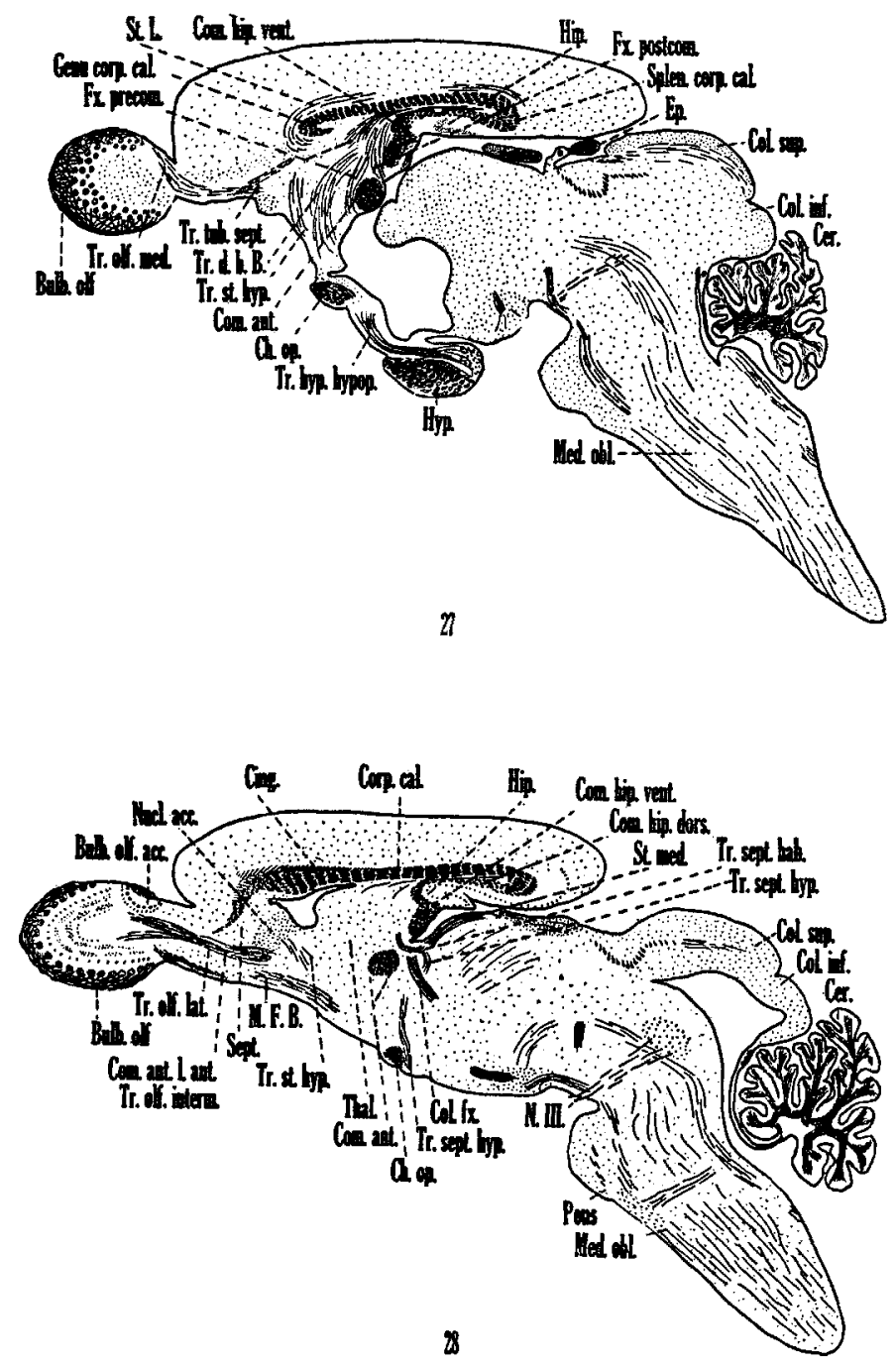

Fig. 27 Sagittal section showing particularly the relations of the commissural systems of the rabbit telencephalon. Chrome silver preparation. $\times 5$.

Fig. 28 Sagittal section lateral to the plane of figure 27, showing especially the relations of the lateral and intermediate olfactory tracts and certain components of the stria medullaris. Rabbit. Chrome silver preparation. $\times 5$. 